\title{
Engineered Magnetic Carbon-Based Adsorbents for the Removal of Water Priority Pollutants: An Overview
}

\author{
H. E. Reynel-Ávila, ${ }^{1,2}$ K. I. Camacho-Aguilar, ${ }^{1}$ A. Bonilla-Petriciolet ${ }^{(\mathbb{D})}{ }^{1}$ \\ D. I. Mendoza-Castillo, ${ }^{1,2}$ H. A. González-Ponce $\mathbb{B}^{1},{ }^{1}$ and R. Trejo-Valencia ${ }^{3}$ \\ ${ }^{1}$ Instituto Tecnológico de Aguascalientes, Aguascalientes 20256, Mexico \\ ${ }^{2}$ CONACyT, Cátedras Jóvenes Investigadores, Ciudad de México 03940, Mexico \\ ${ }^{3}$ Instituto Tecnológico de Minatitlán, Veracruz 96848, Mexico
}

Correspondence should be addressed to A. Bonilla-Petriciolet; petriciolet@hotmail.com

Received 15 March 2021; Accepted 6 October 2021; Published 27 October 2021

Academic Editor: Diana C. S. Azevedo

Copyright (c) 2021 H. E. Reynel-Ávila et al. This is an open access article distributed under the Creative Commons Attribution License, which permits unrestricted use, distribution, and reproduction in any medium, provided the original work is properly cited.

\begin{abstract}
This review covers the preparation, characterization, and application of magnetic adsorbents obtained from carbon-based sources and their application in the adsorption of both inorganic and organic pollutants from water. Different preparation routes to obtain magnetic adsorbents from activated carbon, biochar, hydrochar, graphene, carbon dots, carbon nanotubes, and carbon nanocages, including the magnetic phase incorporated on the solid surface, are described and discussed. The performance of these adsorbents is analyzed for the removal of fluoride, arsenic, heavy metals, dyes, pesticides, pharmaceuticals, and other emerging and relevant water pollutants. Properties of these adsorbents and the corresponding adsorption mechanisms have been included in this review. Overall, this type of magnetic adsorbents offers an alternative for facing the operational problems associated to adsorption process in water treatment. However, some gaps have been identified in the proper physicochemical characterization of these adsorbents, the development of green and low-cost preparation methods for their industrial production and commercialization, the regeneration and final disposal of spent adsorbents, and their application in the multicomponent adsorption of water pollutants.
\end{abstract}

\section{Introduction}

Adsorption has been widely used for water and wastewater purification because of its significant benefits in terms of low cost, easy operation, limited energy consumption, selectivity, and flexibility for process design and scale-up $[1,2]$. In this sense, several types of adsorbents have been prepared, characterized, and tested to remove both organic and inorganic pollutants from water. They include activated carbon (AC) [3], zeolites $[4,5]$, ion exchange resins $[6,7]$, clays [8], and alternative materials like hydrogels [9], polymers [10], and their composites, carbon nanomaterials (CNMs) $[11,12]$, metal oxides [13], and magnetic nanoparticles (NPs) [14]. All these adsorbents show different physicochemical and mechanical properties, adsorption capacities, as well as advantages and drawbacks for water treatment at industrial level.

Functionalized nanomaterials have attracted increasing attention for advanced applications due to their outstanding properties (e.g., long-term stability, low toxicity, and high dispersion) [15]. Iron oxide nanoparticles (IONP) have special magnetic properties with different active sites that can be utilized in diverse applications in biomedicine and environmental fields $[15,16]$. The direct application of IONP, especially as adsorbents in water treatment, implies some drawbacks that restrict their use such as leaching in low $\mathrm{pH}$ range, low structural stability due to oxidative conditions, their aggregation in the solution, and the significant mass loss in an equipment with continuous operation that implies water flow $[15,16]$. Several studies have focused on 
the preparation of composites to provide more stability for magnetic phases using different substrates like carbon nanotubes (CNTs), graphene, mesoporous carbon-materials and AC [17], ion exchange resins [18, 19], zeolites [20], and polymers like chitosan [10].

Therefore, the preparation of adsorbents employing carbon sources and iron has been found to offer several advantages for environmental remediation. Magnetic carbon-based materials are interesting due to magnetic metal particles incorporated on the material structure, chemical inertness, thermal stability, and electrical conductivity obtained from the carbon phase [11]. They have been introduced in various fields including catalysts, magnetic resonance imaging, drug/gene/RNA delivery carriers, energy storage, super capacitance, enzymes immobilization, adsorption, $\mathrm{CO}_{2}$ capture, and biosensors $[11,12]$. A key characteristic of these materials is their easy recovery using an external magnetic field, which allows their application and handling in diverse operations.

Magnetic carbon-based adsorbents are characterized by a magnetic source supported on the surface of carbon materials. These materials show a certain affinity for the separation/purification of a specific target substance and their magnetic properties facilitate different industrial tasks (e.g., deflection and mixing) [21]. The main advantage of this type of adsorbents is its easy recovery from fluid using magnetic decantation where the adsorbent is retained by the magnetic field. Therefore, the magnetic properties of adsorbents enable the use of alternative and intensified equipment (e.g., magnetically stabilized fluidized beds), thus, offering new alternatives for water treatment [21]. According to Mehta et al. [22], the use of magnetism for water purification dates to 1873 thus being an old concept. However, the attention of researchers on magnetic adsorbents has exponentially increased during the last decades. A basic search in Scopus using the phrase "magnetic AND adsorbent" generates a record of 1,284 papers published in 2020 where a considerable increment in the publications has occurred during the last decade thus accumulating more than 8,800 papers on this topic.

A variety of carbon supports (or holders) can be used to prepare magnetic carbon adsorbents such as AC, biochar (BC), fullerenes, nanotubes, and other alternative compounds (e.g., nitro-phenol, polyurethane, yeast alcohol dehydrogenase, low-density polyethylene, acetate, acetylene, and oleates) $[11,12]$. These materials can be produced from low-cost feedstock like agricultural orange peel waste [23], pinewood [24], chestnut shell [25], empty fruit bunch from palm [26], rice straw [27, 28], coconut shell [29], potato stems and leaves [30], and banana biomass [31].

In this sense, the carbon-based feedstock and iron compounds can be utilized to prepare new composite materials thus taking advantage of their unique characteristics to obtain outstanding magnetic adsorbents with enhanced properties for the pollutant(s) removal in water treatment and other environmental applications $[32,33]$.

With this in mind, this review focuses on the preparation of a number of carbon-based magnetic adsorbents from different routes and their application to remove priority water pollutants. Adsorbent properties and removal performance for the adsorption of several priority water pollutants (e.g., arsenic, pharmaceuticals, heavy metals, dyes, fluoride, pesticides, and radionuclides) are discussed and analyzed. Some research gaps and pending topics to be analyzed in future studies of these adsorbents are also outlined.

\section{Sources of Carbon Materials Employed as Supports for Preparing Magnetic Adsorbents}

Carbon is one of the most prevalent elements in nature with a significant scientific interest, and it is also one of the key components in organic molecules [34]. The carbon atoms can exist in different allotropic forms due to their orbital hybridization and electronic configuration, and they include fullerenes, graphene, CNTs, nanocapsules, carbon and graphene quantum dots, onions, or nanocages, which have their own physical and chemical properties. Figure 1 shows some allotropic forms of carbon [35]. Some of these carbon allotropes can be utilized as supports to prepare carbon-based composites but AC [36] and BC [25] are the most used. Each carbon allotrope has different structure, surface functionality, area, porosity, and physicochemical properties. One of the main features to select a carbon material is related to the particle size, and, in this sense, they can be classified arbitrarily into macroparticulated (e.g., BC, AC, and other nongraphitic carbon materials) and nanoparticulated (e.g., CNTs, carbon nanocages CNCs, and graphene). The most important characteristics of some carbon supports are described below.

$\mathrm{BC}$ is a solid material rich in carbon that can be obtained from the biomass thermal decomposition, usually at lower temperatures than those commonly used for the preparation of other adsorbents, in total or partial absence of oxygen [24, $25,37]$. It mainly contains oxygenated functional groups (e.g., hydroxyl, carbonyl, and carboxylate) and has unique properties such as cation exchange capacity with a great potential to adsorb different water pollutants [37]. These characteristics depend on the biomass precursor and the methodology (i.e., preparation conditions) to obtain the BC.

$\mathrm{AC}$ is essentially referred as a carbonaceous solid that has been treated to obtain a high surface area and to develop or to suppress specific surface functional groups in order of tailoring its chemical properties for specific applications [36, 38]. Its structure is amorphous and graphite-like form [38]. Generally, the physical activation to obtain AC includes the treatment of a char under $\mathrm{CO}_{2}$, steam flow, or other gas, while the chemical activation refers to the impregnation and/or surface functionalization of char/precursor with different reagents and compounds $[36,38]$. Both physical and chemical activations contribute to develop specific porous morphology (i.e., surface area and pore network) and surface chemistry (i.e., surface functionalities like carbonyl, carboxyl, phenols, and lactones) [38, 39]. Consequently, the activation protocols can be optimized to obtain high porosity, surface area, adsorption capacity, mechanical strength, and physicochemical stability of the final product for the desired application at hand [38]. These properties 


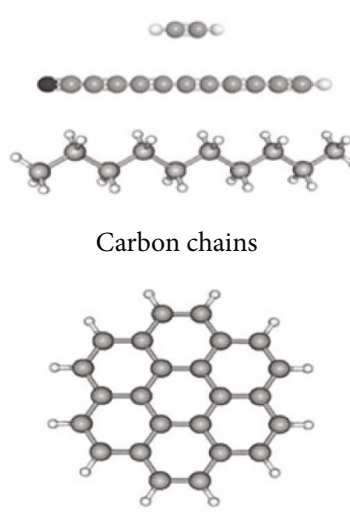

Polycyclic aromatic hydrocarbons

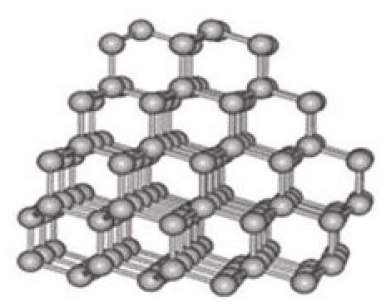

Nanodiamond

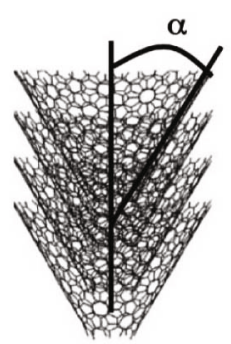

Nanofibers

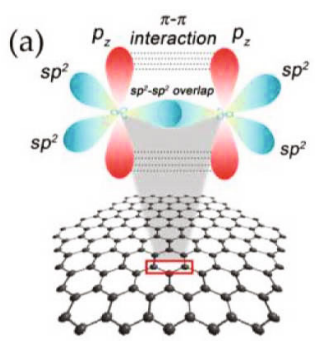

Graphene

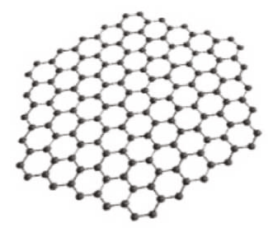

Graphene quantum dot

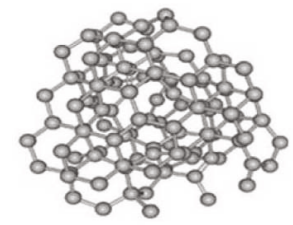

Amorphous carbon

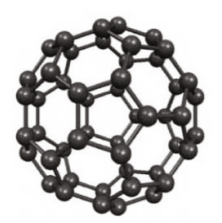

Fulleren C50

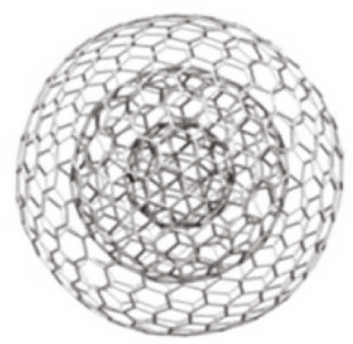

Carbon nano onions

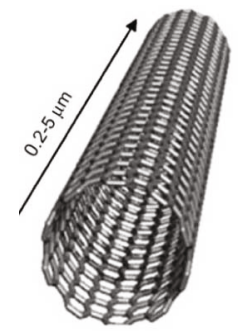

Single walled carbon nanotubes

(b)

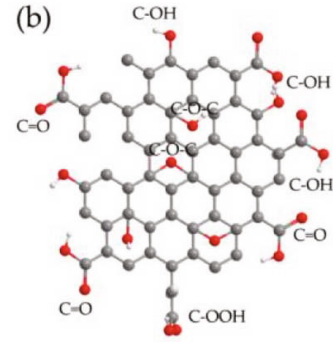

Graphene oxide

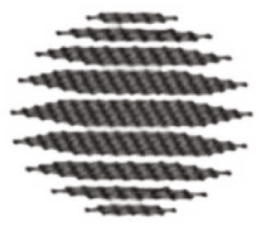

Carbon quantum dot

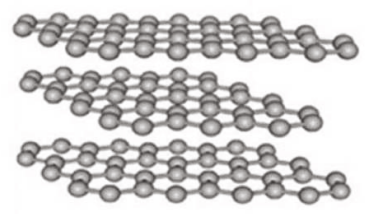

Graphite

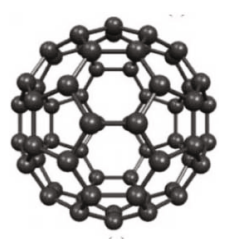

Fulleren C60

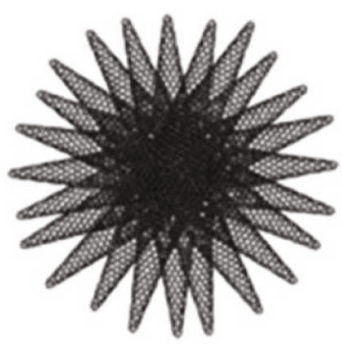

Carbon nano horns

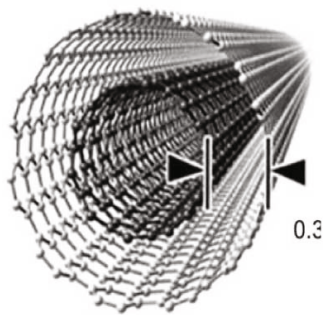

Multi walled carbon nanotubes

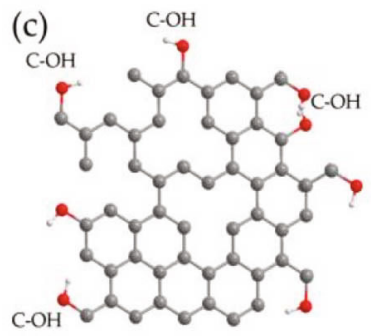

Reduced graphene oxide

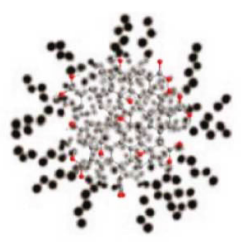

Carbon nanodots

Figure 1: Description of the structure forms of carbon materials. Adapted from [35, 186-188].

are also determined by the nature of precursor and the technology utilized to obtain the adsorbent [36].

On the other hand, graphene consists of $\mathrm{sp}^{2}$-hybridized carbons with a two-dimensional (2D) structure. This mate- rial is described as a free-standing single-layer carbon sheet with a hexagonally packed lattice structure with a theoretical specific surface area of $\sim 2630 \mathrm{~m}^{2} / \mathrm{g}$ and outstanding electronic, thermal, mechanical, and optical properties [40-43]. 
This material offers a wide window for its surface chemistry modification, and, consequently, it has shown a promising performance as adsorbent of different water pollutants [42, 43]. Normally, the graphene oxide (GO) and its reduced form (RGO) can be prepared from graphite. GO is the main precursor of graphene [44]. It is soluble in water with low conductivity and contains a variety of oxygen functional groups due to the oxidation route of graphite to obtain GO, while RGO has a limited solubility in water but good conductivity [45]. The oxygen-containing functional groups of graphene are useful to anchor ions by both coordinate or/and electrostatic interactions [32, 44]. Therefore, GO has been widely applied in water pollution control. Nevertheless, the separation and recovery of graphene from the working medium are restricted by its high dispersibility in water, thus, leading to the generation of wastes that could be hazardous materials for the environment.

CNTs consist of graphene sheets that are perfectly rolled into cylindrical tubes. They can be classed as single- and multiwalled carbon nanotubes (SWCNTs and MWCNTs) [46]. SWCNTs are classified in three crystallographic configurations according to the mode of graphene sheet is rolled up (i.e., chiral, armchair, and zigzag). Two opposite $\mathrm{C}-\mathrm{C}$ bonds of each hexagon are parallel to the tube axis in the zigzag conformation, whereas the armchair conformation implies that the $\mathrm{C}-\mathrm{C}$ bonds are perpendicular to the axis. In the chiral configuration, the opposite $\mathrm{C}-\mathrm{C}$ bonds lie at an angle to the tube axis, thus, generating a so-called helical nanotube chiral [47]. Trojanowicz [48] stated that the CNTs have the simplest chemical composition and atomic configuration, but they can also show the most widely diversity of structures and properties. The thermal, electrical, and mechanical properties of these materials can be exploited in a variety of applications [49]. CNTs also exhibit excellent adsorption properties to bind various organic and inorganic adsorbates [49]. Moreover, the surface chemistry modification and sidewall functionalization of these materials allow their use as support phases to immobilize particles improving their performance as adsorbents in water treatment $[49,50]$.

CNCs (or nanoshells) have 3D spherical structure consisting of a graphitic shell and hollow interior with high surface area [33]. In CNCs, the graphitic walls can isolate magnetic NPs from environment acting as a shield that avoids oxidation and ensures a long-term stability of the magnetic core [34]. CNCs have been applied in data storage, drug and gene delivery, catalysis, environmental remediation, and sensing due to their electrical and physical properties and geometrical structure $[33,51]$.

Carbon quantum dots (CQDs) are a class of structures consisting of quasispherical carbon nanoparticles with sizes of $\sim 10 \mathrm{~nm}$ [52]. They are mainly composed of $\mathrm{sp}^{3}$ hybridized carbon and are usually amorphous. CQDs are fluorescent due to the quantum confinement effect that allows to obtain optoelectronic and photoluminescent properties [52]. The color of CQDs turns to fluorescent light blue under UV light irradiation. However, the fluorescent properties of CQDs are also affected by the emitting properties of carbon precursor used as feedstock [53]. Graphene quantum dots
(GQDs) are zero-dimensional structures, but they are composed by graphene nanosheets "cut" until reaching a size of $<20 \mathrm{~nm}[52,53]$. GQDs are mainly composed of $\mathrm{sp}^{2}$ hybridized carbon and have crystalline structure. Therefore, they are better recognized as graphene disks in the size range of 1-20 nm. Abbas et al. [52] have indicated that the main difference between the GQDs and graphene is their band gap values. Graphene is a zero-band gap material, while GQDs show band gap due to their quantum confinement and edge effects that generate fluorescence properties. CQDs and GQDs are interesting materials for semiconductors, light-emitting diodes, detection of heavy metal ions, and wastewater treatment as catalysts or adsorbents. These materials are characterized by their high stability, biocompatibility, low toxicity, high dispersibility in water, photostability, and low manufacturing cost [53].

Overall, all these carbon-based materials can be used to prepare magnetic adsorbents for water treatment. In the next section, an overview of the synthesis of magnetic carbon-based adsorbents is provided.

\section{Synthesis of Magnetic Carbon- Based Adsorbents}

The most common metallic NPs utilized to prepare magnetic materials are nickel, cobalt, and iron [12, 34]. Nevertheless, the iron compounds are commonly utilized due to their low cost and magnetic characteristics [12]. Siddiqui et al. [12] have reviewed the main sources of iron and they comprise ferrous sulfate $\mathrm{FeSO}_{4}$, ferric nitrate $\mathrm{Fe}\left(\mathrm{NO}_{3}\right)_{3}$, ferric oxide $\mathrm{Fe}_{2} \mathrm{O}_{3}$, ferrous ferric oxide $\mathrm{Fe}_{3} \mathrm{O}_{4}$, ferric chloride $\mathrm{FeCl}_{3}$, and iron ores like magnetite and maghemite. As mentioned by Meng et al. [23], the iron compounds display numerous advantages: they can be used to modify supports at low temperatures (around $180{ }^{\circ} \mathrm{C}$ ), they have low toxicity for ecosystems and human health thus being safe and environmentally friendly, and they also offer physical stability to supports and good magnetic performance. These characteristics can be exploited in water purification and treatment.

Several methods have been used to synthesize magnetic carbon composites (CCs), and, practically, each synthesis route applies more than two stages for obtaining the final material. These preparation protocols can vary according to the carbon source nature, but all approaches generally include the impregnation with iron salts and chemical coprecipitation of IONPs. In this section, the conventional synthesis methods besides recent advances for the preparation of magnetic carbon-based materials are analyzed.

\subsection{Magnetic Versions of Activated Carbon (AC), Biochar} $(B C)$, and Hydrochar (HC). Generally, various stages are necessary to produce magnetic $\mathrm{AC}$ and $\mathrm{BC}$. First, the carbonization of precursor is required, and it can be performed by traditional pyrolysis or hydrothermal method. In a second stage, the impregnation with iron phases in liquid phase is performed to modify AC or BC. Alternatively, the iron salts can be mixed with a carbon-precursor and then the carbonization step is carried out. 
In the direct synthesis, an impregnation stage is required where the support precursor (e.g., a lignocellulosic biomass) is mixed with iron salts or iron phases; then, the pyrolysis or hydrothermal stage is performed for obtaining magnetic BC or HC. Otherwise, the first stage of an indirect synthesis is the precursor carbonization, and, once $\mathrm{BC}$ or $\mathrm{HC}$ has been obtained, the second stage consists of the impregnation of carbon-based material with a magnetic phase of iron oxides for finally obtaining magnetic BC or HC. These procedures are illustrated in Figure 2(a).

The direct synthesis of magnetic AC implies the addition of chemical substances during impregnation stage and the activation in the subsequent stage of carbonization by hydrothermal treatment or pyrolysis, as shown in Figure 2(b). Note that the production of magnetic AC by indirect synthesis relies on the activation stage that can be performed after carbonization by chemical and/or physical pathways and then followed by the impregnation to incorporate magnetic species. A relevant advantage of the synthesis of $\mathrm{AC}, \mathrm{HC}$, and $\mathrm{BC}$, as carbon-based supports, is the use of low-cost raw materials as precursors. In this sense, researchers have prepared $\mathrm{AC}$ and $\mathrm{BC}$ using biomass sources with noncommercial value like orange peels [23], chestnut shell [25], empty fruit bunch from palm [26], and rice straw [27]. Also, alternative carbon sources like industrial and urban residues (e.g., Tetra pack, PET bottles, and tires) can be utilized to obtain these carbon supports [54-56]. Once the precursor for the carbon matrix preparation has been selected and acondicionated (this stage generally includes washing, particle size reduction, and pretreatment), the carbonization stage is the next step. Note that several methods for biomass carbonization can be chosen and some of them are discussed below.

Pyrolysis involves the formation of a low-developed porous solid matrix (usually called as char) where the precursor is submitted to a thermal treatment without oxygen at temperatures from 600 to $1000{ }^{\circ} \mathrm{C}$. This char can be also obtained via thermal treatment under the presence of oxygen, and this process is commonly referred as carbonization $[57,58]$. For BC and char production, pyrolysis or carbonization is the only stage employed in the preparation route, but an additional activation stage is needed for obtaining AC, which can involve the use of different reagents. For instance, an oxidizing gas like $\mathrm{CO}_{2}$ or steam at 600-1200 ${ }^{\circ} \mathrm{C}$ can be utilized to promote the formation of a welldeveloped pore structure $[57,58]$.

On the other hand, the hydrothermal carbonization (HTC) is the thermochemical conversion process that transforms biomass under the presence of pressurized water (at subcritical conditions) into a carbon-based material usually referred as HC (i.e., hydrochar) [59]. This process is regarded as a green route to prepare new materials from biomasses and other feedstocks in a closed reactor or autoclave under the presence of water at low temperatures (150-250 $\left.{ }^{\circ} \mathrm{C}\right)$. HTC offers some advantages in comparison to the conventional thermal treatments because not only helps to generate a surface area rich in functional groups but it also implies a reduced energy consumption and low-cost. Raw $\mathrm{HC}$ obtained at common operating conditions has a low spe- cific surface area $\left(<100 \mathrm{~m}^{2} / \mathrm{g}\right)$ but contains a significant amount of oxygenated functionalities if water is the reaction medium to prepare this adsorbent [23, 60-63]. For example, Cai et al. [64] reported the preparation of a magnetic BC for chromium adsorption using peanut shells, deionized water, hexamethylenediamine, and $\mathrm{FeCl}_{3} \bullet 6 \mathrm{H}_{2} \mathrm{O}$. The adsorbent was obtained via HTC at $220{ }^{\circ} \mathrm{C}$ for $12 \mathrm{~h}$. The maximum adsorption capacity of this magnetic material was $142.86 \mathrm{mg} / \mathrm{g}$ and could be reused in 3 removal cycles. Figure 3 illustrates the methodology used to produce magnetic BC from peanut shell [64]. Note that HC with high surface area and porosity can be prepared if a postactivation step is performed.

Herein, it is convenient to highlight that alternative technologies can be utilized to prepare the carbon-based support, and they include the application of microwave and plasma $[26,58,65]$. For instance, the main objective of microwave-assisted pyrolysis is to reduce the preparation time and to enhance the adsorption properties of the solid matrix [58]. In microwave instruments, the precursor pyrolysis/carbonization and adsorbent activation can be carried out. This technology offers a heating process that is uniform, thus, it is feasible to homogenize the bulk properties of the final product [58]. Microwave power and radiation time can impact on the char textural parameters like surface area and pore volume [66].

As indicated, another important stage is the impregnation with magnetic salts for conferring magnetic properties to $\mathrm{BC}, \mathrm{AC}$, or $\mathrm{HC}$. This task can be performed via:

(1) The nonmagnetic iron oxides (i.e., hematite and goethite that can be transformed in magnetic phases) or iron salts can be mixed with the carbon precursor, before its carbonization, in the aqueous solution at a given temperature and time to ensure its impregnation. The impregnated precursor can be carbonized to obtain directly the magnetic adsorbents

(2) Char or AC can be mixed with the magnetic salts in an aqueous solution following the next alternatives for the support impregnation: (1) with a chemical synthesis of magnetic iron oxide using, for example, sol-gel, or coprecipitation methods; and (2) with magnetic iron oxides already synthesized by thermal decomposition, chemical reduction, sol-gel, or coprecipitation. A detailed description of each approach can be found in the interesting review of Noor et al. [58]

The final magnetic material could acquire different structural, chemical, and physical characteristics depending on the preparation conditions. For instance, the precursor (biomass or other carbon source), temperature, and impregnation ratio could have a significant impact on the final adsorbent properties. Figure 4 illustrates three examples for the preparation of magnetic adsorbents with different methods and stages.

3.2. Magnetic Graphene-Based Materials. GO and RGO are other preferred carbon matrices to prepare magnetic 

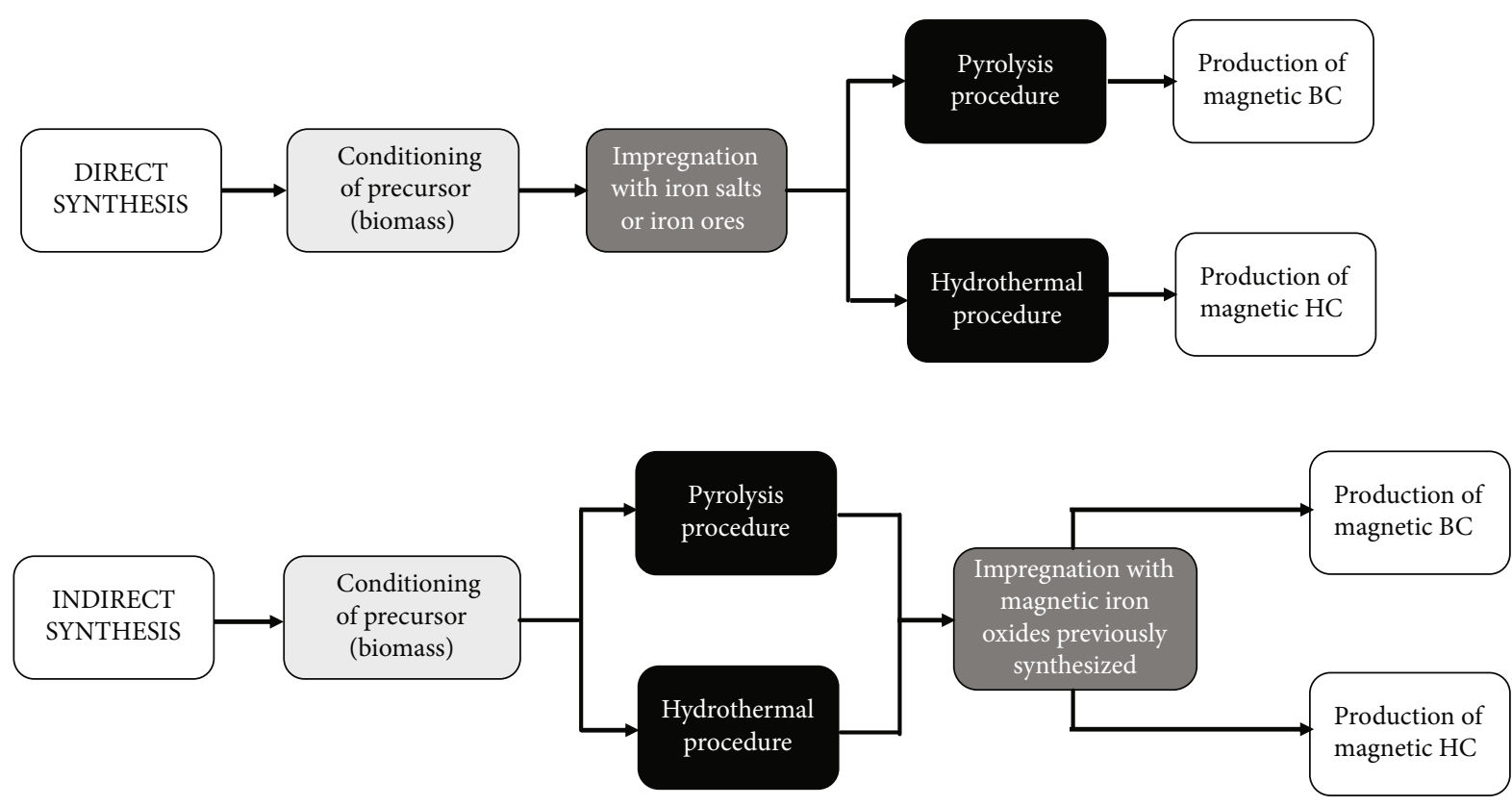

(a)
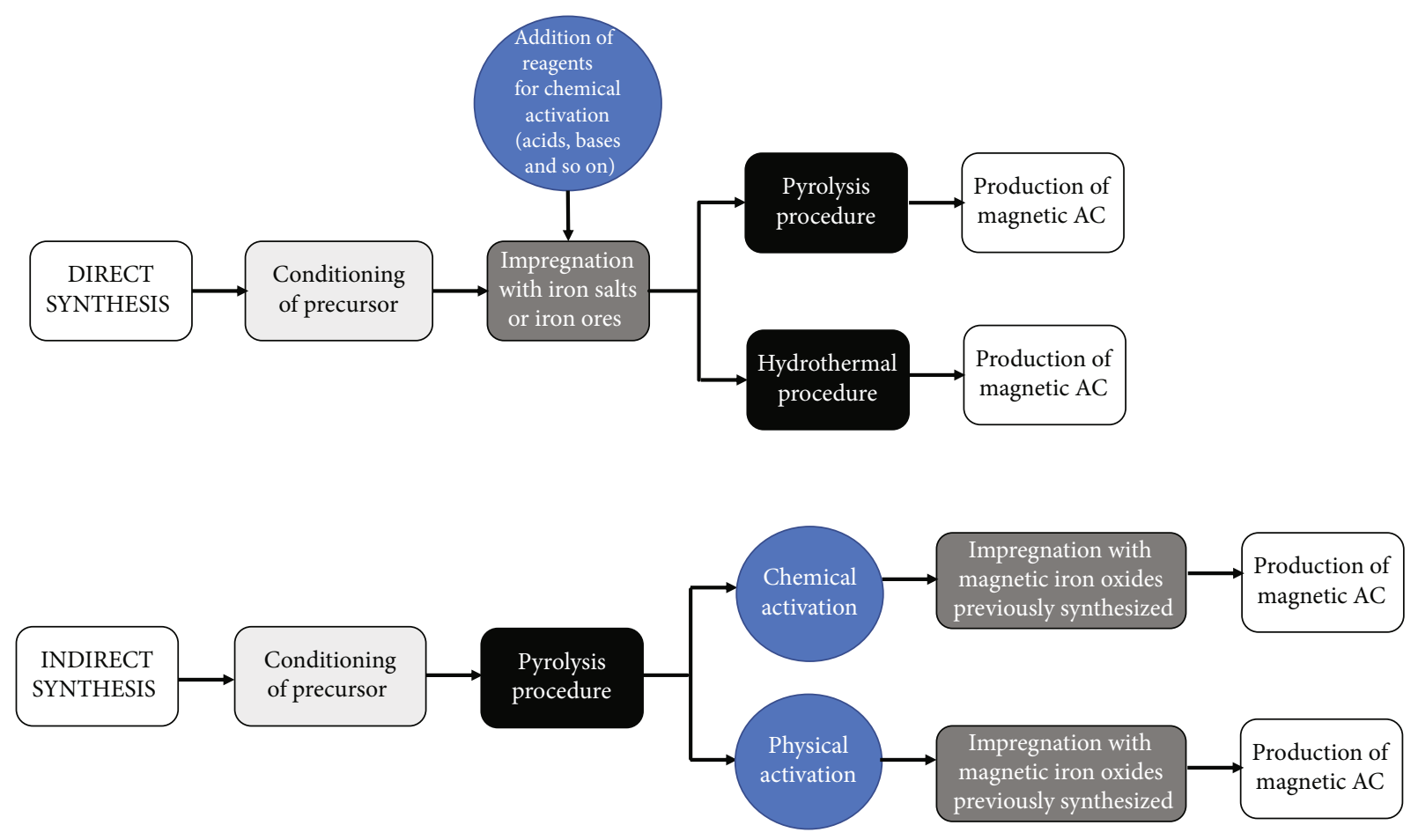

(b)

FIGURE 2: General steps for the preparation of: (a) magnetic hydrochar (HC) and magnetic biochar (BC) by direct or indirect synthesis and (b) magnetic activated carbon (AC) by direct or indirect synthesis.

adsorbents. They have been considered as better graphene derivative nanomaterials than pure graphene, and, compared to raw or commercial chars, they offer high surface areas for the adsorbent preparation. However, these nanopowder adsorbents can aggregate easily in a liquid-phase thus making difficult their separation from aqueous media where additional steps (e.g., centrifugation and granulation by binder) are needed [29]. Magnetic modification is an alternative solution for the recovery and reuse of those materials. For this purpose, magnetic forms of graphene-based materials can be prepared first by GO or RGO synthesis and then modified with magnetic NPs (usually iron oxides).

In general, GO and RGO can be obtained by several synthesis methods such as mechanical cleaving (exfoliation), chemical exfoliation by oxidation, chemical synthesis, arc discharge, and thermal chemical vapor deposition (CVD) 


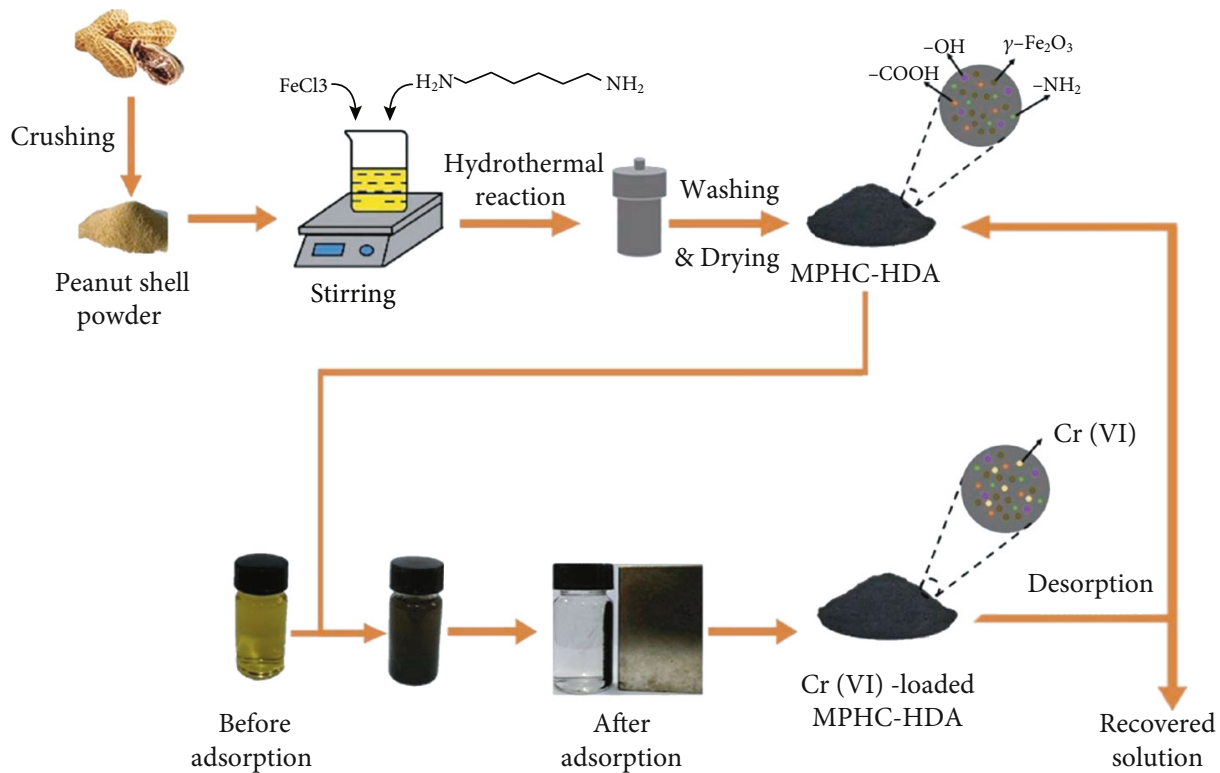

FIGURE 3: HTC used to prepare magnetic adsorbents for Cr (VI) removal from aqueous solution [64].

[67-70]. However, the most usual method to prepare magnetic form of GO or RGO is the exfoliation by oxidation of graphite flakes with the direct or indirect HummersOffeman procedure [71]. There is also an alternative method that consists in biomass carbonization with specific reagents to promote graphitization and to obtain graphene-like carbon nanosheets $[72,73]$. An overview of graphene-based preparation methods is given in the next subsections.

3.2.1. Magnetic $G O$ and $R G O$ Synthesis by Graphite Oxidation Method (GOM). Basically, the chemical exfoliation is a top-down method where the graphite precursor in solution is exfoliated by incorporating large alkali ions between the graphite layers [74]. Herein, it is convenient to remark that the main method to obtain GO implies a mixture of powdered flake graphite, sulfuric acid, and sodium nitrate, which is cooled at $0{ }^{\circ} \mathrm{C}$ with an ice-bath. Potassium permanganate should be carefully added to the mixture under vigorous agitation, preventing that the temperature can exceed $20{ }^{\circ} \mathrm{C}$. Then, the temperature is increased to 35 ${ }^{\circ} \mathrm{C}$ and maintained for $30 \mathrm{~min}$. After this period, water is added and slowly stirred thus causing a violent effervescence and a final temperature of $\sim 98{ }^{\circ} \mathrm{C}$. The diluted color brown suspension is maintained at this temperature for $15 \mathrm{~min}$, and warm water is used to dilute the suspension. Hydrogen peroxide is utilized to reduce the residual permanganate and manganese dioxide to colorless soluble manganese sulfate. This hydrogen peroxide treatment causes that the suspension turns bright yellow, which is a characteristic of GO [71]. RGO can be prepared from GO applying an additional method for reduction that can be carried out by chemical or physical routes [44]. Chemical reagents such as hydrazine hydrate [44], $\mathrm{NH}_{3}$ [75], and L-ascorbic acid [76] have been employed for the chemical reduction of GO. On the other hand, the physical reduction can be performed via thermal reduction [44], hydrothermal reduction [77], and microwave-assisted reduction [78].

Magnetic GO or magnetic RGO can be obtained from the corresponding graphene precursor with different methods to modify its structure for preparing the magnetic composite. The most conventional procedure consists of the material impregnation with IONPs at given time and temperature. Figure 5 provides the general procedure for obtaining magnetic versions of GO and RGO.

Some variations in GO production and its postimpregnation for magnetic modification have been developed by several researchers. Specifically, a magnetic graphene/iron oxide composite for the uranium removal was prepared by Zong et al. [79]. GO synthesis was done with a modified Hummers and Offeman method where $500 \mathrm{~mL}$ of $\mathrm{H}_{2} \mathrm{SO}_{4}$ solution, $4 \mathrm{~g}$ of graphite, and $3 \mathrm{~g}$ of $\mathrm{NaNO}_{3}$ were mixed. This suspension was stirred in an ice-water bath, and $18 \mathrm{~g}$ of $\mathrm{KMnO}_{4}$ was slowly added during $2.5 \mathrm{~h}$. The mixture was stirred for 5 days at $<25{ }^{\circ} \mathrm{C}$ and $560 \mathrm{~mL}$ of $5 \mathrm{wt} \% \mathrm{H}_{2} \mathrm{SO}_{4}$ was added dropwise for $2.5 \mathrm{~h}$ and stirred at $98^{\circ} \mathrm{C}$. The temperature decreased to $55^{\circ} \mathrm{C}$, and $12 \mathrm{~mL}$ of $\mathrm{H}_{2} \mathrm{O}_{2}$ (about 30 wt\%) was also added dropwise and then stirred for $2.5 \mathrm{~h}$ at room temperature. The mixture was centrifuged for 20 min at 19,000 rpm, the liquid and solid phases were separated with bath sonication and potent stirring, and the final product was washed with distilled water. Magnetic GO was obtained by impregnation using $0.50 \mathrm{~g}$ of $\mathrm{GO}$ and a 300 $\mathrm{mL}$ container with $0.58 \mathrm{~g} \mathrm{FeCl}_{2} \cdot 4 \mathrm{H}_{2} \mathrm{O}$ (i.e., $\mathrm{Fe}^{2+}: \mathrm{Fe}^{3+}$ molar ratio of $1: 2)$ and $1.56 \mathrm{~g} \mathrm{FeCl}_{3} \cdot 6 \mathrm{H}_{2} \mathrm{O}$. An ammonia solution (28 wt\%) was slowly added, adjusted the $\mathrm{pH}$ at 10.5 , and stirred for $8 \mathrm{~h}$ at $90{ }^{\circ} \mathrm{C}$. The final black solution was filtered and washed with distilled water until obtaining a $\mathrm{pH} 7$ in the filtrated solution. Besides, Ghorbanian et al. [80] reported the synthesis of a magnetic nanocomposite with GO and a chitosan matrix functionalized with 1,5-diphenylcarbazone (DPC) and magnetite for lead extraction from water. GO 


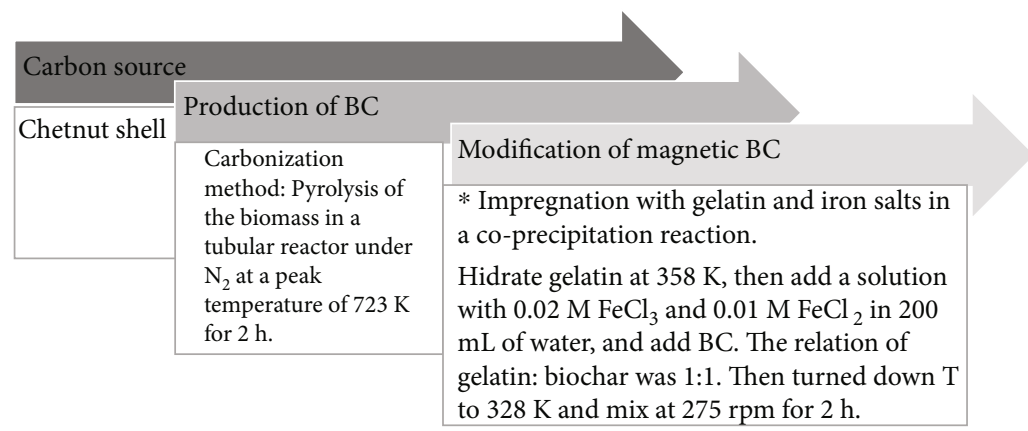

(a)

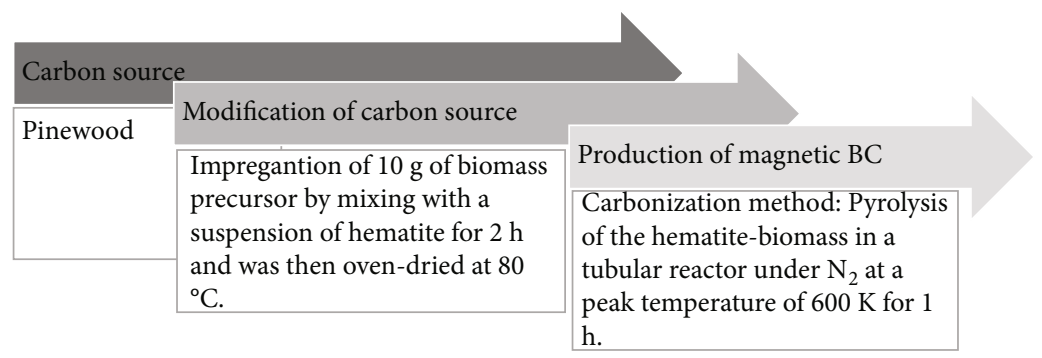

(b)

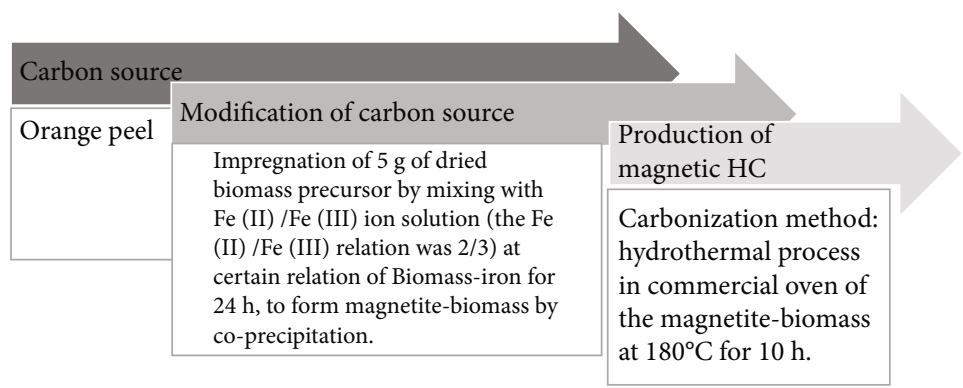

(c)

FIGURE 4: Preparation of magnetic biochar (BC) and hydrochar (HC) using several methods: (a) gelatin modified-magnetic BC [25], (b) magnetic BC by direct pyrolysis [24], and (c) dendrimer-like magnetic HC by direct hydrothermal carbonization [23]. Additional information for the magnetic iron oxides preparation can be found in Noor et al. [58].

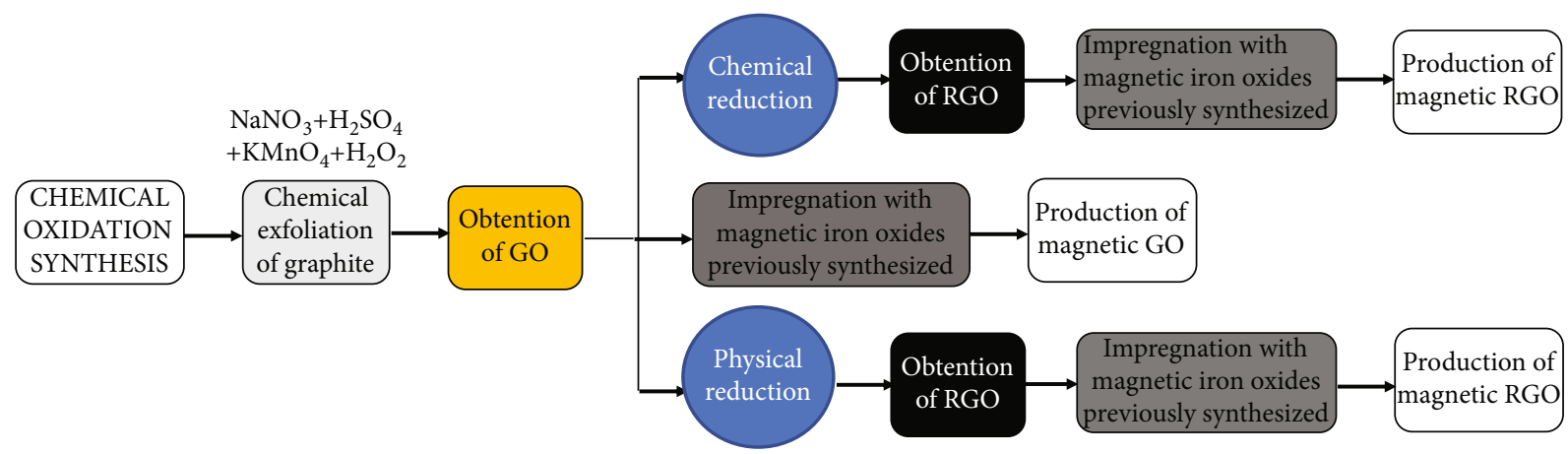

FIGURE 5: General steps for the preparation of magnetic graphene oxide (GO) and magnetic reduced graphene oxide (RGO) by GCEM.

was prepared with a modified Hummers and Offeman method where graphite powder was poured into a 9:1 mixture of concentrated $\mathrm{H}_{2} \mathrm{SO}_{4} / \mathrm{H}_{3} \mathrm{PO}_{4}(360: 40)$. $\mathrm{KMnO}_{4}$ was slowly added to the mixture, and it was heated up to $50{ }^{\circ} \mathrm{C}$ and stirred for $24 \mathrm{~h}$, and the final temperature was decreased to room temperature. $400 \mathrm{~mL}$ of pure ice and $\mathrm{H}_{2} \mathrm{O}_{2}(30 \%$, $v / v$ ) was added to this mixture. GO was washed with water, centrifuged, and dried at $60{ }^{\circ} \mathrm{C}$. Acylated $\mathrm{GO}$ was obtained from GO and dried $\mathrm{SOCl}_{2}$ with reflux at $70{ }^{\circ} \mathrm{C}$ for $24 \mathrm{~h}$. Anhydrous dimethylformamide was used to wash this mixture and then dried. Toluene and $\mathrm{GO}-\mathrm{Cl}$ were mixed by sonication, and DPC was added to the solution, the 
mixture was heated and refluxed for $24 \mathrm{~h}$, rinsed with methanol, and dried at room temperature to obtain GO-DPC. Acetic acid solution $(2 \% v / v)$ was used to dissolve chitosan in an ultrasonic bath to generate a homogeneous solution for magnetic modification. Chitosan solution and magnetic NPs were stirred for $2 \mathrm{~h}$ to obtain a uniform suspension. GO-DPC was added to a reaction flask with 15 glutaraldehyde, the mixture $\mathrm{pH}$ was adjusted at 9.5 by drop wise of $0.1 \mathrm{~mol} / \mathrm{L} \mathrm{NaOH}$, and the solution was maintained at 80 ${ }^{\circ} \mathrm{C}$ for $1 \mathrm{~h}$. The magnetic composite was collected by the magnet, washed with double-distilled water and ethanol to neutral $\mathrm{pH}$, and dried at $50{ }^{\circ} \mathrm{C}$.

It is important to remark that GO is more suitable than RGO for adsorption applications, but some researchers have carried out some experiments to remove water pollutants. As example, magnetic GO and RGO prepared by annealing reduction at $500{ }^{\circ} \mathrm{C}$ under $\mathrm{N}_{2}$ (magnetic annealing-RGO) and by chemical reduction with hydrazine hydrate (magnetic chemically-RGO) were studied by Huang et al. [44]. Magnetic GO was the best adsorbent with competitive adsorption capacities of tetracycline, $\mathrm{Cd}^{2+}$, and $\mathrm{As}^{5+}$ due to its oxygenated functional groups.

\subsubsection{Production of Pseudographene by Biomass} Carbonization Method (BCM). Biomass is a renewable carbon-containing source available worldwide [81]. According to Wang et al. [81], the global production of biomass is estimated in 146 billion tons, which is generated as residue by industry, agriculture, forestry, and other sources. Therefore, several studies have used biomasses as inexpensive raw materials with the aim of solving environmental pollution problems. The development of biomass-based CNMs implies an important effort to contribute to the science progress. However, the use of biomasses to prepare high performance CNMs is still challenging due to its high oxygen content, strong chemical bonding, and complex structure [81]. Several methods for preparing CNMs from biomasses have been studied including CVD (in situ and two-stage), pyrolytic transformation (e.g., thermo-chemical activation, catalytic graphitization, and catalytic graphitization coupled with thermo-chemical activation), mechanical activation, cyclic oxidation, combustion, and microwave-assisted pyrolysis $[58,81]$. A comprehensive discussion of these methodologies is given in the reviews of Noor et al. [58] and Wang et al. [81].

Particularly, the pyrolytic transformation by catalytic graphitization is the most used method to obtain pseudographene $[81,82]$. Conventional graphitization is a type of pyrolysis that requires graphitizable precursors and is carried out at high temperature $\left(>2000{ }^{\circ} \mathrm{C}\right)$, which increases the process cost and security risks thus limiting its industrial scalability [82]. As an alternative method, the catalytic graphitization is a simple strategy consisting of the precursor carbonization using transition metals as catalysts [82]. This process allows that graphitizable and nongraphitizable carbon materials can be converted into crystalline materials at temperatures $<1000{ }^{\circ} \mathrm{C}$ and, consequently, thus reducing the energy consumption and costs [82]. Figure 6 shows some routes to prepare CNMs [81]. Basically, the modification technique to obtain magnetic materials consists of a biomass (carbon precursor) pretreatment and its impregnation with an activating agent and/or catalyst and the final carbonization via conventional or nonconventional methods. The use of metals from group 4-7 (e.g., $\mathrm{Fe}, \mathrm{Co}, \mathrm{Ni}$, and $\mathrm{Mn}$ ) contributes to the conversion of amorphous carbon to graphitic carbon via the reduction of the corresponding activation energy. In fact, they are ideal as graphitization catalysts due to their 2-5 electrons in the d-shell orbitals that allow the formation of strong bonds between carbon-based materials and metal carbides [81]. Some examples of BCM routes are described below.

Graphene-like nanosheet materials with high surface area can be prepared from simple BCM route using coconut shell, $\mathrm{FeCl}_{3}$ and $\mathrm{ZnCl}_{2}$ as carbon precursor, graphitic catalyst precursor, and activating agent, respectively [72]. $\mathrm{ZnCl}_{2}$ and coconut shell were mixed in a $3 \mathrm{M} \mathrm{FeCl}_{3}$ solution, and the impregnation was performed by evaporation at $80{ }^{\circ} \mathrm{C}$ for 2 $\mathrm{h}$ under stirring and a final drying at $100{ }^{\circ} \mathrm{C}$. The activation and graphitization of the coconut shell were performed at $900{ }^{\circ} \mathrm{C}$ for $1 \mathrm{~h}$ with $\mathrm{N}_{2}$ atmosphere in a tubular furnace. Magnetic composites were prepared at 800 and $1000{ }^{\circ} \mathrm{C}$ forming the magnetic species $\mathrm{CFe}_{3}$ and $\alpha$-Fe. Moreover, sugar has been used as a carbon precursor to prepare magnetic graphene-like nanosheets for $\mathrm{U}^{6+}$ adsorption [73]. The disaccharide sugar was slowly heated at $200{ }^{\circ} \mathrm{C}$ for $1 \mathrm{~h}$ under $\mathrm{N}_{2}$ flow in a furnace to achieve its caramelization. The furnace temperature was increased to $750{ }^{\circ} \mathrm{C}$ within 1 $\mathrm{h}$ and then maintained for $3 \mathrm{~h}$ to convert caramel to inorganic carbon. The pyrolyzed sugar was milled, and the final powder was utilized as a sugar-based pseudographene carbon. The oxidized pseudographene form was prepared using a treatment with ozone in water at rate of $5 \mathrm{~g} / \mathrm{h}$ for $1 \mathrm{~h}$ and sonication, and the final product was washed with deionized water and dried at $80{ }^{\circ} \mathrm{C}$ for $8 \mathrm{~h}$. The magnetic phase impregnation was done with a fast in situ synthesis of magnetite where a solution of $\mathrm{FeCl}_{3} \cdot 6 \mathrm{H}_{2} \mathrm{O}$ and $\mathrm{FeCl}_{2} \cdot 4 \mathrm{H}_{2} \mathrm{O}(2: 1$ molar ratio of $\mathrm{Fe}^{3+}: \mathrm{Fe}^{2+}$ ) was dropwise added into oxidized pseudographene sample at room temperature under vigorous stirring and $\mathrm{N}_{2}$ purging. Solution $\mathrm{pH}$ was adjusted to $\geq 10$ and maintained at $80^{\circ} \mathrm{C}$ for $1 \mathrm{~h}$ with continuous stirring where a black precipitate was formed. The final product was washed, separated with an external magnetic field, and dried at $60{ }^{\circ} \mathrm{C}$ for $12 \mathrm{~h}$ under vacuum.

3.2.3. Magnetic Carbon Nanotubes (CNTs). CNTs are also nanomaterials utilized to prepare magnetic adsorbents. A number of methods has been reported for the preparation of magnetic iron oxide/CNTs composites by routes that firstly include the preparation of CNTs (e.g., CVD, arc discharge, and vapor phase growth) [83] and the subsequent modification with MNPs using sol-gel [84], solvothermal [85], reverse microemulsion [86], hydrothermal [87, 88], high-temperature decomposition [89], or coprecipitation method [90-92].

For CNTs synthesis, the CVD is the most conventional method where a carbon precursor, catalyst and growth promoter are usually needed. As example, MWCNTs can be prepared via catalytic CVD of hexane using magnesium/iron 


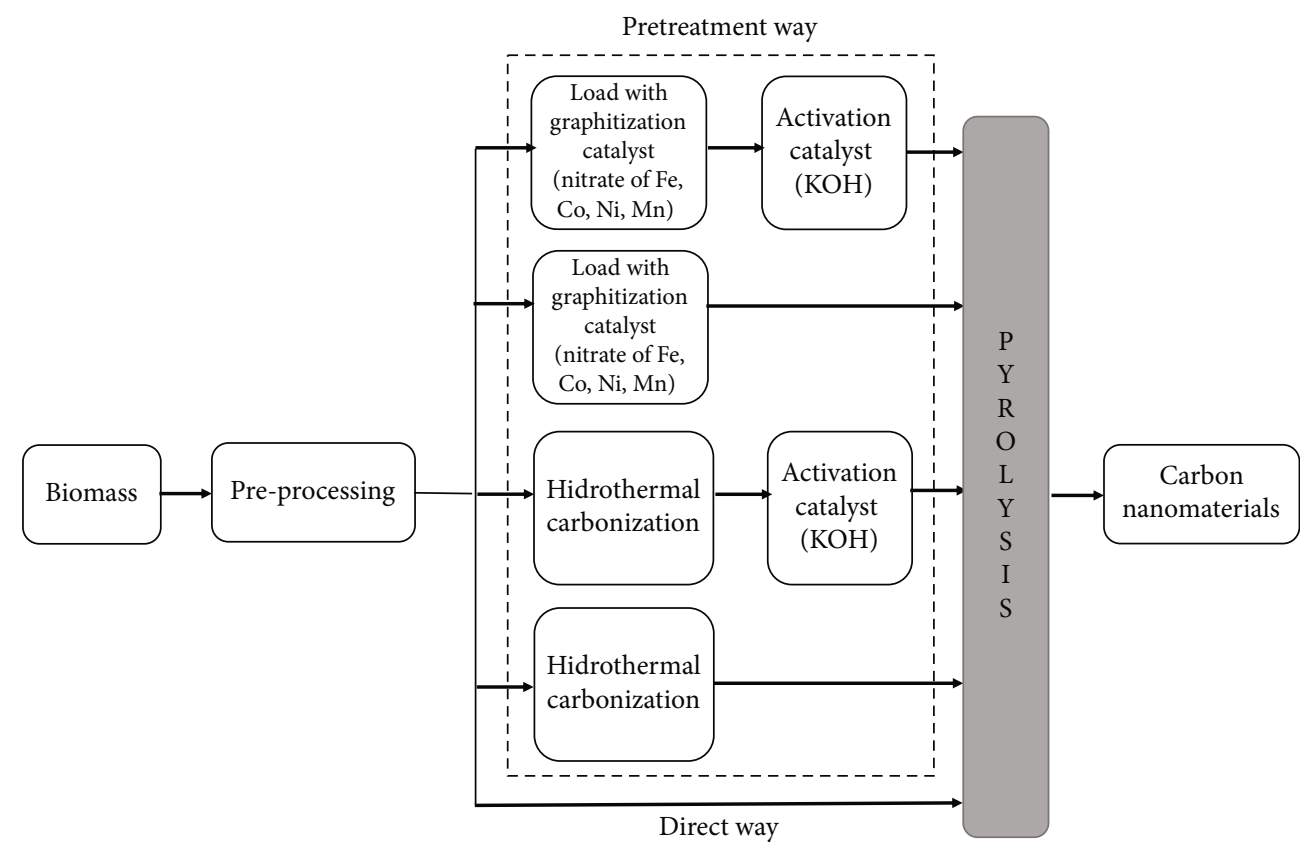

FIgURE 6: Preparation of carbon nanomaterials from biomasses [81].

layered double hydroxide as catalyst precursor [90]. MWCNTs were purified with a $3 \mathrm{M} \mathrm{HNO}_{3}$ solution at room temperature for $24 \mathrm{~h}$, filtered and washed with distilled water. $\mathrm{H}_{2} \mathrm{SO}_{4} / \mathrm{HNO}_{3}$ mixture $(3: 1 v / v)$ and sonication were applied to activate MWCNTs at room temperature. $0.05 \mathrm{M}$ $\mathrm{Fe}\left(\mathrm{NO}_{3}\right)_{3}$ solution and activated MWCNTs were mixed under stirring, and, subsequently, an ammonia solution (2.5 wt.\%) was slowly added until reaching $\mathrm{pH}$ 9.5. Filtration and washing with distilled water were used to obtain the final product that was dried at $100{ }^{\circ} \mathrm{C}$ for $12 \mathrm{~h}$. Finally, MWCNTs-IONPs were obtained via an annealing at 500 ${ }^{\circ} \mathrm{C}$ for $1.5 \mathrm{~h}$ under Ar flow.

Typically, hydrocarbons are sources for CNT synthesis; nevertheless, some studies employed alternative precursors in order to propose a green synthesis. Ma [93] prepared SWCNTs by spray pyrolysis with ethanol (carbon precursor), ferrocene (catalyst), and thiophene (growth promoter). Thiophene and ferrocene were dissolved in ethanol by sonication, and the final solution was employed in spray pyrolysis. A tubular furnace with a quartz tube was heated at $1000-1150{ }^{\circ} \mathrm{C}$ under Ar flow. The mixture (ethanol-ferrocene-thiophene) was sprayed through a nozzle to the furnace and pyrolyzed, and the final sample was collected. For purification stage, the pristine sample was heated at $400{ }^{\circ} \mathrm{C}$ in continuous oxygen flow to oxidize iron NPs, and the oxidized sample was further heated at 800$900{ }^{\circ} \mathrm{C}$ for $1 \mathrm{~h}$ under $\mathrm{Ar}$ flow and exposed to $12 \mathrm{M} \mathrm{HCl}$ treatment at $100{ }^{\circ} \mathrm{C}$ for $4 \mathrm{~h}$. The final product was filtrated and washed until obtaining a neutral $\mathrm{pH}$.

$\mathrm{Ma}$ et al. [17] reported the application of arc discharge evaporation of a carbon electrode with an iron catalyst to obtain SWCNTs. This synthesis was done using two electrodes that were located in the center of a water-cooled stainless-steel chamber. Pure graphite-rod and graphite-rod containing 4 wt $\%$ of iron catalyst were the cathode and anode, respectively. The direct current arc discharge was obtained with $120 \mathrm{~A}$ in a gas mixture of $\mathrm{Ar}$ and $\mathrm{H}_{2}$. After $30 \mathrm{~min}$ of arc evaporation, $\sim 500 \mathrm{mg}$ of iron NPs- SWCNTs was obtained. The product was heated at $350{ }^{\circ} \mathrm{C}$ for $6 \mathrm{~h}$ in air to oxidize iron NPs and to remove the amorphous carbon.

Once CNTs have been obtained, a modification and/or functionalization stage is necessary to obtain magnetic CNTs. Note that interesting purification and modification methods for magnetic CNTs preparation have been reported. For instance, commercial MWCNTs can be functionalized with dibenzo-18-crown- 6 moieties for amoxicillin adsorption [87]. The partial oxidation and impurity removal of MWCNTs were done by dispersion in concentrated $\mathrm{HNO}_{3}$ at $130{ }^{\circ} \mathrm{C}$ for $30 \mathrm{~min}$. For the magnetic modification stage, the pretreated MWCNTs were added to a mixture obtained from ammonium iron sulfate hexahydrate dissolved in water and a hydrazine hydrate solution. This suspension was stirred and sonicated, and the solution $\mathrm{pH}$ was adjusted to 11-13 and refluxed at boiling point for $2 \mathrm{~h}$. Filtration and washing of magnetic MWCNTs were done with water and ethanol, and the product was dried for $24 \mathrm{~h}$ under vacuum. Ethanol was used to disperse magnetic MWCNTs and sonicated for $10 \mathrm{~min}$ to do the crownfunctionalization. This system was mixed with a dicyclohexylcarbodiimide ethanolic solution, stirred for $10 \mathrm{~min}$ and, finally, a solution of 4,4'-diaminodibenzo-18-crown-6 was added to the mixture, which was stirred at room temperature for $24 \mathrm{~h}$. The final products were washed with water and dried for $12 \mathrm{~h}$ under vacuum.

In addition, magnetic MWCNTs were prepared to remove $\mathrm{As}^{5+}$ and $\mathrm{As}^{3+}$ from water [91]. Commercial MWCNTs were treated with $\mathrm{HNO}_{3}$ solution (70\%) at 70 ${ }^{\circ} \mathrm{C}$ for $12 \mathrm{~h}$ to incorporate oxygenated functionalities with the aim of increasing their affinity for the IONPs. $\mathrm{Fe}^{3+} / \mathrm{Fe}^{2+}$ solution (molar ratio $=2$ ) and oxidized MWCNTs were 
mixed by ultrasonication for $4 \mathrm{~h}$. Then, the magnetic material was obtained via the addition dropwise of a $6 \mathrm{M} \mathrm{NaOH}$ solution until reaching $\mathrm{pH}$ 8. In a recent study, magnetic MWCNTs were embedded in a hydrophilic polyvinylidene fluoride (PVDF) membrane for the adsorption of $\mathrm{As}^{3+}$ [50]. First, copper-ferrite was obtained from the dissolution of ethylene glycol, $\mathrm{FeCl}_{3}, \mathrm{CuCl}_{2} \cdot 2 \mathrm{H}_{2} \mathrm{O}$, polyethylene glycol, and sodium acetate. This mixture was heated up for $8 \mathrm{~h}$ at $200{ }^{\circ} \mathrm{C}$ using a teflon-lined autoclave and cooled to room temperature. The substrate for MWCNTs membrane preparation was a flat-sheet PVDF membrane. Specifically, $12 \mathrm{mg}$ of MWCNTs was mixed with $30 \mathrm{~mL}$ of pure water, and this mixture was added to the PVDF membrane where $\mathrm{CuFe}_{2} \mathrm{O}_{4}$ particles were dispersed in water, sonicated, and then injected onto the CNT membrane.

It is important to mention that in several papers related to the use of CNTs as supports to prepare carbon-based adsorbents, CNTs were purchased (i.e., they were available commercial products), and a modification step was used to obtain the adsorbent [87, 91]. Only few studies have reported the CNTs synthesis $[17,93]$ because this step could be expensive, and CNTs are difficult to obtain in laboratory with a suitable quality and reproducible properties.

3.2.4. Magnetic Carbon Nanocages (CNCs). CNCs have interesting applications in energy and environmental protection [33]. They can be utilized to prepare hybrid nanomaterials with multifunctional properties [33]. Currently, various synthesis routes have been reported to prepare CNCs including pyrolysis of organic precursors and sol-gel method, CVD, templating by using different metal particles, and arc discharge [94]. However, these approaches have used pyridine, ethanol, and acetylene as carbon sources, which are unsustainable and expensive due to the use of fossil precursors [94]. Therefore, the utilization of porous carbon materials obtained from biomass precursors is an alternative employing pyrolysis, HTC, template-directed synthesis (soft, hard, and dual template), and direct synthesis. Biomass graphitization was proved to be promising to obtain CNCs structures, especially, for environmental applications [94].

A low-cost, simple, and environmentally friendly method to prepare magnetic CNCs, with multiform pore structure, from the lignin carbonization at low temperature was reported by Qin et al. [94]. They prepared CNCs with lignin, $\mathrm{NaOH}$, formalin solutions, and $\mathrm{Fe}\left(\mathrm{NO}_{3}\right)_{2} \cdot 9 \mathrm{H}_{2} \mathrm{O}$. A conventional pyrolysis was carried out at $600{ }^{\circ} \mathrm{C}$ for $3 \mathrm{~h}$, and the final material was used for methyl orange adsorption.

Cho et al. [95] synthesized magnetic CNCs using sugar as carbon precursor, and this material was applied for methylene blue adsorption, see Figure 7. Magnetic NPs were soaked in a sugar solution for $30 \mathrm{~min}$ with a sugar/magnetite ratio of $1: 2$, then, the water was vaporized under magnetic stirring at $85{ }^{\circ} \mathrm{C}$ for $120 \mathrm{~min}$. The dried and impregnated sugar compound was pyrolyzed at $500{ }^{\circ} \mathrm{C}$ for $30 \mathrm{~min}$ in a tubular reactor. The final adsorbent showed a methylene blue adsorption capacity of $52.6 \mathrm{mg} / \mathrm{g}$.

Zuo et al. [96] proposed a green protocol to synthesize magnetic CNCs that were modified with diethylenetriamine
(DETA) and gold using glucose as carbon source where the final adsorbent was applied in the adsorption of methylene blue from aqueous solution. CNCs were synthetized via the HTC of the glucose solution at $180{ }^{\circ} \mathrm{C}$ for $3 \mathrm{~h}$. CNCs were treated with ethanol and DETA and, finally, impregnated with $\mathrm{Fe}_{3} \mathrm{O}_{4}$ NPs diluted in chloroform/ethanol solution at room temperature for $24 \mathrm{~h}$ under stirring. A solution of ethylene glycol/water was mixed with the black solid product where a $\mathrm{HAuCl}_{4}$ solution was dropwise added and stirred at room temperature for $1 \mathrm{~h}$. Finally, $\mathrm{NaBH}_{4}$ solution was added to this mixture and stirred for $2 \mathrm{~h}$ under $\mathrm{N}_{2}$ atmosphere to obtain the final magnetic product.

Petala et al. [33] also reported a green one-step and simple method to prepare magnetic CNCs from pine resin, iron nitrate impregnation, and pyrolysis at $1000{ }^{\circ} \mathrm{C}$. The morphology, textural, and surface properties of magnetic CNCs were analyzed with surface, spectroscopic, and microscopic techniques. Results indicated that the magnetic CNCs presented a homogeneous distribution of core-shell-type magnetic NPs within the carbon matrix where the surface area was $177 \mathrm{~m}^{2} / \mathrm{g}$ with both micropores and mesopores. These magnetic CNCs showed an adsorption capacity of $263.9 \mathrm{mg} / \mathrm{g}$ for the removal of $\mathrm{As}^{3+}$ from aqueous solutions at $\mathrm{pH} 7$.

A low-cost and easily scalable method was proposed by Rudakov et al. [34] to obtain magnetic CNCs via the simple thermolysis of precursors based on a mixture of citrate acid and transition metal (nickel, cobalt, or iron) acetate salts. The effect of thermolysis temperature (in a range of 500$850^{\circ} \mathrm{C}$ ) on magnetic CNCs structural properties was studied. The theory of Ostwald ripening, Arrhenius law for diffusion, and instrumental characterization were used to analyze the thermal dependence of the particle size. Superparamagnetic characteristics were observed for nickel samples annealed at $<700{ }^{\circ} \mathrm{C}$. CNCs prepared with cobalt at $600{ }^{\circ} \mathrm{C}$ showed higher saturation magnetization than CNCs with nickel, while iron nanoparticles were larger than those of cobalt and nickel thus showing ferromagnetic behavior.

3.2.5. Magnetic Carbon Quantum Dots (CQDs) and Magnetic Graphene Quantum Dots (GQDs). The synthesis of CQDs and GQDs usually involves at least 2 stages. First, it is necessary to obtain the quantum dots and then the corresponding magnetic properties are developed in the second stage [52]. Some authors have reported the functionalization of material surface to add functional groups that can interact with a specific adsorbate. CQDs and GQDs can be prepared from various natural carbon sources, but citric acid is the most common one because it consists of carbonyl, carboxylic, and hydroxyl groups [52]. However, other available and low-cost raw biomasses with similar chemical composition can be employed to prepare CQDs and GQDs [52].

Chemical structure, quantum size, and photoluminescent properties of these materials depend on the feedstock chemical structure and the preparation route [52]. The next examples describe interesting synthesis methods to obtain magnetic CQDs and GQDs. For instance, a typical procedure to prepare CQDs employs a mixture of citric acid, dicyandiamide, and water, which is agitated until 


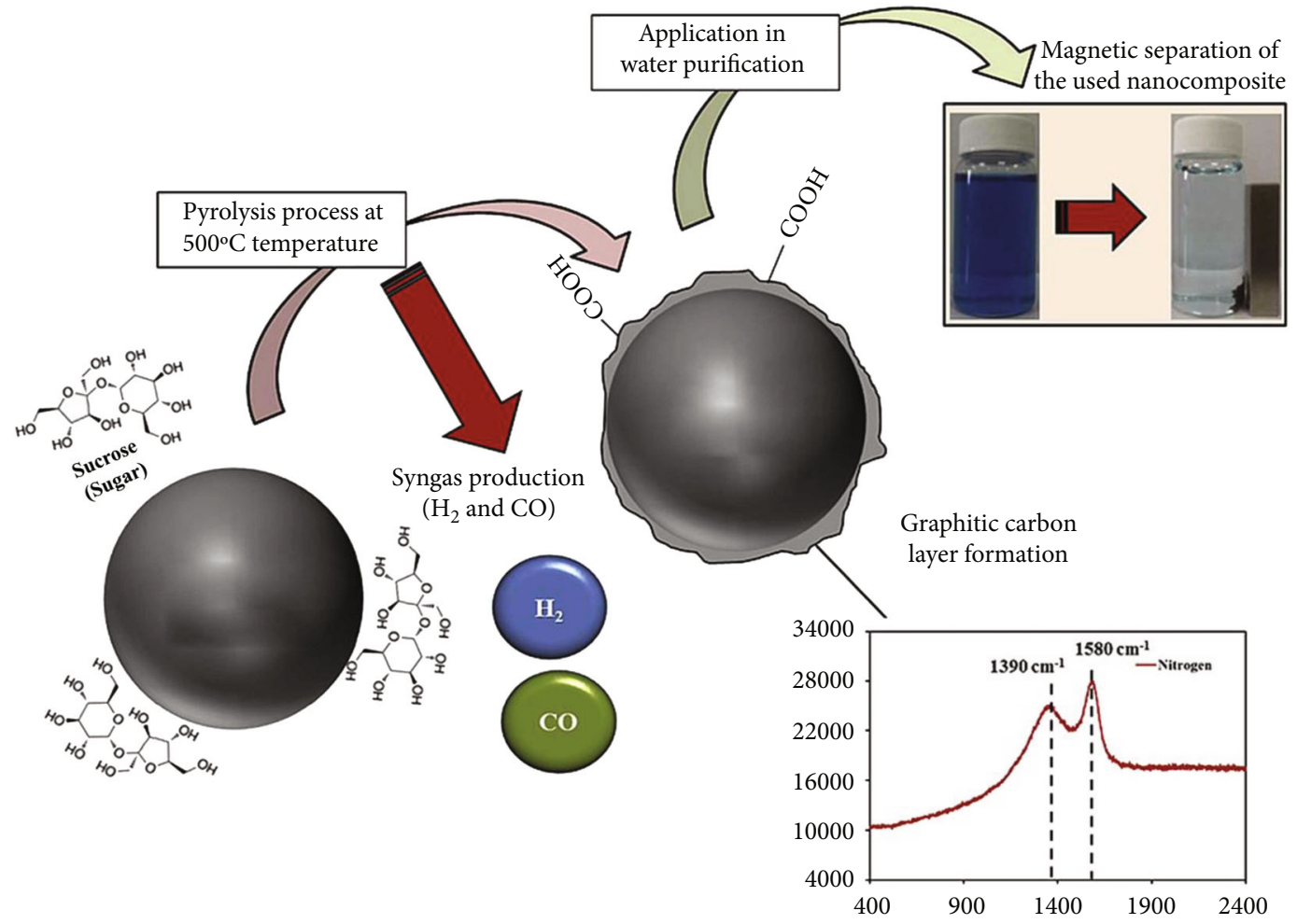

FIgURE 7: Preparation of novel magnetic CNC adsorbent via pyrolysis of sugar for methylene blue adsorption in aqueous solutions [95].

a clear solution is obtained [97]. This solution is transferred to a stainless autoclave and heated to $160{ }^{\circ} \mathrm{C}$ for $4 \mathrm{~h}$. The final product is collected and centrifuged. The magnetic composite can be obtained by coprecipitation where CQDs are dispersed in deionized water by sonication and mixed with $\mathrm{FeCl}_{3} \cdot 6 \mathrm{H}_{2} \mathrm{O}$ solution at room temperature under $\mathrm{N}_{2}$ flow with vigorous stirring. The temperature is increased up to $80{ }^{\circ} \mathrm{C}$, and $\mathrm{FeCl}_{2} \cdot 4 \mathrm{H}_{2} \mathrm{O}$ is slowly added to the solution containing $\mathrm{Fe}^{3+} / \mathrm{CQDs}$ and stirred for additional $30 \mathrm{~min}$. Finally, ammonia is added dropwise to adjust the solution $\mathrm{pH}$ at 10 . The black precipitate can be magnetically separated and washed several times and, subsequently, dried at room temperature [97]. On the other hand, Tadesse et al. [98] proposed a hydrothermal method to prepare nitrogendoped magnetic CQDs using lemon juice and ethylenediamine. These reagents were mixed and heated at $200{ }^{\circ} \mathrm{C}$ for $3 \mathrm{~h}$ to obtain a black paste, which was washed with water to remove insoluble matter. Dichloromethane was added to obtain a brown solution, and a coprecipitation reaction was employed for the magnetic impregnation where metallic salts of $\mathrm{Fe}^{3+} / \mathrm{Fe}^{2+}$ and CQDs were mixed in aqueous solution. $\mathrm{NaOH}$ was added drop wise to this system, and the final product was a magnetic CQDs soluble in water. Recently, Nuengmatcha et al. [99] reported magnetic mercapto-functionalized GQDs for $\mathrm{Cd}^{2+}$ adsorption. GQDs were prepared using citric acid $(2 \mathrm{~g})$ heated at $260{ }^{\circ} \mathrm{C}$ where $100 \mathrm{~mL}$ of $0.25 \mathrm{M} \mathrm{NaOH}$ was added when the color changed to yellow. Maghemite was the magnetic phase and produced by mixing $5 \mathrm{~g}$ of $\mathrm{FeCl}_{3} \cdot 6 \mathrm{H}_{2} \mathrm{O}, 2.5 \mathrm{~g}$ of $\mathrm{FeSO}_{4} \cdot 7 \mathrm{H}_{2} \mathrm{O}$, and deionized water. Subsequently, $20 \mathrm{~mL}$ of $28 \% \mathrm{NH}_{4} \mathrm{OH}$ was added, and the solution was heated at $80{ }^{\circ} \mathrm{C}$ for $30 \mathrm{~min}$ under $\mathrm{N}_{2}$ atmosphere. GQD solution was mixed with maghemite, and this suspension was heated at $80{ }^{\circ} \mathrm{C}$ for 30 min, washed with deionized water, and dried at $90{ }^{\circ} \mathrm{C}$. Magnetic GQDs were modified with $\mathrm{C}_{2} \mathrm{H}_{5} \mathrm{OH}$ and $\mathrm{H}\left(\mathrm{CH}_{2}\right) \mathrm{Si}\left(\mathrm{OCH}_{3}\right)_{3}$. Kahrizi et al. [100] also reported a similar procedure to prepare magnetic GQDs combined with hydroxyapatite for $\mathrm{Cd}^{2+}$ adsorption.

3.3. Magnetic Carbon-Based Adsorbents Prepared from LowCost Feedstocks. One advantage of magnetic carbon-based adsorbents is the possibility of using a wide variety of carbon supports (or holders). However, the preparation and regeneration of adsorbents based on CNTs, graphene, and fullerenes as template are relatively difficult and expensive thus limiting their application at industrial scale [101]. The preparation of carbon materials via simple and low-cost procedures is highly desirable to reach the scale-up and commercialization of magnetic adsorbents [101]. The use of low-cost feedstocks is an alternative to achieve this target. It is necessary to apply raw materials that are abundantly available in nature or produced as by-product and wastes in agro-industrial and other processes. Examples of lowcost feedstocks for the preparation of carbon-based materials include biomasses and urban wastes such as chestnut shell [25], rice straw [27], banana peel [31], pomelo peel [101], rubber tires [102], Tetra pak residues [55], and sewage sludge $[103,104]$. AC, BC, and other carbon-based supports can be obtained from the processing of these wastes via thermal decomposition (e.g., via pyrolysis or HTC) to prepare suitable adsorbents. 
For example, a magnetic AC derived from the carbonization of waste rubber tires and iron impregnation was combined with polyethylenimine to prepare an adsorbent for the removal of methyl red in batch and column experiments [102]. This adsorbent showed a strong dye affinity due to the abundance of hydroxyl and amine groups with an adsorption capacity of $526 \mathrm{mg} / \mathrm{g}$ in batch conditions and a breakthrough time of $150 \mathrm{~min}$. This dye adsorption process was also exothermic. Huang et al. [101] synthesized a magnetic adsorbent using pomelo peels as precursor. This biomass is considered as inedible to humans and is discarded in landfills. These authors proposed a one-pot synthesis method to obtain a magnetic material with a core-shell structure to adsorb apolar parabens and nonpolar fluoroquinolones. This adsorbent showed a competitive removal for both compounds. Also, Deng et al. [105] reported a hybrid magnetic adsorbent obtained from carbon dots and CNTs for carbamazepine removal. Specifically, carbon dots were prepared via $\mathrm{HTC}$ of a mixture of diaminoethane, citric, and nitric acids. Magnetic CNTs and carbon dots were mixed in a rotovapor to prepare this adsorbent, which showed an adsorption capacity of $65 \mathrm{mg} / \mathrm{g}$ at $\mathrm{pH}$ 7. Carbamazepine adsorption was fast and achieved $80 \%$ removal within the first $3 \mathrm{~h}$ of contact time. This adsorbent was easily separated and was regenerated up to 6 times with a capacity loss less than $2.2 \%$

Herein, it should be pointed out that the compounds used to confer magnetic properties in an adsorbent can be also obtained from low cost materials such as urban and industrial wastes (e.g., sewage sludge) [104]. One illustrative example is the iron salts utilized in anaerobic biological wastewater treatment system [104] and chemical precipitation [106]. Sewage sludge contains high amounts of iron species that can be converted to iron oxides with both magnetic and adsorption properties [103, 104]. For instance, a magnetic alkali-acid adsorbent was prepared via the pyrolysis of municipal sewage sludge (containing polyferric sulfate) for the tetracycline removal [103]. Results showed an adsorption capacity of $286 \mathrm{mg} / \mathrm{g}$ where the preparation method affected the adsorption properties of this material. Tetracycline adsorption was dominated by $\pi-\pi$ stacking interaction and strong pore filling effect. Another interesting example is the application of electric arc furnace dust to prepare magnetic adsorbents for water treatment [107]. This material contained a significant amount of iron (37\%) and is generated as by-product from steel industrial sector.

3.4. Techniques for the Characterization of Magnetic CarbonBased Adsorbents. It is important to highlight that the use of instrumental techniques for adsorbent characterization provides key and useful results for understanding the structures and mechanisms involved in the adsorbent preparation route as well as the interactions adsorbate-adsorbent and material performance. The use of these instruments is essential to validate the synthesis routes and analyze the surface chemistry changes of adsorbent after its application to explain its adsorption properties and mechanisms. For the characterization of magnetic adsorbents, there are several techniques that can be used:
(1) Surface chemistry, structural, and morphology characterization using Fourier Transform Infrared Spectroscopy (FTIR), X-Ray Diffraction (XRD), $\mathrm{N}_{2}$ adsorption/desorption isotherms, X-ray Photoelectron Spectroscopy (XPS), High Resolution Transmission Electronic Microscopy (HRTEM), and Transmission Electronic Microscopy (TEM)

(2) Magnetic properties measurement with Vibrating Sample Magnetometry (VSM) and Mössbauer Spectroscopy (MS)

In particular, the electronic microscopy provides important and useful information for understanding the adsorbent performance by (1) analyzing their morphology and chemical composition and (2) studying the specific structures and textures such as the arrangement and dimensions of aromatic layers and interlayer spacing [108]. FTIR analysis gives valuable information about the main surface functional groups, and XRD analysis contributes to study the crystalline structure, while MS is employed to determine oxidation states, electronic spin-state, coordination number, and environment for coordinating compounds. It is convenient to indicate that if iron compounds are analyzed, then the technique is known as Iron-57 Mössbauer Spectroscopy [109-111]. XPS helps to identify the functional states of elements and their chemical bonds on the adsorbent surface [112] $\mathrm{N}_{2}$ adsorption/desorption isotherms give information about the adsorbent textural parameters (i.e., surface area, porosity distribution, and pore volume) [113]. Magnetometry measures the magnetic properties like magnetic moment, permeability, and saturation magnetization. Each instrumental method provides relevant, comparative, and complementary information about the magnetic adsorbents. Based on the fact that the carbon precursor and adsorbent synthesis method generate the possibility to obtain a wide spectrum of materials, the physicochemical properties of magnetic adsorbents can vary substantially. Therefore, a proper and detailed characterization of these adsorbents is fundamental to explain their performance in water treatment and other applications.

\section{Use of Magnetic Adsorbents for Water Pollutant(s) Removal}

Water pollution is undoubtedly a relevant environmental problem where the magnetic carbon-based adsorbents have found to be effective to contribute to its resolution. Adsorption capacities of these materials vary as a function of the adsorbent properties (e.g., surface area and functionalities), the carbon precursor and synthesis route, as well as the adsorption operation conditions like solution $\mathrm{pH}$, temperature, pollutant concentration, among others. Therefore, the adsorption of representative pollutants such as arsenic, pharmaceuticals, heavy metals, dyes, fluoride, pesticides, and other relevant compounds using magnetic carbonbased adsorbents is analyzed and discussed, including their removal performances. Several tables are reported to summarize recent studies about the adsorption of water 
pollutants on magnetic adsorbents where the synthesis route, experimental conditions, adsorption capacities, and properties are shown.

4.1. Arsenic. Arsenic (As) is a geogenic pollutant of water supplies that is a major problem for public health and, consequently, a current and relevant environmental problem for the population of several countries of Southeast Asia, Latin America, and Europe. Natural sources and anthropogenic activities (pesticide usage, fossil fuel combustion, and mining) are the main causes of arsenic pollution [27]. It shows a severe toxicity to humans, and, consequently, the US Environmental Protection Agency (EPA) [114] and World Health Organization (WHO) [115] have recommended a maximum threshold of $10 \mathrm{ppb}$ for arsenic concentration in the water used for human consumption with the aim of protecting consumers supplied by public water systems [26, 33, 116]. However, it has been calculated that over 100 million people can be exposed to arsenic-polluted water [117]. Chronic exposure to arsenic could cause dermal lesions, hypertension, diabetes, cancer, and peripheral vascular disease $[115,118]$. This pollutant can occur in oxidation states of $+5,+3,0$, and -3 , and it is frequently found as arsenates or arsenites [115]. Therefore, the toxicity of this pollutant strongly depends on its chemical nature. Arsenate $\left(\mathrm{AsO}_{4}\right)_{3}$ with $(+5)$ or arsenite $\left(\mathrm{AsO}_{3}\right)_{3}$ with $(+3)$ are the most frequent forms of arsenic in water where arsenite is 20 times more toxic than arsenate [16, 119]. This toxic pollutant can be removed from water using magnetic carbon-based adsorbents. This adsorption process could imply surface complexation and electrostatic attraction between the magnetic adsorbents and arsenic species in the aqueous solution [27, 119]. Table 1 shows recent studies of arsenic adsorption using magnetic forms of AC, CNTs, BC, CNCs, $\mathrm{GO}$, and RGO.

Ntim and Mitra [49] used iron oxide supported on MWCNTs as arsenic adsorbent. MWCNTs were microwave-assisted functionalized and then dispersed in an aqueous solution of $\mathrm{FeCl}_{3}: \mathrm{FeSO}_{4}$ via ultrasonication. This magnetic material showed adsorption capacities of 189 and $1723 \mu \mathrm{g} / \mathrm{g}$ for $\mathrm{As}^{5+}$ and $\mathrm{As}^{3+}$, respectively. Kinetics and isotherms of arsenic adsorption were fitted with the pseudo second-order, Langmuir, and Freundlich models. These authors concluded that arsenic adsorption on this magnetic adsorbent could occur via multiple interactions where the complexation with adsorbent oxyhydroxide sites played a key role.

On the other hand, a novel magnetic adsorbent prepared from orange peel as precursor was studied by Meng et al. [23]. This adsorbent was obtained using hydrothermal process with an iron solution. The influence of operation variables such as solution $\mathrm{pH}$, temperature, and coexisting inorganic coadsorbates on $\mathrm{As}^{5+}$ adsorption was investigated. An $\mathrm{As}^{5+}$ adsorption capacity of $81.3 \mathrm{mg} / \mathrm{g}$ was obtained with an iron/biomass ratio of $10 \mathrm{wt} \%$. Solution $\mathrm{pH}$ affected the arsenic adsorption process, and this removal was also endothermic. The characterization results indicated the formation of a dendrimer-like structure that surrounded the crystal iron NPs inside the branch with the amorphous carbon. Also, an adsorption-reduction phenomenon that included inner reduction and complex adsorption was identified with the characterization data. Removal efficiency after 3 cycles of adsorption-regeneration was found $89 \%$ where deadsorbent showed good mechanical stability with a low iron release (i.e., $<0.3 \mathrm{mg} / \mathrm{L}$ ).

Sahu et al. [16] prepared a novel $\mathrm{Fe}_{3} \mathrm{O}_{4} \mathrm{AC}$ using as precursor cigarette soot. FTIR, Zeta potential, $\mathrm{N}_{2}$ physisorption, EDX, TEM, SEM, XRD, and VSM were used in the adsorbent characterization and to confirm the magnetic phase formation. This adsorbent showed $575.6 \mathrm{~m}^{2} / \mathrm{g}$ of surface area and $10.77 \mathrm{emu} / \mathrm{g}$ of magnetic properties. As ${ }^{5+}$ adsorption was affected by solution $\mathrm{pH}$ where it was reduced with $\mathrm{pH}$ increment, while $\mathrm{As}^{3+}$ adsorption increased from $\mathrm{pH} 3$ to 7 and then decreased. Experimental adsorption data were correlated with pseudo second-order and Langmuir models. The highest adsorption capacities were 80 and $110 \mathrm{mg} / \mathrm{g}$ for $\mathrm{As}^{3+}$ and $\mathrm{As}^{5+}$ at $\mathrm{pH} 7$, respectively. Regeneration studies were performed with $0.5 \mathrm{M} \mathrm{NaOH}$, and results indicated that the adsorption capacities of this adsorbent did not decrease significantly up to 4 consecutive regeneration cycles. The adsorption of $\mathrm{As}^{3+}$ and $\mathrm{As}^{5+}$ species was mainly associated to the hydroxyl groups on the adsorbent surface. Finally, it was concluded that a monodentate complex formation prevailed for $\mathrm{As}^{3+}$ adsorption, while both monodentate and bidentate complex formation and electrostatic attraction were involved in $\mathrm{As}^{5+}$ adsorption.

Multicomponent adsorption of $\mathrm{As}^{3+}$ and $\mathrm{Cd}^{2+}$ was studied using calcium-based magnetic BC with rice straw as carbon source and iron salts [27]. Results demonstrated that the iron favored $\mathrm{As}^{3+}$ adsorption, while calcium enhanced $\mathrm{Cd}^{2+}$ uptake. In the experiments with one adsorbate, the adsorption of both pollutants depended on solution $\mathrm{pH}$ where the maximum removal rate was obtained at $\mathrm{pH} 6$ with maximum adsorption capacities of 10.07 and $6.34 \mathrm{mg} / \mathrm{g}$ for $\mathrm{Cd}^{2+}$ and $\mathrm{As}^{3+}$, respectively. Multicomponent adsorption of these adsorbates included synergistic and competitive effects. In the binary solutions, $\mathrm{As}^{3+}$ adsorption decreased in $15-33 \%$ due to the presence of $\mathrm{Cd}^{2+}$ as coadsorbate, while $\mathrm{Cd}^{2+}$ adsorption increased in $3-16 \%$ due to the presence of $\mathrm{As}^{3+}$. The formation of type $\mathrm{B}$ ternary surface complexes and electrostatic interactions were associated to the multicomponent adsorption effects observed for the binary solution $\mathrm{Cd}^{2+}+\mathrm{As}^{3+}$.

Graphite powder and iron salts were used to prepare a magnetic GO for the $\mathrm{As}^{3+}$ adsorption from aqueous solution [120]. The characteristics of this magnetic GO were studied with FTIR, XRD, and Field Emission SEM/EDX instruments. A central composite design (CCD) was employed to study the $\mathrm{As}^{3+}$ adsorption at batch conditions where the impact of $\mathrm{As}^{3+}$ concentration, contact time, $\mathrm{pH}$, and adsorbent dosage were analyzed by response surface methodology (RSM). The solution $\mathrm{pH}$ impacted the $\mathrm{As}^{3+}$ adsorption where the highest removal was obtained in the range of 26. $\mathrm{As}^{3+}$ removal was $99.95 \%$ at $\mathrm{pH} 7$, adsorbent dosage of $0.3 \mathrm{~g} / \mathrm{L}$, contact time of $77 \mathrm{~min}$, and an initial $\mathrm{As}^{3+}$ concentration of $100 \mathrm{mg} / \mathrm{L} .0 .1 \mathrm{M} \mathrm{NaOH}$ was used to regenerate the magnetic GO where its removal performance decreased up to $80 \%$ after 4 adsorption-desorption cycles. FTIR analysis confirmed that $\mathrm{As}^{3+}$ adsorption involved a monodentate 
TABLE 1: Removal of arsenic from aqueous solution using magnetic carbon-based adsorbents: preparation, removal operating conditions, and adsorption properties.

\begin{tabular}{|c|c|c|c|c|c|c|c|c|c|}
\hline Synthesis route & $\begin{array}{l}\text { Magnetic } \\
\text { source }\end{array}$ & $\begin{array}{l}\text { Carbon } \\
\text { source }\end{array}$ & $\begin{array}{c}\text { As } \\
\text { specie }\end{array}$ & $\begin{array}{l}\text { Adsorption } \\
\text { capacity } \\
(\mathrm{mg} / \mathrm{g})\end{array}$ & $\mathrm{pH}$ & $\begin{array}{c}\mathrm{T} \\
\left({ }^{\circ} \mathrm{C}\right)\end{array}$ & $\begin{array}{l}\text { Magnetization } \\
\quad(\mathrm{emu} / \mathrm{g})\end{array}$ & $\begin{array}{l}\text { BET } \\
\text { area } \\
\left(\mathrm{m}^{2} / \mathrm{g}\right)\end{array}$ & Reference \\
\hline $\begin{array}{l}\text { Magnetic MWCNTs by microwave- } \\
\text { assisted process }\end{array}$ & $\begin{array}{l}\mathrm{Fe}_{3} \mathrm{O}_{4} \\
\text { and } \gamma- \\
\mathrm{Fe}_{2} \mathrm{O}_{3}\end{array}$ & $\begin{array}{l}\text { Commercial } \\
\text { MWCNTs }\end{array}$ & $\begin{array}{l}\mathrm{As}^{3+} \\
\mathrm{As}^{5+}\end{array}$ & $\begin{array}{l}1.723 \\
0.189\end{array}$ & $\begin{array}{l}7 \\
4\end{array}$ & 40 & - & 153 & [49] \\
\hline $\begin{array}{l}\text { Magnetic CNTs by catalytic CVD vapor } \\
\text { deposition with alkali-activated method }\end{array}$ & $\begin{array}{l}\mathrm{Fe}_{3} \mathrm{O}_{4} \\
\text { and } \gamma- \\
\mathrm{Fe}_{2} \mathrm{O}_{3}\end{array}$ & Ethanol & $\begin{array}{l}\mathrm{As}^{3+} \\
\mathrm{As}^{5+}\end{array}$ & $\begin{array}{l}8.13 \\
9.74\end{array}$ & 5.5 & 25 & 27.2 & 662.1 & [119] \\
\hline $\begin{array}{l}\text { Sulfhydryl-functionalized MWCNTs with } \\
\text { CVD synthesis and high-temperature } \\
\text { treatment }\end{array}$ & $\begin{array}{l}\mathrm{Fe}_{3} \mathrm{O}_{4} \\
\text { and } \gamma- \\
\mathrm{Fe}_{2} \mathrm{O}_{3}\end{array}$ & Ethanol & $\mathrm{As}^{3+}$ & 19.12 & 7 & 25 & 27.3 & 139.9 & [89] \\
\hline $\begin{array}{l}\text { Magnetic BC by thermal impregnation of } \\
\text { biomass with natural hematite and direct } \\
\text { pyrolysis procedure }\end{array}$ & $\gamma-\mathrm{Fe}_{2} \mathrm{O}_{3}$ & Pinewood & $\mathrm{As}^{5+}$ & 0.429 & 7 & 22 & - & 193.1 & [24] \\
\hline $\begin{array}{l}\text { Magnetic GO by graphite exfoliation and } \\
\text { coprecipitation }\end{array}$ & $\mathrm{Fe}_{3} \mathrm{O}_{4}$ & Graphite & $\begin{array}{l}\mathrm{As}^{3+} \\
\mathrm{As}^{5+}\end{array}$ & $\begin{array}{l}54.18 \\
26.76\end{array}$ & $\begin{array}{l}8 \\
5\end{array}$ & 25 & 12.8 & 70.20 & [189] \\
\hline $\begin{array}{l}\text { Magnetic MWCNTs by oxidation and } \\
\text { coprecipitation }\end{array}$ & $\mathrm{Fe}_{3} \mathrm{O}_{4}$ & $\begin{array}{l}\text { Commercial } \\
\text { MWCNTs }\end{array}$ & $\begin{array}{l}\mathrm{As}^{3+} \\
\mathrm{As}^{5+}\end{array}$ & $\begin{array}{l}14.26 \\
16.85\end{array}$ & $\begin{array}{c}6.8 \\
3\end{array}$ & 30 & 39.37 & 119.09 & {$[91]$} \\
\hline $\begin{array}{l}\text { Magnetic RGO/CNT composites by } \\
\text { graphite exfoliation and coprecipitation }\end{array}$ & $\mathrm{Fe}_{3} \mathrm{O}_{4}$ & $\begin{array}{l}\text { Commercial } \\
\text { MWCNTs } \\
\text { and graphite }\end{array}$ & $\begin{array}{l}\mathrm{As}^{3+} \\
\mathrm{As}^{5+}\end{array}$ & $\begin{array}{c}9.11 \\
5.1\end{array}$ & 7 & 25 & - & - & {$[190]$} \\
\hline $\begin{array}{l}\text { Si-magnetic GO by graphite exfoliation } \\
\text { and coprecipitation and sol-gel coated }\end{array}$ & $\begin{array}{l}\text { Si-coated } \\
\mathrm{Fe}_{3} \mathrm{O}_{4}\end{array}$ & Graphite & $\begin{array}{l}\mathrm{As}^{3+} \\
\mathrm{As}^{5+}\end{array}$ & $\begin{array}{c}7.5 \\
11.41\end{array}$ & 4 & 25 & - & - & {$[191]$} \\
\hline $\begin{array}{l}\text { Aerogel magnetic CNCs by sol-gel } \\
\text { impregnation and pyrolysis }\end{array}$ & $\mathrm{Fe}_{3} \mathrm{C}$ & Citric acid & $\mathrm{As}^{5+}$ & 56.2 & 7 & 25 & - & 290 & [29] \\
\hline $\begin{array}{l}\text { Magnetic AC by impregnation using iron } \\
\text { and manganese oxides }\end{array}$ & $\gamma-\mathrm{Fe}_{2} \mathrm{O}_{3}$ & $\begin{array}{c}\text { Commercial } \\
\text { AC }\end{array}$ & $\mathrm{As}^{5+}$ & 19.35 & 3 & 25 & 0.35 & 649.4 & [116] \\
\hline $\begin{array}{l}\text { Magnetic BC by hydrothermal } \\
\text { impregnation and carbonization }\end{array}$ & $\mathrm{Fe}_{3} \mathrm{O}_{4}$ & Orange peel & $\mathrm{As}^{5+}$ & 81.3 & 6 & 2 & 45 & 396 & {$[23]$} \\
\hline $\begin{array}{l}\text { Magnetic CNCs by thermal impregnation } \\
\text { with iron salts and pyrolysis method }\end{array}$ & $\mathrm{Fe}_{3} \mathrm{C}$ & Pine resin & $\mathrm{As}^{3+}$ & $\begin{array}{l}263.9 \\
356.6\end{array}$ & $\begin{array}{l}7 \\
4\end{array}$ & - & - & 177 & [33] \\
\hline $\begin{array}{l}\text { Magnetic AC by coprecipitation, } \\
\text { impregnation and carbonization process }\end{array}$ & $\mathrm{Fe}_{3} \mathrm{O}_{4}$ & $\begin{array}{l}\text { Cigarette } \\
\text { soot }\end{array}$ & $\begin{array}{l}\mathrm{As}^{3+} \\
\mathrm{As}^{5+}\end{array}$ & $\begin{array}{c}80.99 \\
107.96\end{array}$ & $\begin{array}{l}7 \\
3\end{array}$ & 25 & 10.77 & 575.6 & {$[16]$} \\
\hline $\begin{array}{l}\text { Gelatin modified-magnetic BC by } \\
\text { pyrolysis and impregnation by } \\
\text { coprecipitation }\end{array}$ & $\gamma-\mathrm{Fe}_{2} \mathrm{O}_{3}$ & $\begin{array}{l}\text { Chestnut } \\
\text { shell }\end{array}$ & $\mathrm{As}^{5+}$ & 45.8 & 4 & 25 & 42 & - & {$[25]$} \\
\hline $\begin{array}{l}\text { Magnetic CNCs by coprecipitation, } \\
\text { impregnation, and hydrothermal synthesis }\end{array}$ & $\mathrm{Fe}_{3} \mathrm{O}_{4}$ & Glucose & $\mathrm{As}^{5+}$ & 20.05 & $\begin{array}{l}1- \\
2\end{array}$ & 25 & 35.1 & - & {$[15]$} \\
\hline $\begin{array}{l}\text { Magnetic SWCNTs prepared by arc } \\
\text { discharge evaporation }\end{array}$ & $\begin{array}{l}\mathrm{Fe}_{3} \mathrm{O}_{4} \\
\text { and } \gamma- \\
\mathrm{Fe}_{2} \mathrm{O}_{3}\end{array}$ & Graphite & $\mathrm{As}^{5+}$ & 49.65 & 4 & 25 & - & - & {$[17]$} \\
\hline $\begin{array}{l}\text { Magnetic BC by thermal impregnation and } \\
\text { pyrolysis with microwave heating }\end{array}$ & $\mathrm{Fe}_{3} \mathrm{O}_{4}$ & $\begin{array}{l}\text { Empty fruit } \\
\text { bunch from } \\
\text { palm }\end{array}$ & $\mathrm{As}^{5+}$ & 88 & $\begin{array}{l}\text { N. } \\
\text { D. }\end{array}$ & 25 & - & 890 & {$[26]$} \\
\hline $\begin{array}{l}\text { Calcium-based magnetic } \mathrm{BC} \text { by } \\
\text { coprecipitation impregnation and pyrolysis }\end{array}$ & $\mathrm{Fe}_{3} \mathrm{O}_{4}$ & Rice straw & $\mathrm{As}^{3+}$ & 6.34 & 5 & 25 & - & - & {$[27]$} \\
\hline $\begin{array}{l}\text { Magnetic CNTs by inverse coprecipitation } \\
\text { and impregnation with Ni-Zn-ferrite }\end{array}$ & $\begin{array}{l}\text { Ni-Zn- } \\
\text { Ferrite }\end{array}$ & $\begin{array}{l}\text { Commercial } \\
\text { MWCNTs }\end{array}$ & $\mathrm{As}^{5+}$ & 66 & 2 & 25 & 15 & 214 & [92] \\
\hline $\begin{array}{l}\text { Magnetic GO by graphite exfoliation and } \\
\text { coprecipitation and magnetic RGO } \\
\text { reduced by hydrazine hydrate }\end{array}$ & $\mathrm{Fe}_{3} \mathrm{O}_{4}$ & Graphite & $\mathrm{As}^{5+}$ & $2-12$ & 14 & 25 & 34 & 148.2 & {$[44]$} \\
\hline
\end{tabular}


TABle 1: Continued.

\begin{tabular}{|c|c|c|c|c|c|c|c|c|c|}
\hline Synthesis route & $\begin{array}{l}\text { Magnetic } \\
\text { source }\end{array}$ & $\begin{array}{l}\text { Carbon } \\
\text { source }\end{array}$ & $\begin{array}{l}\text { As } \\
\text { specie }\end{array}$ & $\begin{array}{l}\text { Adsorption } \\
\text { capacity } \\
(\mathrm{mg} / \mathrm{g})\end{array}$ & $\mathrm{pH}$ & $\begin{array}{l}\mathrm{T} \\
\left({ }^{\circ} \mathrm{C}\right)\end{array}$ & $\begin{array}{l}\text { Magnetization } \\
\quad(\mathrm{emu} / \mathrm{g})\end{array}$ & $\begin{array}{c}\text { BET } \\
\text { area } \\
\left(\mathrm{m}^{2} / \mathrm{g}\right)\end{array}$ & Reference \\
\hline $\begin{array}{l}\text { 3D magnetic GO hydrogel by graphite } \\
\text { exfoliation, coprecipitation, and one-pot } \\
\text { method combining GO sheets, } \mathrm{Fe}_{3} \mathrm{O}_{4} \text {, and } \\
\text { polyacrylamide hydrochloride }\end{array}$ & $\mathrm{Fe}_{3} \mathrm{O}_{4}$ & Graphite & $\begin{array}{l}\mathrm{As}^{3+} \\
\mathrm{As}^{5+}\end{array}$ & $\begin{array}{l}25.1 \\
74.2\end{array}$ & $\begin{array}{l}7.7 \\
6.2\end{array}$ & 25 & 10.5 & - & [192] \\
\hline $\begin{array}{l}\text { MWCNT membranes modified with } \\
\mathrm{CuFe}_{2} \mathrm{O}_{4} \text { by coprecipitation and using } \\
\text { polyvinylidene fluoride (PVDF) membrane } \\
\text { support }\end{array}$ & $\mathrm{Cu}$ ferrite & $\begin{array}{l}\text { Commercial } \\
\text { MWCNTs }\end{array}$ & $\mathrm{As}^{3+}$ & 31.25 & 7 & 25 & - & - & {$[50]$} \\
\hline $\begin{array}{l}\text { Chitosan magnetic GO by graphite } \\
\text { exfoliation and coprecipitation }\end{array}$ & $\mathrm{Fe}_{3} \mathrm{O}_{4}$ & Graphite & $\mathrm{As}^{3+}$ & 45 & 7.3 & 25 & 49.3 & 152.38 & [120] \\
\hline $\begin{array}{l}\text { MGO by graphite exfoliation and } \\
\text { coprecipitation }\end{array}$ & $\mathrm{Fe}_{3} \mathrm{O}_{4}$ & Graphite & $\mathrm{As}^{3+}$ & 99 & 3 & - & - & - & \\
\hline $\begin{array}{l}\text { Multifunctionalized magnetic GO by } \\
\text { coprecipitation and multiple impregnation }\end{array}$ & $\mathrm{Fe}_{3} \mathrm{O}_{4}$ & $\begin{array}{l}\text { Commercial } \\
\text { GO }\end{array}$ & $\begin{array}{l}\mathrm{As}^{3+} \\
\mathrm{As}^{5+}\end{array}$ & $\begin{array}{l}62.7 \\
19.3\end{array}$ & 7 & 25 & 23 & - & {$[76]$} \\
\hline $\begin{array}{l}\text { 1,4-butane sultone modified magnetic AC } \\
\text { by carbonization, activation, and finally } \\
\text { magnetic impregnation with magnetic } \\
\text { phase coprecipitated }\end{array}$ & $\mathrm{Fe}_{3} \mathrm{O}_{4}$ & $\begin{array}{l}\text { Pistachio } \\
\text { shell }\end{array}$ & $\mathrm{As}^{3+}$ & 151.51 & 5.5 & 25 & 11.6 & - & [143] \\
\hline $\begin{array}{l}\text { Magnetic BC by coprecipitation, pyrolysis, } \\
\text { and high-energy ball milling impregnation }\end{array}$ & $\begin{array}{l}\mathrm{Fe}_{3} \mathrm{O}_{4} \\
\text { and } \gamma- \\
\mathrm{Fe}_{2} \mathrm{O}_{3}\end{array}$ & $\begin{array}{l}\text { Slovak } \\
\text { Lignite }\end{array}$ & $\mathrm{As}^{5+}$ & 19.9 & 3.9 & 25 & - & 10.6 & [193] \\
\hline $\begin{array}{l}\mathrm{HTC} \text { with iron salt followed by } \mathrm{NaOH} \\
\text { addition }\end{array}$ & $\mathrm{FeCl}_{3}$ & $\begin{array}{l}\text { Olive } \\
\text { pomace }\end{array}$ & $\mathrm{As}^{5+}$ & 3.5 & 5 & 25 & - & - & [194] \\
\hline Pyrolysis and two step magnetization & $\gamma-\mathrm{Fe}_{2} \mathrm{O}_{3}$ & Corn straw & $\mathrm{As}^{5+}$ & 6.77 & 7 & 25 & 17.5 & 115.43 & {$[195]$} \\
\hline
\end{tabular}

Adsorbent nomenclature: activated carbon (AC), biochar (BC), carbon nanocages (CNCs), carbon nanotubes (CNTs), graphene oxide (GO), multiwalled carbon nanotubes (MWCNTs), single-walled carbon nanotubes (SWCNTs), and reduced graphene oxide (RGO).

complexation between arsenic oxyanions and magnetic GO surface functionalities.

It is important to highlight that arsenic adsorption studies have been carried out mainly at batch conditions, and only few authors have reported packed bed columns for this purpose [117]. Particularly, Xu et al. [117] reported the breakthrough curves for the $\mathrm{As}^{5+}$ adsorption with a magnetic composite obtained from bagasse biomass and iron oxide. The biomass was first impregnated with iron salts in microwave oven, then, it was sonicated with ethanol and subsequently carbonized at $500{ }^{\circ} \mathrm{C}$. Breakthrough curves of $\mathrm{As}^{5+}$ adsorption were quantified at different conditions of bed height, solution flow rate, $\mathrm{pH}$, and $\mathrm{As}^{5+}$ feed concentration. Results showed that the increment of $\mathrm{As}^{5+}$ feed concentration reduced the exhaustion time and breakthrough points. The increment of solution $\mathrm{pH}$ and bed height decreased the $\mathrm{As}^{5+}$ adsorption rate. This adsorbent can be regenerated with $1 \mathrm{M}$ EDTA to recover its $\mathrm{As}^{5+}$ adsorption capacity.

4.2. Pharmaceuticals. Pharmaceutical products, once used or expired, are considered a special type of waste in the environment that have been catalogued as chemicals of emerging concern to the public because of their potential to pollute water $[115,121,122]$. The global pharmaceutical consumption is estimated as $\sim 1,000,000$ tons/year with $15 \mathrm{~g} /$ year as per capita use [123]. Several pharmaceutical molecules cannot be totally absorbed and metabolized, thus, they are excreted and released to the environment. Therefore, a significant amount of pharmaceutics is discharged into the environment during its production, delivery, use, application, and excretion $[115,124]$. For example, the tetracycline (TC) is an important antibiotic widely utilized as antimicrobial in livestock industry and human therapy. It has been established that $50-80 \%$ of TC used in the farming industry can be excreted as unmodified parent compounds via urine and feces [125]. Besides, conventional water treatment plants are not designed to remove pollutants at trace concentrations, and, consequently, the degradation or separation of this and other pharmaceutical compounds is not effective $[122,126]$. Pharmaceutical molecules could be found in concentrations ranging from $\mathrm{ng} / \mathrm{L}$ to $\mu \mathrm{g} / \mathrm{L}$ in ground waters, wastewaters, and surface waters [124]. Wastewaters could contain significant amounts of more than 55 pharmaceuticals over the 150 daily used compounds [127-129]. Most of these compounds have been categorized as essential by the WHO. The bioaccumulation of these compounds represents a serious eco-toxicological risk and implies adverse effects like organism drug resistance, metabolism disruptions, and bacteria strain proliferation [125, 129-131]. There are no international regulations to establish the threshold concentration for pharmaceuticals in the environment, which is mainly due to the lack of studies reporting the long-term effects caused by a chronic exposure to these 
emerging pollutants and their metabolites [132, 133]. The concentration of pharmaceutical compounds can be effectively reduced in water via adsorption [123]. Carbamazepine (CBZ), atenolol, erythromycin, diclofenac, ibuprofen (IBP), and naproxen are the common adsorbates analyzed in adsorption studies. A compilation of the magnetic carbonbased adsorbents utilized for pharmaceuticals removal is presented in Table 2.

Baghdadi et al. [134] reported the preparation of a magnetic nanocomposite using a commercial AC and the CBZ adsorption tests. Different instrumental techniques (SEM, FTIR, $\mathrm{N}_{2}$ physisorption, VSM, XRD, and SEM) were utilized to characterize the surface chemistry, textural parameters, and magnetic properties of this adsorbent. CBZ adsorption from urban wastewater was optimized with a CCD by analyzing different operating conditions (total dissolved solids TDS, CBZ concentration, and adsorbent dosage). It was observed that a high magnetite content for the adsorbent preparation caused the blockage of composite porous structure and the reduction of CBZ adsorption capacities. The maximum CBZ adsorption capacities ranged from 182.9 to $280 \mathrm{mg} / \mathrm{g}$. Besides, the CBZ adsorption decreased slightly with TDS concentration. Authors explained that CBZ adsorption was associated to carboxylic groups, and it was also concluded that the removal of CBZ was exothermic and spontaneous.

The adsorption of amoxicillin (AMX), which is an antibiotic, on magnetic graphene nanoplatelets (GNPs) from aqueous solution was reported by Kerkez-Kuyumcu et al. [135]. Magnetite NPs and GNPs were used to obtain this adsorbent. Results showed that the magnetic GNPs outperformed GNPs and magnetite alone. The increase in solution $\mathrm{pH}$ reduced AMX adsorption, and this adsorbent showed a maximum adsorption capacity of $14.10 \mathrm{mg} / \mathrm{g}$. Electrostatic and $\pi-\pi$ interactions were associated to the AMX adsorption mechanism with magnetic GNPs. Pseudo secondorder kinetic model fitted AMX adsorption, which was spontaneous and exothermic. Magnetic GNPs were regenerated with $0.15 \mathrm{M} \mathrm{NaOH}$, and the adsorbent was utilized during 4 adsorption-desorption cycles where its adsorption capacity remained as $35 \%$.

$\mathrm{Fe}_{3} \mathrm{O}_{4}$ NPs and glucose were the feedstocks to obtain reusable magnetic carbon microspheres (CMs) via HTC [136]. This adsorbent was utilized to remove the antibiotic sulfonamide. Magnetic CMs samples were also calcined at $600{ }^{\circ} \mathrm{C}$ for $1 \mathrm{~h}$ to improve their surface properties thus obtaining a pore volume of $0.448 \mathrm{~m}^{3} / \mathrm{g}$ and surface area of $1228 \mathrm{~m}^{2} / g$. Pseudo second-order and Langmuir equations correlated the antibiotic adsorption data. The adsorption capacity of magnetic CMs decreased with $\mathrm{pH}$ and temperature, and the highest value of $24.22 \mathrm{mg} / \mathrm{g}$ was obtained at $10{ }^{\circ} \mathrm{C}$ and $\mathrm{pH}$ 4. Magnetic CMs were regenerated with $\mathrm{NaOH}$ thus obtaining an adsorption capacity of 18.31 $\mathrm{mg} / \mathrm{g}$ after the antibiotic desorption, and this adsorbent was reused 4 times.

Another type of antibiotics that represents a hidden danger to human health is the fluoroquinolones (FQs). Enrofloxacin (ENR), norfloxacin (NOR), and ciprofloxacin (CIP) were employed as FQs adsorbates to study the adsorp- tion properties of a humic acid-magnetic BC [30]. These authors prepared a magnetic $\mathrm{BC}$ from potato stems and leaves, which were coated with humic acid (HA), see Figure 8. Humic acid-magnetic BC showed the presence of oxygenated functional groups that conferred its adsorption capacity. It exhibited FQ uptakes up to 1.8-3.4 times higher than those reported for raw and magnetic BC for these compounds. Specifically, this magnetic material showed adsorption capacities of $6.0,7.5$, and $7.1 \mathrm{mg} / \mathrm{g}$ for adsorbates ENR, NOR, and CIP, respectively, at $35^{\circ} \mathrm{C}$. The adsorption experimental data were adjusted and analyzed with Langmuir isotherm and pseudo second-order kinetic. FQ adsorption on this magnetic carbon-based adsorbent was associated to $\pi-\pi$, H-bond, hydrophobic, and electrostatic interactions.

Liyanage et al. [133] proposed the preparation of magnetic adsorbent using the IONP precipitation to modify a commercial Douglas fir BC. This magnetic BC was applied to remove 3 emerging water pollutants: caffeine (CF), IBP, and acetylsalicylic acid (ASA) in adsorption systems at batch conditions. This magnetic adsorbent showed a surface area of $322 \mathrm{~m}^{2} / \mathrm{g}$, which was lower than that of BC $(468.2$ $\mathrm{m}^{2} / \mathrm{g}$ ). The adsorption of these pharmaceuticals depended on solution $\mathrm{pH}$ and temperature. Authors concluded that $\mathrm{H}$-bonding, electrostatic, and $\pi-\pi$ interactions were present at different $\mathrm{pH}$ conditions. The adsorption capacities of this adsorbent were 80,40 , and $140 \mathrm{mg} / \mathrm{g}$ for CF, IBP, and ASA, respectively, at $\mathrm{pH} 8$ and $35^{\circ} \mathrm{C}$. Competitive experiments in binary $\mathrm{CF} / \mathrm{IBP}$ solutions showed a decrement in its adsorption capacity of 13.6 and $52.3 \%$, respectively. Surface protonation and CF polarity contributed to generate strong adsorbate-adsorbent interactions thus leading to high adsorption capacities. Adsorbent regeneration was carried out with methanol and water, and results showed that the adsorption capacity remained almost constant during 5 adsorption-desorption cycles.

Wei et al. [123] prepared 7 deep eutectic solvents (DESs) known as green sustainable solvents that were used to regulate the preparation of a magnetic composite from MOF MUiO-66- $\mathrm{NH}_{2}$ and $\mathrm{Fe}_{3} \mathrm{O}_{4}$. The removal of pharmaceuticals mefenamic acid (MF) and ofloxacin (OX) was analyzed with this nanoadsorbent, labelled as DES-MUiO-66- $\mathrm{NH}_{2}$. Under optimal conditions, the adsorption capacities were up to 97.60 and $79.22 \mathrm{mg} / \mathrm{g}$ for OX and MF, respectively. Hydrogen bonding, hydrophobic interaction, $\pi-\pi$ stacking, chelation, and electrostatic interactions were the main forces involved in the adsorption mechanisms. Density functional theory calculations demonstrated the formation of chelation. It was also concluded that DES structures determined the adsorption properties of DESMUiO-66- $\mathrm{NH}_{2}$, thus, offering a green preparation route of tailored adsorbents for emerging water pollutants. The presence of coions (e.g., sulphates, nitrates, chlorides, calcium, potassium, and sodium) did not affect the adsorption. Desorption and regeneration tests were also carried out.

4.3. Heavy Metals. Heavy metals are also relevant water pollutants that are characterized by low biodegradability and high chemical stability. Heavy metals are toxic for ecosystems and human beings at certain concentration thresholds. 


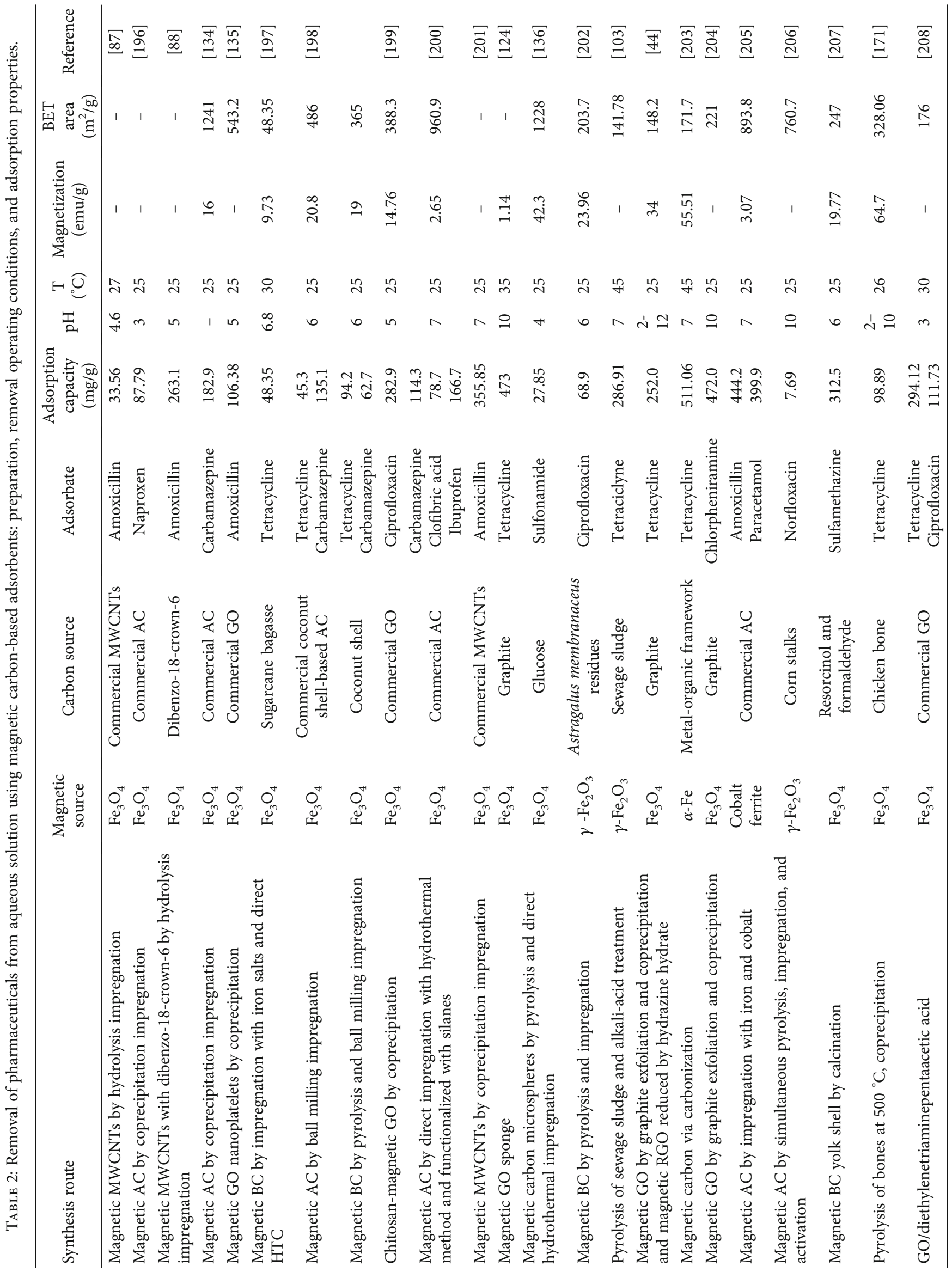




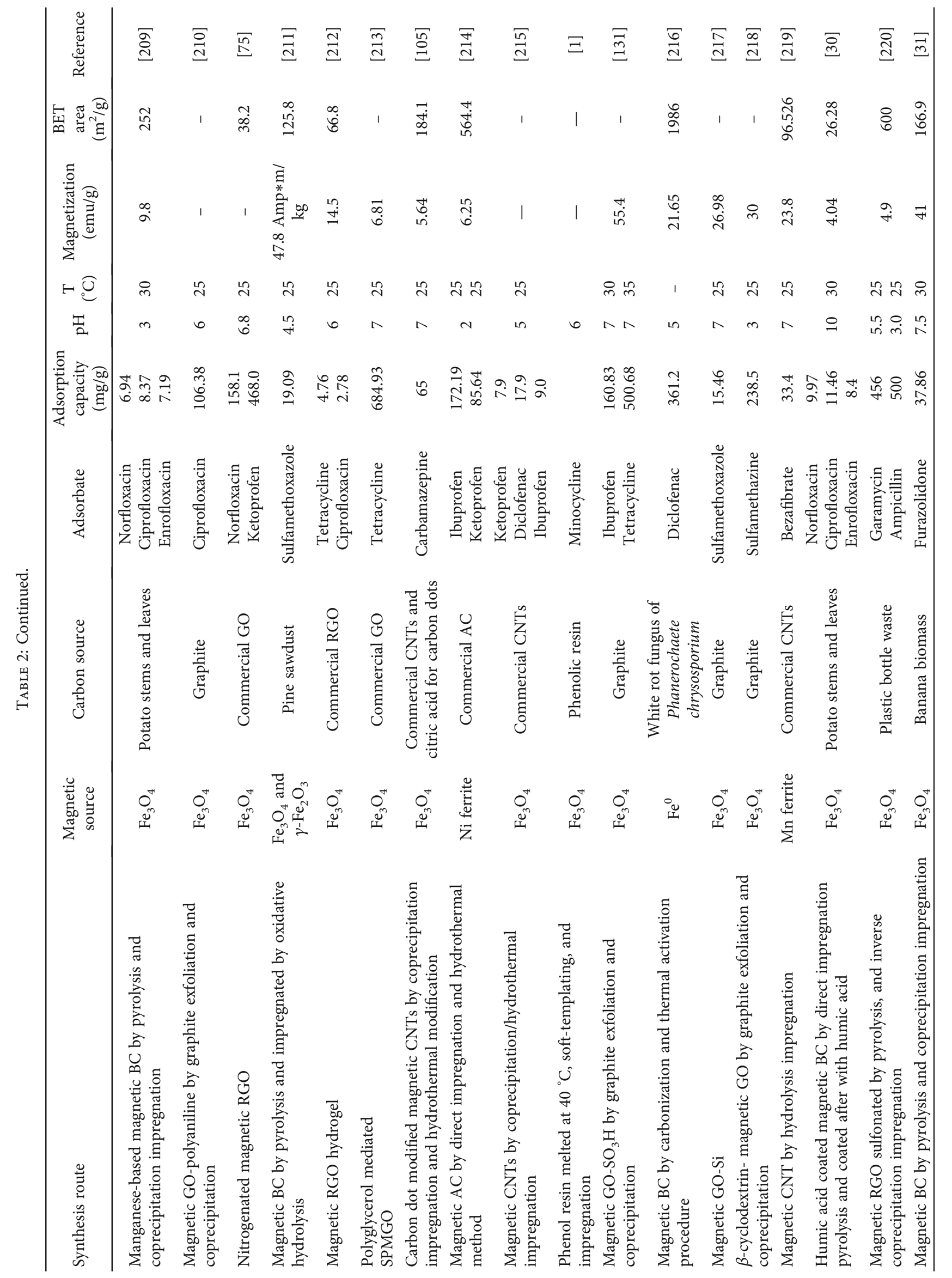




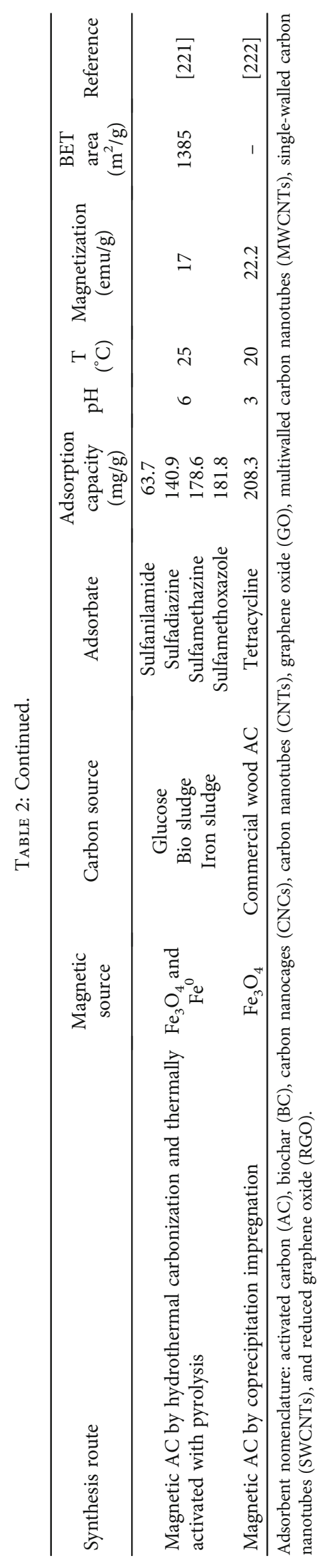




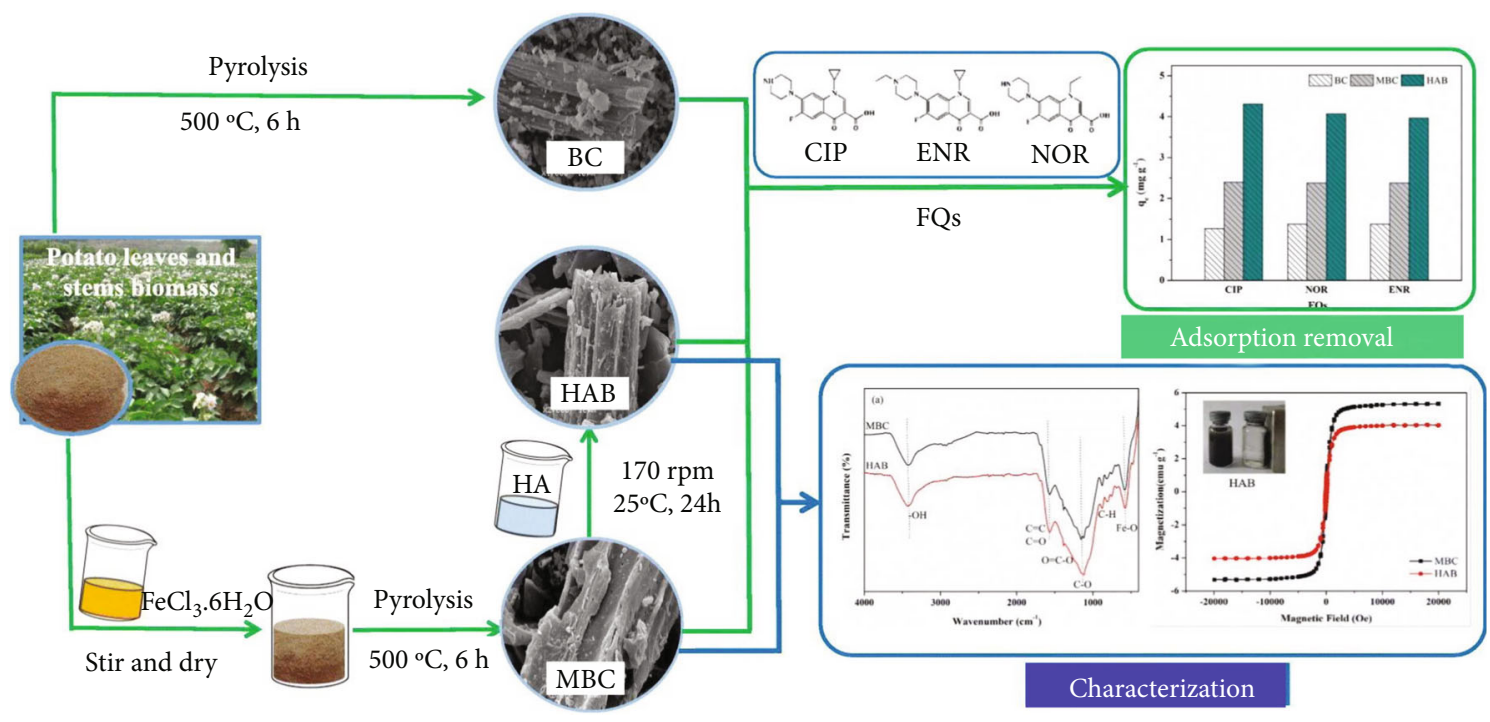

FIGURE 8: Humic acid coated magnetic biochar (MBC) derived from potato leaves and stems for fluoroquinolone antibiotics removal from water [30].

Toxicological effects of heavy metals include reproductive problems, neurological disorder, renal disease, gastrointestinal bleeding, lung disease, hypertension, and cancer [137]. Lead $(\mathrm{Pb})$, cadmium $(\mathrm{Cd})$, copper $(\mathrm{Cu})$, zinc $(\mathrm{Zn})$, nickel $(\mathrm{Ni})$, chromium $(\mathrm{Cr})$, mercury $(\mathrm{Hg})$, and manganese $(\mathrm{Mn})$ are common heavy metals found in the environment and considered as priority water pollutants [137-139]. Water pollution by heavy metals is associated to the several industrial activities including, for instance, chemical processing, oil refining, electronic manufacturing, and mineral smelting [139]. Different magnetic adsorbents have been used in heavy metal adsorption, and Table 3 describes a survey of magnetic carbon-based materials used for this purpose.

Peanut hulls are an abundant residual biomass with low cost that can be employed to prepare a magnetic BC for $\mathrm{Cr}^{6+}$ adsorption [140]. The best adsorbent was obtained via pyrolysis at $650{ }^{\circ} \mathrm{C}$ with an adsorption capacity of $77.54 \mathrm{mg} / \mathrm{g}$. Adsorption studies showed that low solution $\mathrm{pH}$ and the particle size of magnetic BC were relevant variables to remove this pollutant. Characterization results suggested that iron oxide was crucial to obtain the magnetic properties of adsorbent. $\mathrm{Cr}^{6+}$ was desorbed up to $55.9 \%$ using $\mathrm{NaOH}$. The removal mechanism of this pollutant involved an electrostatic attraction of the anionic chromium to the protonated $-\mathrm{OH}_{2}{ }^{+}$of maghemite.

Fu and Huang [141] analyzed the removal of $\mathrm{Hg}^{2+}, \mathrm{Pb}^{2+}$, $\mathrm{Cd}^{2+}$, and $\mathrm{Cu}^{2+}$ using a RGO that was functionalized with magnetic dithiocarbamate (DTC). A modified Hummers method was implemented to prepare GO, and the reduced and functionalized RGO composite was obtained via GO bromination, polyethylenimine nucleophilic substitution, reaction with $\mathrm{CS}_{2}$, and loading of $\mathrm{Fe}_{3} \mathrm{O}_{4}$ NPs. XRD, TEM, FTIR, and XPS techniques allowed the characterization of this magnetic adsorbent. The surface area of this adsorbent was $194.8 \mathrm{~m}^{2} / \mathrm{g}$. The increment of solution $\mathrm{pH}$ from 2 to 4 improved the heavy metal adsorption. This adsorbent exhibited high adsorption capacities with the next trend: $165 \mathrm{mg} / \mathrm{g}$ of $\mathrm{Hg}^{2+}>135 \mathrm{mg} / \mathrm{g}$ of $\mathrm{Pb}^{2+}>105 \mathrm{mg} / \mathrm{g}$ of $\mathrm{Cd}^{2+}>90 \mathrm{mg} / \mathrm{g}$ of $\mathrm{Cu}^{2+}$. These experimental adsorption data were fitted with the pseudo second-order kinetic and Langmuir isotherm. Nanocomposite regeneration was done with a one-step organic reaction obtaining satisfactory heavy metal uptakes in 5 adsorption-regeneration cycles.

Magnetic CCs and BC were prepared using pinewood sawdust, and they were subsequently applied for $\mathrm{Hg}^{2+}$ removal [142]. Pinewood sawdust was soaked in iron solutions and hydrothermally treated. Magnetic BC was obtained via pyrolysis, while magnetic CCs were prepared by calcination. Magnetic BC showed a surface area of 80.35 $\mathrm{m}^{2} / \mathrm{g}$, which was higher than magnetic CCs (i.e., 43.29 $\mathrm{m}^{2} / \mathrm{g}$ ); their adsorption capacities were 31.80 and 167.22 $\mathrm{mg} / \mathrm{g}$, respectively. These results suggested that textural parameters of these magnetic materials did not play a relevant role for $\mathrm{Hg}^{2+}$ adsorption. This finding was supported on the fact that magnetic CCs contained higher amounts of hydroxyl, lactone, and carboxyl groups than those identified for the surface of magnetic BC. Additionally, it was identified that magnetic CCs contained $\gamma-\mathrm{Fe}_{2} \mathrm{O}_{3}$ with a high crystallization degree. In fact, this adsorbent showed better regeneration and magnetic properties. $\mathrm{Hg}^{2+}$ adsorption mechanism implied coprecipitation, surface complexation, and electrostatic attraction.

Heavy metals and antibiotics usually coexist in wastewater thus magnifying its toxicological profile. Therefore, Huang et al. [44] studied the application of magnetic GO and its reduced forms via chemical and annealing routes to remove $\mathrm{As}^{5+}, \mathrm{Cd}^{2+}$, and TC. The adsorption properties of these adsorbents and the corresponding mechanism for these pollutants were analyzed. In aqueous solutions with only one adsorbate, the adsorption of these pollutants was affected by solution $\mathrm{pH}$ and the adsorption capacities showed the next trend: magnetic annealing RGO < magnetic chemically RGO < magnetic GO. In particular, the magnetic GO showed the best adsorption capacities with 
TABLE 3: Removal of heavy metals from aqueous solution using magnetic carbon-based adsorbents: preparation, removal operating conditions, and adsorption properties.

\begin{tabular}{|c|c|c|c|c|c|c|c|c|c|}
\hline Synthesis route & $\begin{array}{l}\text { Magnetic } \\
\text { source }\end{array}$ & Carbon source & Adsorbate & $\begin{array}{l}\text { Adsorption } \\
\text { capacity } \\
(\mathrm{mg} / \mathrm{g})\end{array}$ & $\mathrm{pH}$ & $\begin{array}{c}\mathrm{T} \\
\left({ }^{\circ} \mathrm{C}\right)\end{array}$ & $\begin{array}{l}\text { Magnetization } \\
\quad(\mathrm{emu} / \mathrm{g})\end{array}$ & $\begin{array}{l}\text { BET area } \\
\left(\mathrm{m}^{2} / \mathrm{g}\right)\end{array}$ & Reference \\
\hline $\begin{array}{l}\text { Magnetic CNTs by in situ } \\
\text { coprecipitation modification }\end{array}$ & $\gamma-\mathrm{Fe}_{2} \mathrm{O}_{3}$ & $\begin{array}{l}\text { Commercial } \\
\text { CNTs }\end{array}$ & $\mathrm{Cr}^{6+}$ & 11.256 & 3 & 25 & 43.29 & 119.09 & [223] \\
\hline $\begin{array}{l}\text { Magnetic } \mathrm{BC} \text { by impregnation } \\
\text { and direct pyrolysis }\end{array}$ & $\gamma-\mathrm{Fe}_{2} \mathrm{O}_{3}$ & Peanut hulls & $\mathrm{Cr}^{6+}$ & 77.54 & 5 & 25 & 36.79 & 145.25 & {$[140]$} \\
\hline $\begin{array}{l}\text { Magnetic GO by hummers } \\
\text { method and impregnation in } \\
\text { situ hydrothermal synthesis }\end{array}$ & $\mathrm{Fe}_{3} \mathrm{O}_{4}$ & Graphite & $\mathrm{Cr}^{6+}$ & 31.8 & 7 & 25 & 12 & 182 & {$[224]$} \\
\hline $\begin{array}{l}\text { Amino functionalized magnetic } \\
\text { GO by hummer method and } \\
\text { impregnation in situ } \\
\text { hydrothermal synthesis }\end{array}$ & $\mathrm{Fe}_{3} \mathrm{O}_{4}$ & Graphite & $\mathrm{Cr}^{6+}$ & 123.4 & 2 & 25 & 30.2 & 57.55 & [225] \\
\hline $\begin{array}{l}\text { Nitrogen doped magnetic AC by } \\
\text { impregnation and direct } \\
\text { pyrolysis processes using } \\
\text { glucose as nitrogen source }\end{array}$ & $\begin{array}{l}\mathrm{Fe}_{3} \mathrm{O}_{4} \\
\text { and } \mathrm{Fe}_{3} \mathrm{C}\end{array}$ & $\begin{array}{l}\text { Glucose and } \\
\text { melamine }\end{array}$ & $\mathrm{Cr}^{6+}$ & 29.46 & 7 & 25 & 130.7 & 56.2 & [226] \\
\hline $\begin{array}{l}\text { Carboxyl functionalized } \\
\text { magnetic CNTs by solvothermal } \\
\text { method }\end{array}$ & $\mathrm{Fe}_{3} \mathrm{O}_{4}$ & $\begin{array}{l}\text { Commercial } \\
\text { CNTs }\end{array}$ & $\mathrm{Cr}^{6+}$ & 22.22 & 2 & 25 & 70.62 & - & [227] \\
\hline $\begin{array}{l}\text { Chitin-magnetic CNTs by } \\
\text { simple milling }\end{array}$ & $\mathrm{Fe}_{3} \mathrm{O}_{4}$ & $\begin{array}{l}\text { Commercial } \\
\text { CNTs }\end{array}$ & $\mathrm{Cr}^{6+}$ & 10.7 & 2 & 25 & 5.775 & 69.1 & [228] \\
\hline $\begin{array}{l}\text { Dithiocarbamate functionalized } \\
\text { magnetic RGO by hummer } \\
\text { method, reduction with } \\
\text { hydrobromic acid, and magnetic } \\
\text { impregnation by } \\
\text { coprecipitation. }\end{array}$ & $\mathrm{Fe}_{3} \mathrm{O}_{4}$ & Graphite & $\begin{array}{l}\mathrm{Cu}^{2+} \\
\mathrm{Cd}^{2+} \\
\mathrm{Pb}^{2+} \\
\mathrm{Hg}^{2+}\end{array}$ & $\begin{array}{l}113.64 \\
116.28 \\
147.06 \\
181.82\end{array}$ & $\begin{array}{l}5 \\
6 \\
6 \\
6\end{array}$ & 25 & - & 194.8 & {$[141]$} \\
\hline $\begin{array}{l}\text { Magnetic fluorine and nitrogen } \\
\text { codoped carbon }\end{array}$ & $\mathrm{Fe}_{3} \mathrm{O}_{4}$ & $\begin{array}{l}\text { Melamine and } \\
\text { polyvinylidene } \\
\text { fluoride }\end{array}$ & $\mathrm{Cr}^{6+}$ & 740.7 & 1 & & 53.41 & 82.7 & [229] \\
\hline $\begin{array}{l}\text { Magnetic AC high temperature } \\
\text { carbonization and activation }\end{array}$ & $\begin{array}{c}\mathrm{Fe}^{0} \\
\mathrm{Fe}_{3} \mathrm{O}_{4}, \\
\text { and } \mathrm{Fe}_{3} \mathrm{C}\end{array}$ & $\begin{array}{l}\text { Activated } \\
\text { sludge }\end{array}$ & $\mathrm{Cr}^{6+}$ & 203 & 3 & 25 & 7.6 & 114.24 & [230] \\
\hline $\begin{array}{l}\text { Magnetic BC by iron salts } \\
\text { impregnation and hydrothermal } \\
\text { pyrolysis }\end{array}$ & $\gamma-\mathrm{Fe}_{2} \mathrm{O}_{3}$ & $\begin{array}{l}\text { Pinewood } \\
\text { sawdust }\end{array}$ & $\mathrm{Hg}^{2+}$ & 167.2 & 7 & 25 & 15.58 & 43.29 & [142] \\
\hline $\begin{array}{l}\text { One step hydrothermal method } \\
\text { with iron salt and } \\
\text { hexamethylenediamine }\end{array}$ & $\gamma-\mathrm{Fe}_{2} \mathrm{O}_{3}$ & Peanut hull & $\mathrm{Cr}^{6+}$ & 142.86 & - & 25 & - & 62.4 & {$[64]$} \\
\hline $\begin{array}{l}\text { Magnetic AC by low } \\
\text { temperature carbonization, } \\
\text { impregnation, and high } \\
\text { temperature for magnetic } \\
\text { modification and activation }\end{array}$ & $\mathrm{Fe}_{3} \mathrm{O}_{4}$ & Termite feces & $\mathrm{Cr}^{6+}$ & 66 & 3 & 25 & 1.46 & 699 & [231] \\
\hline $\begin{array}{l}\text { 1,4-Butane sultone modified } \\
\text { magnetic AC by carbonization, } \\
\text { activation, and finally magnetic } \\
\text { impregnation with magnetic } \\
\text { phase coprecipitated }\end{array}$ & $\mathrm{Fe}_{3} \mathrm{O}_{4}$ & Pistachio shell & $\begin{array}{l}\mathrm{Pb}^{2+} \\
\mathrm{Cd}^{2+}\end{array}$ & $\begin{array}{l}147.05 \\
119.04\end{array}$ & 5.5 & 25 & 11.6 & - & [143] \\
\hline $\begin{array}{l}\text { Magnetic BC by pyrolysis and } \\
\text { impregnation with } \\
\text { coprecipitation of magnetic } \\
\text { phase }\end{array}$ & $\mathrm{Fe}_{3} \mathrm{O}_{4}$ & Banana peels & $\begin{array}{l}\mathrm{Zn}^{2+} \\
\mathrm{Cu}^{2+} \\
\mathrm{Hg}^{2+}\end{array}$ & $\begin{array}{l}72.8 \\
75.9 \\
83.4\end{array}$ & 6 & 25 & 39.55 & 323.2 & [232] \\
\hline
\end{tabular}


TABLE 3: Continued.

\begin{tabular}{|c|c|c|c|c|c|c|c|c|c|}
\hline Synthesis route & $\begin{array}{l}\text { Magnetic } \\
\text { source }\end{array}$ & Carbon source & Adsorbate & $\begin{array}{l}\text { Adsorption } \\
\text { capacity } \\
(\mathrm{mg} / \mathrm{g})\end{array}$ & $\mathrm{pH}$ & $\begin{array}{c}\mathrm{T} \\
\left({ }^{\circ} \mathrm{C}\right)\end{array}$ & $\begin{array}{l}\text { Magnetization } \\
\quad(\mathrm{emu} / \mathrm{g})\end{array}$ & $\begin{array}{l}\text { BET area } \\
\left(\mathrm{m}^{2} / \mathrm{g}\right)\end{array}$ & Reference \\
\hline $\begin{array}{l}\text { Magnetic GO by graphite } \\
\text { exfoliation and coprecipitation } \\
\text { and magnetic RGO reduced by } \\
\text { hydrazine hydrate }\end{array}$ & $\mathrm{Fe}_{3} \mathrm{O}_{4}$ & Graphite & $\mathrm{Cd}^{2+}$ & $2-12$ & 234 & 25 & 34 & 148.2 & {$[44]$} \\
\hline $\begin{array}{l}\text { Impregnation with humic acid, } \\
\text { solvothermal process, and } \\
\text { calcination }\end{array}$ & $\mathrm{Fe}_{3} \mathrm{O}_{4}$ & $\begin{array}{l}\text { Layered double } \\
\text { hydroxides }\end{array}$ & $\begin{array}{l}\mathrm{Cu}^{2+} \\
\mathrm{Cd}^{2+} \\
\mathrm{Pb}^{2+}\end{array}$ & $\begin{array}{l}400.0 \\
375.0 \\
200.0\end{array}$ & 6 & 25 & - & 132.4 & [233] \\
\hline $\begin{array}{l}\text { Magnetic BC modified with } \\
\text { MnO by pyrolysis and } \\
\text { impregnation with magnetic } \\
\text { phase }\end{array}$ & $\mathrm{Fe}_{3} \mathrm{O}_{4}$ & $\begin{array}{l}\text { Palm kernel } \\
\text { cake residue }\end{array}$ & $\begin{array}{l}\mathrm{Cd}^{2+} \\
\mathrm{Cr}^{3+} \\
\mathrm{Hg}^{2+} \\
\mathrm{Pb}^{2+}\end{array}$ & $\begin{array}{l}18.60 \\
19.92 \\
49.64 \\
13.69\end{array}$ & 7 & 25 & 20.94 & 89.38 & {$[144]$} \\
\hline $\begin{array}{l}\text { Direct pyrolysis and } \\
\text { sonochemical method }\end{array}$ & $\mathrm{Fe}_{3} \mathrm{O}_{4}$ & Biogas residue & $\begin{array}{l}\mathrm{Cu}^{2+} \\
\mathrm{Pb}^{2+}\end{array}$ & $\begin{array}{c}75.76 \\
181.82\end{array}$ & 5 & - & 39.96 & 79.64 & [234] \\
\hline $\begin{array}{l}\text { Pyrolysis at } 600{ }^{\circ} \mathrm{C} \text { and physical } \\
\text { comixing }\end{array}$ & $\mathrm{Fe}_{3} \mathrm{O}_{4}$ & $\begin{array}{l}\text { Wheat stalk } \\
\text { and rice husk }\end{array}$ & $\mathrm{Pb}^{2+}$ & $\begin{array}{c}73.34- \\
179.5\end{array}$ & 5 & 25 & $26.1-28.6$ & $\begin{array}{c}13.96- \\
224.6\end{array}$ & [235] \\
\hline $\begin{array}{l}\text { Pyrolysis at } 500{ }^{\circ} \mathrm{C} \text {, } \\
\text { impregnation with iron salt }\end{array}$ & $\gamma-\mathrm{Fe}_{2} \mathrm{O}_{3}$ & $\begin{array}{l}\text { Blooms of alga } \\
\text { Enteromorpha }\end{array}$ & $\mathrm{Cr}^{6+}$ & 11.13 & 2 & 25 & 39.29 & - & [236] \\
\hline
\end{tabular}

Adsorbent nomenclature: activated carbon (AC), biochar (BC), carbon nanocages (CNCs), carbon nanotubes (CNTs), graphene oxide (GO), multiwalled carbon nanotubes (MWCNTs), single-walled carbon nanotubes (SWCNTs), and reduced graphene oxide (RGO).

values of $13.9,234$ and $252 \mathrm{mg} / \mathrm{g}$ for $\mathrm{TC}, \mathrm{Cd}^{2+}$, and $\mathrm{As}^{5+}$, respectively. The interaction effects of $\mathrm{Cd}^{2+}$ and $\mathrm{TC}$ in the multiadsorbate solutions were not significant. The presence of TC in the solution decreased significantly the $\mathrm{As}^{5+}$ adsorption, while $\mathrm{As}^{5+}$ did not affect TC removal in multicomponent solutions. The adsorption of $\mathrm{As}^{5+}$ and $\mathrm{Cd}^{2+}$ in the multiadsorbate solutions increased by 30 and $65 \%$, respectively.

A green synthesis was proposed to prepare a magnetic adsorbent with AC, 1,4-butane sultone, and $\mathrm{Fe}_{3} \mathrm{O}_{4} \mathrm{NPs}$ for the removal of $\mathrm{Cd}^{2+}, \mathrm{As}^{3+}$, and $\mathrm{Pb}^{2+}$ under ultrasound [143]. Adsorption results showed that the heavy metal uptake under ultrasound conditions was fast and increased during the first $10 \mathrm{~min}$. Nevertheless, the adsorption capacity decreased at operating times $>10 \mathrm{~min}$, and this phenomenon was associated to the release of metallic species from adsorbent surface. The maximum adsorption capacities in the aqueous solutions with one adsorbate were 95, 130, and $140 \mathrm{mg} / \mathrm{g}$ for $\mathrm{Cd}^{2+}, \mathrm{As}^{3+}$, and $\mathrm{Pb}^{2+}$, respectively. Competitive (i.e., multiadsorbate) adsorption experiments indicated that the adsorption capacities reduced in 12,21 , and $22 \%$ for $\mathrm{Pb}^{2+}, \mathrm{As}^{3+}$, and $\mathrm{Cd}^{2+}$, respectively. Thermodynamic parameters confirmed that the adsorption of these pollutants was feasible, exothermic, and spontaneous. Characterization techniques supported that the mechanisms of adsorption implied the heavy metal complexation with the $\mathrm{SO}_{3} \mathrm{H}$ and $\mathrm{OH}$ groups from the magnetic adsorbent surface.

Maneechakr and Mongkollertlop [144] prepared and tested a $\mathrm{MnO}_{2}$-modified magnetic $\mathrm{BC}$ for the removal of $\mathrm{Hg}^{2+}, \mathrm{Pb}^{2+}, \mathrm{Cr}^{3+}$, and $\mathrm{Cd}^{2+}$. This magnetic adsorbent was obtained from $\mathrm{Fe}_{3} \mathrm{O}_{4}$ and palm kernel cake residue. Different techniques (SEM-EDS, FTIR, Boehm titration, $\mathrm{N}_{2}$ physisorption, XRD, and VSM) were utilized to characterize the adsorbent physicochemical properties. As expected, the pollutant adsorption was enhanced with increments of solution $\mathrm{pH}$. Adsorption temperature did not show a high impact on the heavy metal removal although the process was endothermic. The maximum experimental adsorption capacities of $\mathrm{Cd}^{2+}, \mathrm{Cr}^{3+}, \mathrm{Pb}^{2+}$, and $\mathrm{Hg}^{2+}$ were 19.90 , 21.20, 49.64, and $13.69 \mathrm{mg} / \mathrm{g}$, respectively. Experimental data were modeled, and thermodynamic parameters were also obtained.

4.4. Pesticides and Other Pest Controllers. Pests and associated-diseases cause around 30\% of global crop loss [145]. The pesticides are quite toxic chemical compounds tailored to kill off pests via their environment spread [146]. The biotransformation of these compounds is difficult thus causing their bioaccumulation for long periods. Agriculture production has increased the usage of pesticides, herbicides, insecticides, and fungicides thus generating an additional source of water and soil pollution [146, 147]. In particular, their residues can be still found on fruits and vegetables, and they could enter into water resources due to their microbial degradation resistance and chemical stability in the water $[146,148]$. To illustrate the serious environmental problem associated to these pollutants, it can be indicated that studies performed in the United States detected 5 or more pesticides in several samples obtained from different streams, while $\sim 400,000$ tons of pesticides are used annually in China $[149,150]$. In Europe, pesticides have been considered among the main pollutants of drinking water supplies [151].

Since these chemicals are nonselective, they can be toxic for wildlife populations and humans that are the nontarget organisms [146]. Long-term exposure to these substances could lead to serious health effects like neurodegenerative 
diseases, cancer, hypertension, reproductive, endocrinal, mutagenic, genotoxic, and respiratory effects [146-148]. In particular, glyphosate is a pesticide widely used in agriculture and nonagriculture areas [147]. It causes acute toxic endocrinal, mutagenic, and carcinogenic effects [147]. On the other hand, acetochlor is an herbicide used to control gramineae weeds and has been reported in surface waters of United States at $2.5 \mu \mathrm{g} / \mathrm{L}$, which is an enough concentration to induce health damage [148]. Also, atrazine is one of the most frequently detected pesticides in freshwater in United States. Therefore, a concentration limit of $3 \mathrm{ng} / \mathrm{L}$ was established by EPA for this compound in drinking water [114].

Adsorption is effective to remove these toxic substances from water sources. Table 4 summarizes the adsorption of pesticides and other pest controllers using magnetic carbon-based adsorbents. For instance, a hybrid composite obtained from the decoration of $\mathrm{RGO}$ with $\mathrm{MnFe}_{2} \mathrm{O}_{4}$ microspheres was used as adsorbent to remove glyphosate [147]. $\mathrm{N}_{2}$ physisorption, XPS, XRD, FTIR, and TEM analyses were performed for the adsorbent characterization. The glyphosate adsorption on this magnetic composite was associated to ion exchange and electrostatic interactions where 39 $\mathrm{mg} / \mathrm{g}$ was the maximum adsorption capacity at $5{ }^{\circ} \mathrm{C}$. Kinetic data were fitted with the pseudo second-order model, while Freundlich equation correlated the experimental isotherms. Glyphosate adsorption on this composite was exothermic at $5-45^{\circ} \mathrm{C}$. Surface area of this composite was $305.7 \mathrm{~m}^{2} / \mathrm{g}$ with the predominance of mesopores where TEM and SEM analyses also confirmed a proper dispersion of $\mathrm{MnFe}_{2} \mathrm{O}_{4}$ microspheres on the graphene nanosheets.

MWCNTs and MOF ZIF-8 were utilized to obtain a magnetic adsorbent for the adsorption of organophosphorus pesticides from soil and water [152]. Isazofos, sulfotep, ethoprop, methidathion, profenofos, phosalone, diazinon, and triazophos were considered as adsorbates for this study. Multicomponent solutions with concentrations ranging from 0.2 to $8 \mathrm{mg} / \mathrm{L}$ were prepared with these 8 pesticides. Results of this study suggested that coordinationpolymerization was involved in the incorporation of ZIF-8 particles on the magnetic MWCNTs surface. Adsorbent pore structure contained meso and macropores with a surface area of $127.95 \mathrm{~m}^{2} / \mathrm{g}$. The adsorption capacities of this magnetic adsorbent for tested pollutants ranged from 2.18 to $3.89 \mathrm{mg} / \mathrm{g}$ where the lowest and highest removal were for ethoprop and profenofos, respectively. The authors determined that these adsorption capacities were lower than those reported in previous papers, and this finding was associated to the competitive (i.e., antagonistic) adsorption in multicomponent system in comparison to individual pesticide solutions. Solution $\mathrm{pH}$ played an important role in pesticides adsorption with $\mathrm{pH} 4$ as an optimum condition. Langmuir model was outperformed by Freundlich equation to correlate the experimental data. It was concluded that the active sites of this magnetic adsorbent and pesticide molecules interacted via a valence-electron-driven adsorption with electrons exchanging or sharing.

The glyphosate adsorption mechanism using a modified $\mathrm{BC}$ was reported by Jiang et al. [153]. A liquid-phase chem- ical reduction was employed to functionalize palm-based $\mathrm{BC}$ with nano-zero-valent iron. SEM, TEM, FTIR, and XPS techniques were utilized to characterize the final composite, which showed a surface rich in oxygenated functionalities and complex ligands with $253.97 \mathrm{~m}^{2} / \mathrm{g}$ of specific surface area. Experimental adsorption data were processed and analyzed with Langmuir and pseudo second-order equations. Authors concluded that the maximum glyphosate adsorption was obtained at $\mathrm{pH} 4$, which was twice (i.e., $80 \mathrm{mg} / \mathrm{g}$ ) than that of raw BC. The presence of phosphate or $\mathrm{Cd}^{2+}$ at low concentrations did not affect the glyphosate adsorption. But, an antagonistic effect was identified in the treatment of agricultural wastewaters that were polluted with organic compounds. Electrostatic forces, complexation, and hydrogen bonding were associated to the glyphosate adsorption mechanism using this magnetic adsorbent.

Organophosphorus pesticide adsorption on GO-based silica coated magnetic NPs functionalized with 2phenylethylamine was studied [154]. Malathion, parathion, and chlorpyrifos were considered as the target pollutants. Magnetic and physical properties of this adsorbent were characterized via VSM, $\mathrm{N}_{2}$ adsorption/desorption, Zeta potential, XRD, TEM, and FTIR. This adsorbent was spherical in shape and agglomerated, showing $33 \mathrm{emu} / \mathrm{g}$ of magnetic saturation and $133 \mathrm{~m}^{2} / \mathrm{g}$ of surface area. No significant differences in adsorption performance were found at different $\mathrm{pH}$. This study showed that the interaction of pesticides with the adsorbent was not affected by deprotonation/protonation caused by $\mathrm{pH}$ adjustment. Pesticide adsorption capacities in aqueous solutions ranged from 10.9 to 11.1 where the minimum and maximum removal were for parathion and chlorpyrifos. Note that the parathion and chlorpyrifos adsorption was caused by $\pi-\pi$ interactions and hydrogen bonding, while hydrogen bonding governed the malathion adsorption. These findings explained the order of adsorption capacities. DubininRadushkevich and Sips models fitted the experimental adsorption data. Acetone was used for adsorbent regeneration where the recovery of tested pesticides was 89$100 \%$ in 10 adsorption-desorption cycles.

Mashile et al. [155] reported the synthesis of a recyclable magnetic adsorbent using chitosan and waste tyre AC for the simultaneous adsorption of propylparaben and methylparaben. Adsorbent characterization was done with FTIR, SEM, TEM, and XRD. Surface area of this composite was 1281 $\mathrm{m}^{2} / \mathrm{g}$. Pseudo second-order kinetic model described the adsorption of these pollutants. Redlich-Peterson and Langmuir models were used to correlate the binary adsorption of propylparaben and methylparaben. It was calculated that the maximum Langmuir monolayer adsorption capacities for propylparaben and methylparaben were 90.0 and 85.9 $\mathrm{mg} / \mathrm{g}$, respectively. This magnetic composite was chemically stable and useful after 7 cycles of adsorption-desorption.

Agani et al. [156] evaluated the atrazine adsorption from water using a fixed-bed column packed with a magnetic composite prepared from AC, chitosan, and magnetite. $\mathrm{XRD}$ and FTIR techniques allowed to analyze the composite surface chemistry. Experimental designs based on CCD and RSM optimized the adsorption operating variables (i.e., flow 
TABLE 4: Removal of pesticides and other pest controllers from aqueous solution using magnetic carbon-based adsorbents: preparation, removal operating conditions, and adsorption properties.

\begin{tabular}{|c|c|c|c|c|c|c|c|c|c|}
\hline Synthesis route & $\begin{array}{l}\text { Magnetic } \\
\text { source }\end{array}$ & $\begin{array}{l}\text { Carbon } \\
\text { source }\end{array}$ & Adsorbate & $\begin{array}{l}\text { Adsorption } \\
\text { capacity } \\
(\mathrm{mg} / \mathrm{g})\end{array}$ & $\mathrm{pH}$ & $\begin{array}{c}\mathrm{T} \\
\left({ }^{\circ} \mathrm{C}\right)\end{array}$ & $\begin{array}{l}\text { Magnetization } \\
\quad(\mathrm{emu} / \mathrm{g})\end{array}$ & $\begin{array}{l}\text { BET area } \\
\left(\mathrm{m}^{2} / \mathrm{g}\right)\end{array}$ & Reference \\
\hline $\begin{array}{l}\text { Magnetic GO by } \\
\text { chemical exfoliation } \\
\text { and coprecipitation } \\
\text { impregnation }\end{array}$ & $\begin{array}{l}\text { Mn } \\
\text { ferrite }\end{array}$ & Graphite & Glyphosate & 33.44 & 4.7 & 25 & - & 305.7 & {$[147]$} \\
\hline $\begin{array}{l}\text { Magnetic AC by direct } \\
\text { impregnation with } \\
\text { hydrothermal method } \\
\text { and functionalized } \\
\text { with silanes }\end{array}$ & $\mathrm{Fe}_{3} \mathrm{O}_{4}$ & $\begin{array}{c}\text { Commercial } \\
\text { AC }\end{array}$ & Bisphenol A & 126.9 & 7 & 25 & 2.65 & 960.9 & [200] \\
\hline $\begin{array}{l}\text { Magnetic GO } \\
\text { modified with } \mathrm{Cu} \\
\text { MOF and } \beta \text { - } \\
\text { cyclodextrin by } \\
\text { coprecipitation } \\
\text { impregnation and } \\
\text { chemical modification }\end{array}$ & $\mathrm{Fe}_{3} \mathrm{O}_{4}$ & $\begin{array}{c}\text { Commercial } \\
\text { GO }\end{array}$ & $\begin{array}{l}\text { Thiamethoxam } \\
\text { Imidacloprid } \\
\text { Acetamiprid } \\
\text { Nitempyram } \\
\text { Dinotefuran } \\
\text { Clothianidin } \\
\text { Thiacloprid }\end{array}$ & $\begin{array}{l}2.88 \\
3.11 \\
2.96 \\
2.56 \\
1.77 \\
2.88 \\
3.21\end{array}$ & - & - & 10.47 & 250.33 & [237] \\
\hline $\begin{array}{l}\text { Phenyl-modified } \\
\text { magnetic GO/ } \\
\text { mesoporous silica by } \\
\text { hierarchical bridge- } \\
\text { pore structure }\end{array}$ & $\mathrm{Fe}_{3} \mathrm{O}_{4}$ & Graphite & $\begin{array}{l}\text { Avemerctin } \\
\text { Imidacloprid } \\
\text { Pyridaben } \\
\text { Dichlorvos } \\
\text { Acetamiprid } \\
\text { Dursban } \\
\text { Isocarbophos } \\
\text { Phoxim }\end{array}$ & $\begin{array}{c}9.21 \\
6.40 \\
12.72 \\
47.78 \\
5.11 \\
8.01 \\
2.88 \\
8.23\end{array}$ & - & 25 & 25 & 446.5 & [238] \\
\hline $\begin{array}{l}\text { Magnetic BC by direct } \\
\text { molten salt method }\end{array}$ & $\mathrm{Fe}_{3} \mathrm{O}_{4}$ & Fir dust & $\begin{array}{l}\text { Dichlorophenol } \\
\text { Atrazine }\end{array}$ & $\begin{array}{l}298.12 \\
102.17\end{array}$ & - & 25 & 40.02 & 404 & [239] \\
\hline $\begin{array}{l}\text { Palm carbonization at } \\
773 \mathrm{~K} \text {, liquid phase } \\
\text { reduction method for } \\
\text { iron impregnation }\end{array}$ & $\mathrm{Fe}^{0}$ & Palm & Glyphosate & 80.0 & 4 & 25 & - & 253.97 & [153] \\
\hline $\begin{array}{l}\text { Magnetic MWCNTs } \\
\text { modified with Zn } \\
\text { MOF by } \\
\text { coprecipitation } \\
\text { impregnation and } \\
\text { chemical coordination } \\
\text { method }\end{array}$ & $\mathrm{Fe}_{3} \mathrm{O}_{4}$ & $\begin{array}{l}\text { Commercial } \\
\text { MWCNTs }\end{array}$ & $\begin{array}{l}\text { Triazophos } \\
\text { Diazinon } \\
\text { Phosalone } \\
\text { Profenofos } \\
\text { Methidathion } \\
\text { Ethoprop } \\
\text { Sulfotep } \\
\text { Isazofos }\end{array}$ & $\begin{array}{l}3.12 \\
2.59 \\
3.80 \\
3.89 \\
2.34 \\
2.18 \\
2.84 \\
3.00\end{array}$ & 4 & - & 53.56 & 128 & {$[152]$} \\
\hline $\begin{array}{l}\text { Carboxilated magnetic } \\
\text { GO modified with } \\
\text { silica-coated } \\
\text { magnetite by covalent } \\
\text { coupling }\end{array}$ & $\mathrm{Fe}_{3} \mathrm{O}_{4}$ & Graphite & $\begin{array}{l}\text { Chlorpyrifos } \\
\text { Malathion } \\
\text { Parathion }\end{array}$ & $\begin{array}{l}135 \\
61.9 \\
35.6\end{array}$ & 7 & 25 & 33 & 133 & {$[154]$} \\
\hline $\begin{array}{l}\text { Magnetic CNTs } \\
\text { functionalized with } \\
\text { imidazole zeolite by } \\
\text { thermal procedure }\end{array}$ & $\mathrm{Fe}_{3} \mathrm{O}_{4}$ & $\begin{array}{l}\text { Commercial } \\
\text { carboxylic- } \\
\text { CNTs }\end{array}$ & Tetrabromobisphenol & 77.07 & 7 & 30 & 9.65 & - & {$[240]$} \\
\hline $\begin{array}{l}\text { Magnetic GO by } \\
\text { electrochemical } \\
\text { exfoliation }\end{array}$ & $\mathrm{NiO}$ & Graphite & $\begin{array}{l}\text { Methylparaben } \\
\text { Ethylparaben } \\
\text { Propylparaben } \\
\text { Butylparaben }\end{array}$ & $\begin{array}{c}3.12 \\
5.28 \\
8.42 \\
10.46\end{array}$ & 5 & 25 & - & 227.5 & {$[241]$} \\
\hline
\end{tabular}


TABLE 4: Continued.

\begin{tabular}{|c|c|c|c|c|c|c|c|c|c|}
\hline Synthesis route & $\begin{array}{l}\text { Magnetic } \\
\text { source }\end{array}$ & $\begin{array}{l}\text { Carbon } \\
\text { source }\end{array}$ & Adsorbate & $\begin{array}{c}\text { Adsorption } \\
\text { capacity } \\
(\mathrm{mg} / \mathrm{g})\end{array}$ & $\mathrm{pH}$ & $\begin{array}{c}\mathrm{T} \\
\left({ }^{\circ} \mathrm{C}\right)\end{array}$ & $\begin{array}{l}\text { Magnetization } \\
(\mathrm{emu} / \mathrm{g})\end{array}$ & $\begin{array}{c}\text { BET area } \\
\left(\mathrm{m}^{2} / \mathrm{g}\right)\end{array}$ & Reference \\
\hline $\begin{array}{l}\text { Magnetic GO-AC by } \\
\text { chemical exfoliation, } \\
\text { solvothermal } \\
\text { impregnation }\end{array}$ & $\begin{array}{c}\mathrm{Mn} \\
\text { ferrite }\end{array}$ & $\begin{array}{l}\text { Graphite } \\
\text { and } \\
\text { commercial } \\
\text { vegetal } \\
\text { origin AC }\end{array}$ & Glyphosate & 6.78 & 4.7 & 25 & - & 19.77 & [242] \\
\hline $\begin{array}{l}\text { Chemical activation } \\
\text { with } \mathrm{H}_{3} \mathrm{PO}_{4} \text { for AC } \\
\text { production, composite } \\
\text { produced by } \\
\text { coprecipitation } \\
\text { method }\end{array}$ & $\mathrm{Fe}_{3} \mathrm{O}_{4}$ & Peanut shells & Atrazine & 62.32 & 5.07 & - & - & 189.50 & {$[156]$} \\
\hline $\begin{array}{l}\text { Magnetic AC coated } \\
\text { with by pyrolysis, } \\
\text { microwave activation } \\
\text { and coprecipitation } \\
\text { impregnation }\end{array}$ & $\mathrm{Fe}_{3} \mathrm{O}_{4}$ & Waste tyre & $\begin{array}{l}\text { Methylparaben } \\
\text { Propylparaben }\end{array}$ & $\begin{array}{l}85.9 \\
90.0\end{array}$ & 6 & 25 & - & 1281 & [155] \\
\hline $\begin{array}{l}\text { Pyrolysis of bagasse at } \\
600{ }^{\circ} \mathrm{C} \text {, impregnation } \\
\text { of salts, activation with } \\
\mathrm{KOH}\end{array}$ & Zn ferrite & $\begin{array}{c}\text { Sugarcane } \\
\text { bagasse }\end{array}$ & Imidacloprid & 313.0 & 6 & 25 & 5.99 & 660.0 & [243] \\
\hline
\end{tabular}

Adsorbent nomenclature: activated carbon (AC), biochar (BC), carbon nanocages (CNCs), carbon nanotubes (CNTs), graphene oxide (GO), metal-organic framework (MOF), multiwalled carbon nanotubes (MWCNTs), single-walled carbon nanotubes (SWCNTs), and reduced graphene oxide (RGO).

rate, bed depth, atrazine initial concentration, and $\mathrm{pH})$. The impact of these operating variables on adsorption process was also analyzed. The experimental results indicated the preparation of a mesoporous adsorbent with $188.50 \mathrm{~m}^{2} / \mathrm{g}$ of surface area and $62.32 \mathrm{mg} / \mathrm{g}$ of atrazine adsorption capacity. Yoon-Nelson, Yan, Bohart-Adams, and Thomas models were used to fit the breakthrough curves. These models allowed to analyze the limiting step of mass transfer for atrazine adsorption with this composite. Bohart-Adams model offered the best correlations for the adsorption data. Composite regeneration and atrazine desorption was studied with $\mathrm{NaOH}$ and $\mathrm{HCl}$, thus, confirming the recycling potential of this magnetic material.

4.5. Fluoride. Fluorine is a geogenic water pollutant with a wide environmental distribution [157]. Different studies have documented its natural existence in soil, rocks, and groundwater [157]. Also, fluoride has been detected in effluents and wastewaters from fertilizers, electroplating, metal processing, cement, electronic manufacturing, and other industrial sectors, which also contributes as anthropogenic sources of water pollution $[158,159]$. Fluoride can contribute to bone tissue development in human beings, but its chronic exposure can cause dental and skeletal fluorosis $[157,159]$. The prevalence of dental fluorosis has been reported in more than 50 countries where the population of China is significantly affected by this disease [157]. It has been estimated that fluoride concentration in drinking water exceeds the WHO limit concentration $(1.5 \mathrm{mg} / \mathrm{L})$ in more than 25 countries [158]. As a result, over 300 million of people around the world are exposed to develop health problems associated to a chronic fluoride exposure. Herein, it is convenient to highlight that recent epidemiological advances have demonstrated that soft tissues are also affected by fluoride, and its toxic effect is known as nonskeletal fluorosis [159], which also could include damage to the respiratory, renal, immune, endocrine, digestive, central nervous, and cardiovascular systems [157, 159]. Therefore, low-cost and effective methods for the reduction of fluoride concentrations in water are required and demanded in particular for low-income countries.

Adsorption is the most commercial technology for fluoride water depollution. Table 5 summarizes the adsorption of fluoride using magnetic carbon-based adsorbents. For example, Mohan et al. [160] prepared a corn stover BC with slow pyrolysis at $500{ }^{\circ} \mathrm{C}$, which was magnetized with an aqueous $\mathrm{Fe}^{3+} / \mathrm{Fe}^{2+}$ solution and treated with $\mathrm{NaOH}$. BC with and without magnetic properties was characterized by Raman, energy dispersive X-Ray fluorescence (EDXRF), TEM, SEM-EDX, FTIR, and XRD analyses where magnetic moment and textural parameters were also measured. Maximum fluoride adsorption capacities were 6.0 and $4.11 \mathrm{mg} / \mathrm{g}$ for $\mathrm{BC}$ without and with magnetic properties, respectively, at $25{ }^{\circ} \mathrm{C}$ and $\mathrm{pH}$ 2. An exothermic fluoride adsorption was identified for both adsorbents at $25-45{ }^{\circ} \mathrm{C}$. Fluoride adsorption kinetics were adjusted with the pseudo first order model. Fluoride adsorption in real ground water was reduced by the interference of solids and other ions such as $\mathrm{Na}^{+}, \mathrm{Cl}^{-}$, and $\mathrm{NO}_{3}{ }^{-}$.

Dewage et al. [161] prepared a Douglas fir BC with $\mathrm{Fe}_{3} \mathrm{O}_{4}$ and $\alpha-\mathrm{Fe}_{2} \mathrm{O}_{3} . \mathrm{N}_{2}$ physisorption, XPS, XRD, TEM, and SEM/EDX were applied to characterize $\mathrm{BC}$ precursor and the magnetic $\mathrm{BC}$. Adsorbent magnetization and generation of additional adsorption sites were obtained with the 
TABLE 5: Removal of fluoride from aqueous solution using magnetic carbon-based adsorbents: preparation, removal operating conditions, and adsorption properties.

\begin{tabular}{|c|c|c|c|c|c|c|c|c|}
\hline Synthesis route & $\begin{array}{l}\text { Magnetic } \\
\text { source }\end{array}$ & $\begin{array}{l}\text { Carbon } \\
\text { source }\end{array}$ & $\begin{array}{l}\text { Adsorption } \\
\text { capacity } \\
\text { (mg/g) }\end{array}$ & $\mathrm{pH}$ & $\begin{array}{l}\mathrm{T} \\
\left({ }^{\circ} \mathrm{C}\right)\end{array}$ & $\begin{array}{l}\text { Magnetization } \\
\quad(\mathrm{emu} / \mathrm{g})\end{array}$ & $\begin{array}{l}\text { BET area } \\
\left(\mathrm{m}^{2} / \mathrm{g}\right)\end{array}$ & Reference \\
\hline Impregnation method & $\gamma-\mathrm{Fe}_{2} \mathrm{O}_{3}$ & $\begin{array}{l}\text { Cotton } \\
\text { cellulose }\end{array}$ & 18.6 & $4-9$ & 25 & - & 2.23 & {$[244]$} \\
\hline $\begin{array}{l}\text { Pyrolysis at } 500{ }^{\circ} \mathrm{C} \text { and coprecipitation } \\
\text { method }\end{array}$ & $\mathrm{Fe}_{3} \mathrm{O}_{4}$ & $\begin{array}{l}\text { Corn } \\
\text { stover }\end{array}$ & 4.11 & 2 & 25 & 5.1 & 3.61 & {$[160]$} \\
\hline Chemical deposition of $\mathrm{Fe}_{3} \mathrm{O}_{4}$ & $\gamma-\mathrm{Fe}_{2} \mathrm{O}_{3}$ & Graphite & 77.12 & 7 & 25 & 22.66 & - & {$[245]$} \\
\hline Impregnation method & $\mathrm{Fe}_{3} \mathrm{O}_{4}$ & Yak dung & 3.98 & $5-6$ & 25 & - & 79.49 & [246] \\
\hline $\begin{array}{l}\text { BC impregnation with iron salt, pyrolysis at } \\
600{ }^{\circ} \mathrm{C} \text {. }\end{array}$ & $\mathrm{Fe}_{3} \mathrm{O}_{4}$ & $\begin{array}{l}\text { Douglas fir } \\
\text { biochar }\end{array}$ & $\begin{array}{l}7.58 \\
15.5\end{array}$ & 7 & 25 & - & 494 & {$[161]$} \\
\hline $\begin{array}{l}\text { Impregnation with } \mathrm{CaCl}_{2} \text { and } \mathrm{FeCl}_{3} . \\
\text { Carbonization at } 300-700{ }^{\circ} \mathrm{C} \text { during } 2 \mathrm{~h}\end{array}$ & $\gamma-\mathrm{Fe}_{2} \mathrm{O}_{3}$ & $\begin{array}{l}\text { Cattle } \\
\text { dung }\end{array}$ & 15 & 7.5 & $25-45$ & - & 19.2 & [247] \\
\hline $\begin{array}{l}\text { Impregnation with } \mathrm{FeCl}_{3} \text { and pyrolysis after } \\
\text { impregnation. }\end{array}$ & $\gamma-\mathrm{Fe}_{2} \mathrm{O}_{3}$ & $\begin{array}{l}\text { Bovine } \\
\text { bone }\end{array}$ & 5.23 & 8 & 25 & 4.43 & 41.77 & {$[162]$} \\
\hline $\begin{array}{l}\text { Oak shell calcination at } 800^{\circ} \mathrm{C} \text { and iron salt } \\
\text { impregnation }\end{array}$ & $\mathrm{Fe}_{3} \mathrm{O}_{4}$ & Oak shell & 454.54 & & & 69.46 & 226.78 & {$[163]$} \\
\hline $\begin{array}{l}\text { AC impregnation and pyrolysis at } 500{ }^{\circ} \mathrm{C} \\
\text { during } 2 \mathrm{~h} \text {. }\end{array}$ & $\mathrm{Fe}_{3} \mathrm{O}_{4}$ & Pea peel & 4.71 & $2-10$ & $25-55$ & - & - & [164] \\
\hline
\end{tabular}

Adsorbent nomenclature: biochar (BC).

dispersion of $\mathrm{Fe}_{3} \mathrm{O}_{4}$ and $\alpha-\mathrm{Fe}_{2} \mathrm{O}_{3}$ particles. In fact, the magnetic adsorbent showed higher fluoride and nitrate adsorption capacities than those of BC. An endothermic and $\mathrm{pH}-$ dependent fluoride removal was identified. Experimental isotherms were analyzed and correlated with Langmuir model. Fluoride and nitrate adsorption capacities of magnetic BC were 9 and $15 \mathrm{mg} / \mathrm{g}$, respectively, which outperformed the values reported for other oxide-based adsorbents and BC. Adsorption mechanism of both adsorbates (i.e., fluoride and nitrate) implied the hydrogen bond formation with the participation of protonated surface hydroxyls on the iron oxides.

BCs and their magnetic versions were prepared with bovine bone and peanut hull for fluoride adsorption [162]. XPS, FTIR, XRD, SEM-EDX, and VSM were used to analyze the surface chemistry and magnetic properties of these adsorbents. A prepyrolysis approach (i.e., biomass + iron salts + pyrolysis) enhanced the fluoride adsorption capacity of the magnetic $\mathrm{BC}$ in comparison to the adsorbent obtained from a postpyrolysis where $\mathrm{BC}$ was mixed with $\mathrm{Fe}^{3+} / \mathrm{Fe}^{2+}$ solution. Fluoride adsorption capacity of bovine-based magnetic adsorbent was $>5 \mathrm{mg} / \mathrm{g}$ mainly due to $\gamma-\mathrm{Fe}_{2} \mathrm{O}_{3}$ and hydroxyapatite, which outperformed the nonmagnetic BC. It was inferred an ion exchange process in this endothermic fluoride removal. Freundlich model fitted the experimental adsorption isotherms of magnetic BC. Fluoride desorption was studied with $0.1 \mathrm{M} \mathrm{NaOH}$ solution, and results indicated that the magnetic BC maintained an acceptable adsorption performance for several regeneration cycles.

A nanocomposite obtained from $\mathrm{Fe}_{3} \mathrm{O}_{4}$ and oak shell AC was used and assessed in fluoride adsorption [163]. Surface areas reported were 226.78 and $65.33 \mathrm{~m}^{2} / \mathrm{g}$ for $\mathrm{AC} / \mathrm{Fe}_{3} \mathrm{O}_{4}$ and $\mathrm{Fe}_{3} \mathrm{O}_{4}$, respectively. Freundlich equation fitted satisfactorily the fluoride adsorption isotherms where the maximum adsorption capacity of $\mathrm{AC} / \mathrm{Fe}_{3} \mathrm{O}_{4}$ was $454.54 \mathrm{mg} / \mathrm{g}$, which is an outstanding performance for adsorbents reported for fluoride removal considering that their adsorption capacities ranged usually from 1 to $10 \mathrm{mg} / \mathrm{g}$. The $\mathrm{pH}$ increment did not favor the fluoride adsorption and thermodynamic calculations confirmed an endothermic fluoride removal employing this magnetic adsorbent.

Sahu et al. [164] evaluated the fluoride adsorption with a magnetic AC prepared using pea peel biomass impregnated with $\mathrm{FeCl}_{3}$ and pyrolyzed at $500{ }^{\circ} \mathrm{C}$. Fluoride removal tests were performed with column and agitated tank modes. Initial fluoride concentration, solution $\mathrm{pH}$, adsorbent dosage, and contact time were the operating parameters analyzed at batch adsorption conditions. The maximum fluoride adsorption capacity was $4.71 \mathrm{mg} / \mathrm{g}$; it was established that water defluoridation was endothermic and $\mathrm{pH}$ dependent. Freundlich model was better than Langmuir model to fit fluoride adsorption isotherms. In the case of column studies, the breakthrough curves were analyzed with Clark, YoonNelson, Adams-Bohart, and Thomas equations. This magnetic adsorbent showed a promising performance for water defluoridation in both batch and column operation modes. Fluoride adsorption mechanism was governed by fluorideadsorbent interactions involving ketone, methyl, and hydroxyl groups, while the iron species imparted a positive charge to the adsorbent surface that generated electrostatic attraction forces for binding fluoride ions.

4.6. Dyes, Other Organic Pollutants, and Radionuclides. Dyes are complex organic molecules that are the most evident indicator of water pollution [165]. These compounds affect the aesthetic of aquatic systems and interfere with the sunlight transmission thus impacting the photosynthesis [165]. Dye classification includes different categories like nonionic 
(disperse dyes), cationic (basic dyes), and anionic (reactive, acid, and direct dyes), which can also consider their chemical structures like azo, anthraquinone, indigo, triphenylmethyl, and phthalocyanine derivative $[165,166]$. These organic compounds are toxic and persistent pollutants with low degradability that can cause serious health effects with mutagenic and carcinogenic impacts on organisms [167-169]. Textile and dyeing industrial sectors are considered as the main contributors to this environmental pollution due to a significant release of dyes and related compounds into the water sources. It has been estimated that more than 100,000 commercial dyes are known, and their production is $\sim 1.6$ million tons of dyes/year where $10-15 \%$ can be released in wastewaters thus affecting the ecosystems [166, 168]. Dye adsorption with magnetic carbon-based adsorbents has proved to be effective. For illustration, Table 6 summarizes the dye adsorption using magnetic carbon-based adsorbents.

Mubarak et al. [170] tested orange- $G$ and methylene blue removal with a magnetic $\mathrm{BC}$, which was prepared using the empty fruit bunch. This biomass was first treated with $\mathrm{FeCl}_{3}$ and pyrolyzed in a microwave muffle. Dye removal was optimized via the analysis of contact time, stirring speed, adsorbent dosage, and $\mathrm{pH}$. Methylene blue adsorption was maximum with a $125 \mathrm{rpm}$ stirring, $1.0 \mathrm{~g}$ of adsorbent ratio, and $120 \mathrm{~min}$ of contact time at $\mathrm{pH} 10$. The best removal conditions for orange- $G$ were $125 \mathrm{rpm}$ stirring, $1.0 \mathrm{~g}$ of adsorbent dosage, $120 \mathrm{~min}$ of contact time, and $\mathrm{pH} 2.32 .36$ and $31.25 \mathrm{mg} / \mathrm{g}$ were the maximum adsorption capacities for orange- $G$ and methylene blue dyes, respectively. Experimental data followed a pseudo second-order kinetic.

Oladipo and Ifebajo [171] prepared a magnetic chicken bone $\mathrm{BC}$ for the adsorption of rhodamine $\mathrm{B}(\mathrm{RB})$ and TC. This adsorbent displayed a pHpzc of 8.3 with a magnetization value of $64.7 \mathrm{emu} / \mathrm{g}$ and $328 \mathrm{~m}^{2} / \mathrm{g}$ of surface area. The magnetic adsorbent was utilized for the adsorption of TC and $\mathrm{RB}$ with single and two-stage stirred adsorbers. This configuration reduced adsorbent fouling, mass transfer resistances, and pressure drops. The configuration of two-stage stirred adsorbers was optimized to obtain 98 and $96 \% \mathrm{RB}$ and TC removal with 22.2 and $33.2 \mathrm{~g}$ of adsorbent for initial concentrations of $100 \mathrm{mg} / \mathrm{L}$ and $180 \mathrm{~min}$ of contact time. Freundlich equation correlated the adsorption results where the experimental adsorption capacities were 109.66 and $93.11 \mathrm{mg} / \mathrm{g}$ for RB and TC, respectively.

Estradiol is an endocrine disrupting chemical that has become of public concern. Therefore, Yin et al. [28] analyzed $\mathrm{Cu}^{2+}$ and $17 \beta$-estradiol (E2) adsorption on activated and magnetic BC. One-step method was utilized to obtain these adsorbents at 300,500 , and $700{ }^{\circ} \mathrm{C}$. Oxygenated functional groups, pore volume, and surface area of the magnetic adsorbent were higher than those of BC without modification. Also, the magnetic adsorbent showed better adsorption capacities for the removal of these pollutants in single and binary aqueous solutions. The adsorbent obtained at 300 ${ }^{\circ} \mathrm{C}$ showed the highest adsorption capacity of $85.93 \mathrm{mg} / \mathrm{g}$ for $\mathrm{Cu}^{2+}$, and the adsorbent prepared at $700{ }^{\circ} \mathrm{C}$ had an adsorption capacity of $153.2 \mathrm{mg} / \mathrm{g}$ for E2 in single aqueous solutions. Langmuir and pseudo second-order equations fitted the $\mathrm{E} 2$ and $\mathrm{Cu}^{2+}$ adsorption. Solution $\mathrm{pH}$ affected the adsorption of both pollutants. Binary experiments indicated an antagonistic (i.e., competition) adsorption. It appeared that $\mathrm{Cu}^{2+}$ adsorption occurred via a chemical complexation with the oxygenated functionalities, while E2 adsorption implied $\pi-\pi$ interactions and hydrogen bonds.

Also, a graphene-like magnetic adsorbent was synthesized with $\mathrm{K}_{2} \mathrm{FeO}_{4}$ and lotus seedpod for its application in the adsorption of $17 \beta$-estradiol (E2) [172]. Adsorption variables (e.g., foreign ions, humic acids, ionic strength, and solution $\mathrm{pH}$ ) including the presence of other water pollutants like microplastics (MPs) and $\mathrm{Al}_{2} \mathrm{O}_{3} \mathrm{NPs}$ were analyzed, and their impact on the E2 adsorption was established. Surface area of this adsorbent was $828.37 \mathrm{~m}^{2} / \mathrm{g}$ and displayed some graphene-like properties. E2 removal was interpreted with Langmuir isotherm and pseudo second-order kinetic. Sulfate ions, ionic strength, and solution $\mathrm{pH}$ impacted on E2 adsorption, while background electrolytes (e.g., $\mathrm{NO}_{3}{ }^{-}$, $\mathrm{Cl}^{-}, \mathrm{Ca}^{2+}, \mathrm{K}^{+}$, and $\mathrm{Na}^{+}$) and humic acids did not reduce the removal of this pollutant. MPs and $\mathrm{Al}_{2} \mathrm{O}_{3}$ significantly reduced the adsorption equilibrium time, but without a significant effect on the final E2 removal. The corresponding adsorption mechanism implied multiple interactions such as electrostatic $\pi-\pi$ interactions besides micropore filling effects.

GO-carboxymethyl cellulose and $\mathrm{Fe}_{3} \mathrm{O}_{4}$ were the feedstocks to prepare a magnetic composite to adsorb dye reactive red 2 (RR2), acid red 1 (AR1), and congo red (CR) [168]. FTIR, XRD, VSM, $\mathrm{N}_{2}$ physisorption, TGA, and SEM/TEM techniques were used to characterize the main adsorbent properties. This magnetic adsorbent showed adsorption capacities of $46.21,47.32$, and $45.09 \mathrm{mg} / \mathrm{g}$ for RR2, AR1, and CR, respectively. Freundlich equation showed the best fit for dye adsorption equilibrium experiments. Thermodynamic calculations confirmed an endothermic dye removal at tested operating conditions. Adsorption of these dyes on the magnetic composite was associated to surface complexation, $\pi-\pi$ stacking, hydrogen bonding, and electrostatic forces. Particularly, there was a complex formation involving $\mathrm{Fe}_{3} \mathrm{O}_{4}$, while the composite and dye molecules interacted via electrostatic interactions with hydroxyl and carboxyl groups. $\mathrm{NaOH}$ solution $(0.1$ $\mathrm{M})$ regenerated this adsorbent with an effectiveness of $65 \%$ up to adsorption-desorption cycles.

Radionuclides are elements that emit alpha, beta, gamma rays, or neutrons [173], and they can occur naturally (e.g., terrestrial and cosmogenic) or anthropogenic (e.g., nuclear plants, weapons, testing sites, lignit burning, and fertilizers use) $[173,174]$. Some radionuclides can be found in water due to the rock lixiviation and accidents in nuclear facilities $[173,175]$. These radioactive elements can have a long lifetime and radioactivity. The toxicology of these pollutants is associated to neurological damage, birth defects, and cancer $[173,175,176]$. Some magnetic adsorbents have prepared and tested to remove radionuclides. For instance, a magnetic GO was utilized for the cesium adsorption [176]. This adsorbent was prepared via coprecipitation reaction of iron salts and characterized with FTIR, Mössbauer, XRD, and TEM 
TABLE 6: Removal of dyes, organic pollutants and radionuclides from aqueous solution using magnetic carbon-based adsorbents: preparation, removal operating conditions, and adsorption properties.

\begin{tabular}{|c|c|c|c|c|c|c|c|c|c|}
\hline Synthesis route & $\begin{array}{l}\text { Magnetic } \\
\text { source }\end{array}$ & $\begin{array}{l}\text { Carbon } \\
\text { source }\end{array}$ & Adsorbate & $\begin{array}{l}\text { Adsorption } \\
\text { capacity } \\
(\mathrm{mg} / \mathrm{g})\end{array}$ & $\mathrm{pH}$ & $\begin{array}{c}\mathrm{T} \\
\left({ }^{\circ} \mathrm{C}\right)\end{array}$ & $\begin{array}{l}\text { Magnetization } \\
\quad(\mathrm{emu} / \mathrm{g})\end{array}$ & $\begin{array}{c}\text { BET area } \\
\left(\mathrm{m}^{2} / \mathrm{g}\right)\end{array}$ & Reference \\
\hline One-pot method & - & CNTs & $\begin{array}{l}\text { Rhodamine B } \\
\text { Congo red } \\
\text { Malachite } \\
\text { green } \\
\text { Methylene } \\
\text { blue } \\
\text { Neutral red }\end{array}$ & $\begin{array}{c}28.0 \\
52.0 \\
76.0 \\
82.0 \\
101.0\end{array}$ & & 25 & 3.64 & 186.3 & {$[248]$} \\
\hline Impregnation-pyrolisis & $\mathrm{Fe}_{3} \mathrm{O}_{4}$ & $\begin{array}{l}\text { Empty fruit } \\
\text { brunch }\end{array}$ & $\begin{array}{l}\text { Methylene } \\
\text { blue } \\
\text { Orange G }\end{array}$ & $\begin{array}{l}31.25 \\
32.36\end{array}$ & $\begin{array}{l}2- \\
10 \\
10\end{array}$ & 25 & - & - & {$[170]$} \\
\hline Impregnation method & $\mathrm{Fe}_{3} \mathrm{O}_{4}$ & $\begin{array}{l}\text { Coconut } \\
\text { shell- } \\
\text { activated } \\
\text { carbon }\end{array}$ & Sunset yellow & 22.3 & $\begin{array}{l}3- \\
10\end{array}$ & - & $16.55-28.74$ & $238-372$ & [249] \\
\hline $\begin{array}{l}\text { Electromagnetization } \\
\text { technique }\end{array}$ & $\mathrm{Fe}_{3} \mathrm{O}_{4}$ & $\begin{array}{c}\text { Brown } \\
\text { marine } \\
\text { macroalgae }\end{array}$ & Acid orange 7 & 382 & 5 & 30 & 26.79 & 336.97 & {$[250]$} \\
\hline Pyrolisis of $\mathrm{SrFe}_{12} \mathrm{O}_{19}$ and $\mathrm{BC}$ & $\mathrm{SrFe}_{12} \mathrm{O}_{19}$ & $\begin{array}{l}\text { Sewage } \\
\text { sludge }\end{array}$ & $\begin{array}{l}\text { Malachite } \\
\text { green }\end{array}$ & 388.65 & 7 & 25 & 11.11 & - & {$[251]$} \\
\hline $\begin{array}{l}\text { Pyrolysis of rubber tires, } \\
\text { impregnation with iron, and } \\
\text { functionalization with } \\
\text { polyethylenimine }\end{array}$ & $\mathrm{Fe}_{3} \mathrm{O}_{4}$ & $\begin{array}{l}\text { Waste rubber } \\
\text { tires }\end{array}$ & Methyl red & 526.0 & - & 25 & - & 153 & {$[102]$} \\
\hline $\begin{array}{l}\beta \text {-Cyclodextrin-L-glutamic } \\
\text { acid-magnetic GO }\end{array}$ & $\mathrm{Fe}_{3} \mathrm{O}_{4}$ & Graphite & Estradiol & 85.80 & 7 & 25 & 90.43 & 298.9 & {$[252]$} \\
\hline One step coprecipitation & $\mathrm{Fe}_{3} \mathrm{O}_{4}$ & Sludge & Acid orange 7 & 20.79 & 5.22 & 25 & 8.49 & 65.47 & {$[253]$} \\
\hline Coprecipitation & $\mathrm{Fe}_{3} \mathrm{O}_{4}$ & Bone char & $\begin{array}{l}\text { Reactive } 5 G \\
\text { blue }\end{array}$ & 91.58 & - & 50 & 9.79 & 142.43 & {$[254]$} \\
\hline $\begin{array}{l}\text { Pyrolysis of bones at } 500{ }^{\circ} \mathrm{C} \text {, } \\
\text { coprecipitation }\end{array}$ & $\mathrm{Fe}_{3} \mathrm{O}_{4}$ & $\begin{array}{l}\text { Chicken } \\
\text { bone }\end{array}$ & Rhodamine B & 109.66 & $\begin{array}{c}2- \\
10\end{array}$ & 26 & 64.7 & 328.06 & {$[171]$} \\
\hline $\begin{array}{l}\text { Magnetic BC by } \\
\text { impregnation and direct } \\
\text { pyrolysis }\end{array}$ & Zn ferrite & Rice straw & Estradiol & 153.2 & 5 & - & 2.242 & 357.8 & {$[28]$} \\
\hline Coprecipitation method & $\mathrm{Fe}_{3} \mathrm{O}_{4}$ & $\begin{array}{l}\text { Pineapple } \\
\text { crown leaf } \\
\text { waste }\end{array}$ & Methyl violet & 16.76 & 5 & - & 15.0 & $\begin{array}{l}95.11- \\
314.08\end{array}$ & {$[255]$} \\
\hline Microwave method & $\gamma-\mathrm{Fe}_{2} \mathrm{O}_{3}$ & $\begin{array}{l}\text { Sugarcane } \\
\text { bagasse }\end{array}$ & $\begin{array}{l}\text { Methylene } \\
\text { blue }\end{array}$ & 36.14 & $\begin{array}{c}2- \\
10\end{array}$ & - & - & $\begin{array}{l}54.49- \\
109.07\end{array}$ & {$[256]$} \\
\hline Thermal graphitization & $\mathrm{Fe}_{3} \mathrm{O}_{4}$ & Bamboo & $\begin{array}{l}\text { Methylene } \\
\text { blue }\end{array}$ & 286.6 & $\begin{array}{c}2- \\
10\end{array}$ & 25 & - & - & {$[257]$} \\
\hline $\begin{array}{l}\text { Impregnation of husk with } \\
\mathrm{ZnCl} 2 \text {, carbonization at } 400 \\
{ }^{\circ} \mathrm{C} \text {, wet impregnation of iron } \\
\text { salt }\end{array}$ & $\mathrm{Fe}_{3} \mathrm{O}_{4}$ & Rice husk & $\begin{array}{l}\text { Methylene } \\
\text { blue } \\
\text { Methyl } \\
\text { orange }\end{array}$ & $\begin{array}{l}17.78 \\
13.21\end{array}$ & 3 & 25 & - & 375.02 & {$[2]$} \\
\hline $\begin{array}{l}\text { Pyrolysis of straw at } 500{ }^{\circ} \mathrm{C} \text {, } \\
\text { impregnation with iron salt }\end{array}$ & $\mathrm{Fe}^{0}$ & Corn straw & $\begin{array}{l}\text { Malachite } \\
\text { green }\end{array}$ & 515.77 & 6 & 25 & 38.7 & 80.1 & {$[167]$} \\
\hline $\begin{array}{l}\text { Ball-mill extrusion with } \\
\mathrm{Fe}_{3} \mathrm{O}_{4}\end{array}$ & $\mathrm{Fe}_{3} \mathrm{O}_{4}$ & $\begin{array}{l}\mathrm{AC} \\
\mathrm{BC}\end{array}$ & $\begin{array}{l}\text { Methylene } \\
\text { blue }\end{array}$ & $\begin{array}{l}310.0 \\
500.0\end{array}$ & - & 25 & $\begin{array}{l}33.8 \\
34.9\end{array}$ & $\begin{array}{l}75.4 \\
90.6\end{array}$ & {$[258]$} \\
\hline $\begin{array}{l}\text { Pyrolysis at } 650{ }^{\circ} \mathrm{C} \text {, } \\
\text { impregnation with iron salt, } \\
\text { and carbonization at } 900{ }^{\circ} \mathrm{C}\end{array}$ & $\mathrm{K}_{2} \mathrm{FeO}_{4}$ & $\begin{array}{l}\text { Lotus } \\
\text { seedpod }\end{array}$ & Estradiol & 98.73 & 7 & 25 & 147 & 828.37 & {$[172]$} \\
\hline
\end{tabular}


TABLE 6: Continued.

\begin{tabular}{|c|c|c|c|c|c|c|c|c|c|}
\hline Synthesis route & $\begin{array}{l}\text { Magnetic } \\
\text { source }\end{array}$ & $\begin{array}{l}\text { Carbon } \\
\text { source }\end{array}$ & Adsorbate & $\begin{array}{l}\text { Adsorption } \\
\text { capacity } \\
(\mathrm{mg} / \mathrm{g})\end{array}$ & $\mathrm{pH}$ & $\begin{array}{c}\mathrm{T} \\
\left({ }^{\circ} \mathrm{C}\right)\end{array}$ & $\begin{array}{l}\text { Magnetization } \\
\quad(\mathrm{emu} / \mathrm{g})\end{array}$ & $\begin{array}{c}\text { BET area } \\
\left(\mathrm{m}^{2} / \mathrm{g}\right)\end{array}$ & Reference \\
\hline $\begin{array}{l}\text { Hummer method and } \\
\text { exfoliation of GO }\end{array}$ & $\mathrm{Fe}_{3} \mathrm{O}_{4}$ & Graphite & $\begin{array}{l}\text { Methylene } \\
\text { blue } \\
\text { Orange G } \\
\text { Alizarine } \\
\text { cyanine green }\end{array}$ & $\begin{array}{l}91 \% \\
71 \% \\
70 \%\end{array}$ & 7 & - & - & - & [259] \\
\hline $\begin{array}{l}\text { Carbothermal magnetization } \\
\text { by microwave-assisted } \\
\text { impregnation with zinc and } \\
\text { iron onto agriculture shell } \\
\text { wastes }\end{array}$ & Zn ferrite & Walnut shell & $\begin{array}{l}\text { Methylene } \\
\text { blue }\end{array}$ & 130 & 7 & 25 & - & 1000 & {$[260]$} \\
\hline Coprecipitation method & $\mathrm{Fe}_{3} \mathrm{O}_{4}$ & $\begin{array}{l}\text { GO and } \\
\text { cellulose }\end{array}$ & $\begin{array}{c}\text { Congo red } \\
\text { Acid red } 1 \\
\text { Reactive red } 2\end{array}$ & $\begin{array}{l}45.09 \\
47.32 \\
46.21\end{array}$ & $3-6$ & 30 & 8.9 & 197.8 & {$[168]$} \\
\hline $\begin{array}{l}\text { Pyrolysis at } 700{ }^{\circ} \mathrm{C} \text { and } \\
\text { impregnation with iron salt } \\
\text { and cetyl trimethyl } \\
\text { ammonium bromide }\end{array}$ & $\mathrm{Fe}_{3} \mathrm{O}_{4}$ & Nut shells & $\begin{array}{l}\text { Acid chrome } \\
\text { blue K }\end{array}$ & 108.8 & 3 & 50 & 2.08 & - & {$[261]$} \\
\hline $\begin{array}{l}\text { Direct mixing of the polymer } \\
\text { matrix with the nanofillers }\end{array}$ & $\mathrm{Fe}_{3} \mathrm{O}_{4}$ & $\mathrm{AC}$ & $\begin{array}{l}\text { Methylene } \\
\text { blue }\end{array}$ & 10.63 & 6 & $\begin{array}{c}35- \\
65\end{array}$ & 1.2 & 8 & {$[262]$} \\
\hline Hydrothermal carbonization & $\begin{array}{l}\mathrm{Fe}_{3} \mathrm{O}_{4} \\
\text { and } \mathrm{Fe}^{0}\end{array}$ & Carbohydrate & $\begin{array}{l}\text { Methylene } \\
\text { blue }\end{array}$ & 570 & & 25 & 8 & 766 & {$[263]$} \\
\hline Sol-gel and coprecipitation & $\begin{array}{l}\text { Spinel } \\
\text { ferrite }\end{array}$ & $\begin{array}{l}\text { Ethylene } \\
\text { glycol }\end{array}$ & $\begin{array}{c}{ }^{60} \text { Cobalt } \\
152 \\
+154 \text { Europium }\end{array}$ & $\begin{array}{c}82.51 \\
136.98\end{array}$ & 9 & 25 & - & - & {$[177]$} \\
\hline Coprecipitation & $\mathrm{Fe}_{3} \mathrm{O}_{4}$ & GO & Cesium & 362 & 7 & 25 & - & - & {$[176]$} \\
\hline
\end{tabular}

Adsorbent nomenclature: activated carbon (AC), biochar (BC), and graphene oxide (GO).

techniques. The adsorption capacity was $362 \mathrm{mg} / \mathrm{g}$ where Langmuir model was employed in the data correlation. Cesium removal was favored with $\mathrm{pH}$, and it was concluded that an ion exchange was involved in its adsorption mechanism. Maksoud et al. [177] prepared carbon-modified zirconia/spinel ferrite nanostructures for the removal of cobalt and europium. The adsorption of these radionuclides was assessed at different conditions of $\mathrm{pH}$ and temperature. The adsorption was endothermic with adsorption capacities of 137 and $83 \mathrm{mg} / \mathrm{g}$ for europium and cobalt. Langmuir and pseudo second-order models were employed to fit the adsorption equilibrium and kinetics.

\section{Patents and Status of the Commercialization of Magnetic Carbon- Based Adsorbents}

There are several patents related to the preparation of magnetic adsorbents, and some of them are summarized in Table 7. For instance, Kirsten et al. [178] obtained the patent WO2003053860A1 related to the preparation of ferromagnetic adsorbents derived from fly ash for the removal of metallic ions from wastewater. The patent JP2005137973A describes the preparation of a magnetic adsorbent combining iron oxide and porous adsorbents (e.g., activated carbon, zeolite, silica gel, and alumina) to treat water polluted with heavy metals, organic compounds, and microorganisms [179]. The patent JP2005046728A covers the production of magnetic adsorbent containing aminopropyl group for the adsorption of arsenic from water [180]. In the patent KR20060024312A, a wastewater treatment system was proposed that included a superconducting magnetic separation and activated carbon as adsorbent [181]. Sony Corp [182] patented a composite obtained from porous carbon material derived from plant-material and an oxide semiconductor. This composite can be applied for the adsorption of organic compounds, cosmetics, and photocatalysis. The University of Jinan obtained the patent CN105688825A, which was related to a method for the preparation of a magnetic adsorbent using ferrous metalorganic framework [183]. $\mathrm{FeCl}_{3}, \mathrm{La}\left(\mathrm{NO}_{3}\right)_{3}$, and sodium citrate were utilized in the adsorbent synthesis. This adsorbent can be employed for the removal of phosphate in water. In 2018, the Carbonxt Group obtained the patent AU2018203359 B2 associated to the impregnation of iron oxide on activated carbon with additives such as halogen or halide [184]. These additives were useful to enhance the oxidation of mercury contained in contaminated streams. In 2019, Honda Motor Co. obtained the patent number US20190091661A1 related to the preparation of magnetic adsorbents using different carbon allotropes. These magnetic adsorbents were tested to remove drugs, oil, and heavy metals [185]. 
TABLE 7: Summary of patents related to the preparation of carbon-based magnetic adsorbents.

\begin{tabular}{|c|c|c|c|c|}
\hline Adsorbent & Adsorbate & Patent (year) & Status & Reference \\
\hline Fly ash-ferromagnetic salts & Metallic ions & $\begin{array}{l}\text { WO2003053860A1, } \\
2003\end{array}$ & Active & {$[178]$} \\
\hline $\begin{array}{l}\text { Magnetic adsorbents using activated carbon, zeolite, } \\
\text { silica gel, and alumina }\end{array}$ & $\begin{array}{l}\text { Heavy metals, organic compounds, } \\
\text { and microorganisms }\end{array}$ & $\begin{array}{l}\text { JP2005137973A, } \\
2005\end{array}$ & $\begin{array}{l}\text { Pending } \\
\text { since } 2005\end{array}$ & {$[179]$} \\
\hline Aminopropyl groups-zirconium ferrite & Arsenic & $\begin{array}{l}\text { JP2005046728A, } \\
2005\end{array}$ & Active & {$[264]$} \\
\hline $\begin{array}{l}\text { Porous carbon material composite obtained from } \\
\text { plant-derived material and an oxide semiconductor }\end{array}$ & $\begin{array}{l}\text { Organic compounds and other } \\
\text { applications in cosmetics and } \\
\text { photocatalysis }\end{array}$ & $\begin{array}{l}\text { US20160243529A1, } \\
2009\end{array}$ & Abandoned & {$[182]$} \\
\hline Magnetic nanoparticles & Selenates & JP6494468B2, 2009 & Active & [265] \\
\hline $\begin{array}{l}\text { Hierarchical magnetic nanoparticle-enzyme } \\
\text { mesoporous assemblies embedded in macroporous } \\
\text { scaffolds }\end{array}$ & Aromatic compounds & $\begin{array}{l}\text { US20180087043A1, } \\
2013\end{array}$ & Active & [266] \\
\hline $\begin{array}{l}\text { Magnetic nanoparticles decorated activated carbon } \\
\text { nanocomposites }\end{array}$ & $\begin{array}{l}\text { Methylene blue and methyl orange } \\
\text { dyes }\end{array}$ & $\begin{array}{l}\text { US20160243523A1, } \\
2014\end{array}$ & Abandoned & [267] \\
\hline $\begin{array}{l}\text { Magnetic adsorbent using polyacrylamide solution } \\
\text { and ferrite }\end{array}$ & Heavy metals and phosphate & $\begin{array}{l}\text { US10569250B2, } \\
2015\end{array}$ & Active & {$[268]$} \\
\hline Ferrous metal-organic framework & Phosphate & $\begin{array}{l}\text { CN105688825A, } \\
2016\end{array}$ & Active & [183] \\
\hline Activated carbon impregnated with iron oxide & Mercury & $\begin{array}{l}\text { AU2018203359B2, } \\
2018\end{array}$ & Active & {$[184]$} \\
\hline $\begin{array}{l}\text { Carbon allotropes surrounding the ferromagnetic } \\
\text { particles }\end{array}$ & Heavy metals, drugs and oils & $\begin{array}{l}\text { US20190091661A1, } \\
2019\end{array}$ & Abandoned & [185] \\
\hline
\end{tabular}

Herein, it is convenient to remark that the industrial exploitation of these patents has not been reached. For example, Carbonxt Grupo is an Australian company that produces powder activated carbons, and its catalog of commercial products does not contain neither the patented adsorbent nor the corresponding adsorption system. Overall, the number of patents related to magnetic adsorbents is limited in comparison to the wide portfolio of adsorbents reported in the literature. It is clear that some magnetic materials can outperform the adsorption capacities reported for other commercial adsorbents like activated carbon, zeolites, or alumina. However, the large-scale production of these adsorbents imply additional technological and economical challenges to be resolved with the aim of exploiting these materials in water purification and other applications.

\section{Conclusions and Perspectives of Magnetic Carbon-Based Adsorbents for Water Purification}

Adsorption is a successful and mature technology for water treatment and purification due to its economic and operational advantages. In this direction, the magnetic adsorbents obtained from carbon precursors have gained a significant attention in this field due to their attractive features, which combine the magnetic characteristics of metals supported and those of the carbon matrix to promote their selectivity and performance for the adsorption of a wide spectrum of both organic and inorganic pollutants. The magnetic properties allow the adsorbents to be easily separated and recov- ered employing an external magnetic field thus contributing to their reutilization and reducing the limitations caused by the application of nanodimension adsorbent particles. Therefore, the preparation of magnetic adsorbents with iron and carbon matrices can be considered as a win-win approach, which takes advantage and outstanding properties of both phases: magnetic particles and carbon supports. This review enables readers to broaden their vision and analyze the progress and developments on this type of adsorbents to remove important pollutants such as fluoride, dyes, pharmaceuticals, heavy metals, arsenic, and other relevant compounds in the context of environmental pollution. To date, a great effort has been made to offer novel and competitive magnetic adsorbents, thus, enriching the experimental evidence related to the applications of these materials. It is evident the scarce of magnetic adsorbents produced at commercial stage and their limited number of patents with respect to the number of publications related to these materials. Overall, these indicators highlight the necessity of further development and research of improved magnetic adsorbents to achieve commercial products and consolidating their use in real life applications. In this direction, there are important topics to be researched and studied in future publications:

(1) The identification and selection of alternative green and low-cost feedstocks for the adsorbent preparation

(2) The study of the preparation conditions to control the adsorbent properties especially at large scale production 
(3) The development of specific, low-cost, and green preparation methods to improve the adsorbent selectivity for target pollutant(s)

(4) The application of residual biomasses and wastes as feedstocks to avoid secondary pollution and to reduce the environmental impacts and costs of adsorbent production

(5) The proper characterization of the physicochemical properties of these adsorbents in order to determine the adsorption mechanism

(6) The evaluation of the adsorbent performance in real water systems and operating with dynamic conditions (column operation)

(7) The regeneration, reuse, and final disposal of the adsorbent to determine its lifetime and the corresponding life cycle analysis

In particular, the overcoming of technical challenges involved in the scale-up and industrial production of novel magnetic adsorbents is fundamental to reach a successful commercialization. Despite the various gaps and current challenges, an extensive and increasing progress is evident in this relevant topic for water treatment and purification.

\section{Data Availability}

Data of this paper are available on request to the corresponding author.

\section{Conflicts of Interest}

The authors declared no potential conflicts of interest with respect to the research, authorship, and/or publication of this article.

\section{References}

[1] X. Hu, L. Jia, J. Cheng, and Z. Sun, "Magnetic ordered mesoporous carbon materials for adsorption of minocycline from aqueous solution: preparation, characterization and adsorption mechanism," Journal of Hazardous Materials, vol. 362, pp. 1-8, 2019.

[2] K. Azam, R. Raza, N. Shezad et al., "Development of recoverable magnetic mesoporous carbon adsorbent for removal of methyl blue and methyl orange from wastewater," Journal of Environmental Chemical Engineering, vol. 8, no. 5, p. 104220, 2020.

[3] C. Duan, T. Ma, Y. Wang, and Y. Zhou, "Removal of heavy metals from aqueous solution using carbon-based adsorbents: a review," Journal of Water Process Engineering, vol. 37, p. 101339, 2020.

[4] A. Mohseni-Bandpi, J. Tariq, E. G. Al-Musawi, Z. Mansur, M. Samira, and A. V. Shiva, "Improvement of zeolite adsorption capacity for cephalexin by coating with magnetic $\mathrm{Fe}_{3} \mathrm{O}_{4}$ nanoparticles," Journal of Molecular Liquids, vol. 218, pp. 615-624, 2016.

[5] H. Duanet, H. Xiang, and S. Zhirong, "Magnetic zeolite imidazole framework material- 8 as an effective and recyclable adsorbent for removal of ceftazidime from aqueous solution," Journal of Hazardous Materials, vol. 384, p. 121406, 2020.

[6] Z. Li, W. Zhaohe, W. Chengtong, D. Shilei, L. Fuwei, and L. Hongfei, "Preparation of magnetic resin microspheres MP(MMA-DVB-GMA) and the adsorption property to heavy metal ions," Applied Surface Science, vol. 496, p. 143708, 2019.

[7] T. Zhang, D. Shaotao, M. Siming et al., "Magnetic ionexchange resins for superconducting magnetic separation system: kinetics, isotherm, and mechanism of heavy metals removal," IOP Conference Series: Materials Science and Engineering, vol. 490, 2019.

[8] A. M. Awad, S. M. R. Shaikh, R. Jalab et al., "Adsorption of organic pollutants by natural and modified clays: a comprehensive review," Separation and Purification Technology, vol. 228, p. 115719, 2019.

[9] M. Chen, Y. Shen, L. Xu, G. Xiang, and Z. Ni, "Highly efficient and rapid adsorption of methylene blue dye onto vinyl hybrid silica nano-cross-linked nanocomposite hydrogel," Colloids and Surfaces A: Physicochemical and Engineering Aspects, vol. 613, p. 126050, 2021.

[10] T. M. Freire, L. M. U. Fechine, D. C. Queiroz et al., "Magnetic porous controlled $\mathrm{Fe} 3 \mathrm{O} 4-\mathrm{Chitosan}$ nanostructure: an ecofriendly adsorbent for efficient removal of azo dyes," Nanomaterials, vol. 10, no. 6, p. 1194, 2020.

[11] L. Hao, X. Meng, C. Wang, Q. Wu, and Z. Wang, "Preparation of nickel-doped nanoporous carbon microspheres from metal-organic framework as a recyclable magnetic adsorbent for phthalate esters," Journal of Chromatography A, vol. 1605, p. $460364,2019$.

[12] M. T. Siddiqui, S. Nizamuddin, H. Baloch et al., "Fabrication of advance magnetic carbon nano-materials and their potential applications: A review," Journal of Environmental Chemical Engineering, vol. 7, no. 1, p. 102812, 2019.

[13] M. K. Abugazleh, B. Rougeau, and H. Ali, "Adsorption of catechol and hydroquinone on titanium oxide and iron (III) oxide," Journal of Environmental Chemical Engineering, vol. 8, no. 5, p. 104180, 2020.

[14] H. Elbalkiny, A. Yehia, S. Riad, and Y. Elsaharty, "Potentiometric diclofenac detection in wastewater using functionalized nanoparticles," Michochemical Journal, vol. 145, pp. 90-95, 2019.

[15] P. T. Huong, L. Huy, H. Lan et al., "Magnetic iron oxidecarbon nanocomposites: impacts of carbon coating on the $\mathrm{As}(\mathrm{V})$ adsorption and inductive heating responses," Journal of Alloys and Compounds, vol. 739, no. 5, pp. 139-148, 2018.

[16] U. Sahu, S. Sumanta, S. Siba, and K. Raj, "Cigarette soot activated carbon modified with $\mathrm{Fe}_{3} \mathrm{O}_{4}$ nanoparticles as an effective adsorbent for $\mathrm{As}(\mathrm{III})$ and $\mathrm{As}(\mathrm{V})$ : material preparation, characterization and adsorption mechanism study," Journal of Molecular Liquids, vol. 243, pp. 395-405, 2017.

[17] M. D. Ma, W. Hao, D. Zhen-yan, and Z. Xinluo, "Arsenic removal from water by nanometer iron oxide coated singlewall carbon nanotubes," Journal of Molecular Liquids, vol. 259, pp. 369-375, 2018.

[18] T. Ahamad, M. Naushad, G. Eldesoky, A. Alqadami, and A. Khan, "Synthesis and characterization of egg-albumenformaldehyde based magnetic polymeric resin (MPR): Highly efficient adsorbent for Cd(II) ion removal from aqueous medium," Journal of Molecular Liquids, vol. 286, p. 110951, 2019. 
[19] Y. Yang, Z. Zheng, W. Ji, M. Yang, Q. Ding, and Z. Zhang, "The study of bromate adsorption onto magnetic ion exchange resin: optimization using response surface methodology," Surfaces and Interfaces, vol. 17, p. 100385, 2019.

[20] G. Supelano, J. Gómez, L. Moreno-Aldana et al., "Synthesis of magnetic zeolites from recycled fly ash for adsorption of methylene blue," Fuel, vol. 263, p. 116800, 2020.

[21] M. Franzreb, "New classes of selective separations exploiting magnetic adsorbents," Colloid \& Interface Science, vol. 46, pp. 65-76, 2020.

[22] D. Mehta, S. Mazumdar, and S. Singh, "Magnetic adsorbents for the treatment of water/wastewater-A review," Journal of Water Process Engineering, vol. 7, pp. 244-265, 2015.

[23] F. Meng, Y. Bowen, W. Baodong, D. Shibo, C. Zhen, and M. Wei, "Novel dendrimerlike magnetic biosorbent based on modified orange peel waste: adsorption-reduction behavior of arsenic," ACS Sustainable Chemistry and Engineering, vol. 5, no. 11, pp. 9692-9700, 2017.

[24] S. Wang, G. Bin, Z. Andrew et al., "Removal of arsenic by magnetic biochar prepared from pinewood and natural hematite," Bioresource Technology, vol. 175, pp. 391-395, 2015.

[25] Z. Zhou, Y. Liu, S. Liu et al., "Sorption performance and mechanisms of arsenic $(\mathrm{V})$ removal by magnetic gelatinmodified biochar," Chemical Engineering Journal, vol. 314, pp. 223-231, 2017.

[26] N. Mubarak, J. Sahu, and E. Abdullah, "Synthesis of novel magnetic biochar using microwave heating for removal of arsenic from waste water," Iranian Journal of Chemistry and Chemical Engineering, vol. 37, no. 5, pp. 111-115, 2018.

[27] J. Wu, H. Dan, L. Xingmei, M. Jun, T. Caixian, and X. Jianming, "Remediation of $\mathrm{As}(\mathrm{III})$ and $\mathrm{Cd}(\mathrm{II})$ cocontamination and its mechanism in aqueous systems by a novel calcium-based magnetic biochar," Journal of Hazardous Materials, vol. 348, pp. 10-19, 2018.

[28] Z. Yin, Y. Liu, S. Liu et al., "Activated magnetic biochar by one-step synthesis: enhanced adsorption and coadsorption for $17 \beta$-estradiol and copper," Science of the Total Environment, vol. 639, pp. 1530-1542, 2018.

[29] G. Shen, X. Yewen, and L. Bin, "Preparation and adsorption properties of magnetic mesoporous $\mathrm{Fe} 3 \mathrm{C} /$ carbon aerogel for arsenic removal from water," Desalination and Water Treatment, vol. 57, no. 51, pp. 24467-24475, 2016.

[30] J. Zhao, G. Liang, X. Zhang et al., "Coating magnetic biochar with humic acid for high efficient removal of fluoroquinolone antibiotics in water," Science of the Total Environment, vol. 688, pp. 1205-1215, 2019.

[31] R. Gurav, S. Bhatia, T. Choi et al., "Treatment of furazolidone contaminated water using banana pseudostem biochar engineered with facile synthesized magnetic nanocomposites," Bioresource Technology, vol. 297, p. 122472, 2020.

[32] Y. Cao and X. Li, "Adsorption of graphene for the removal of inorganic pollutants in water purification : a review," Adsorption, vol. 20, no. 5-6, pp. 713-727, 2014.

[33] E. Petala, G. Yiannis, K. Vasilis et al., "Magnetic carbon nanocages: an advanced architecture with surface- and morphology-enhanced removal capacity for arsenites," ACS Sustainable Chemistry and Engineering, vol. 5, no. 7, pp. 5782-5792, 2017.

[34] G. Rudakov, K. Tsiberkin, R. Ponomarev et al., "Magnetic properties of transition metal nanoparticles enclosed in car- bon nanocages," Journal of Magnetism and Magnetic Materials, vol. 472, pp. 34-39, 2019.

[35] A. Tripathi, S. Saraf, and S. Saraf, "Carbon nanotropes: a contemporary paradigm in drug delivery," Materials, vol. 8, no. 6, pp. 3068-3100, 2015.

[36] M. Jeguirim, M. Belhachemi, L. Limousy, and S. Bennici, "Adsorption/reduction of nitrogen dioxide on activated carbons: textural properties versus surface chemistry - a review," Chemical Engineering Journal, vol. 347, pp. 493-504, 2018.

[37] D. Mohan, A. Sarswat, Y. Ok, and C. Pittman, "Organic and inorganic contaminants removal from water with biochar, a renewable, low cost and sustainable adsorbent - A critical review," Bioresource Technology, vol. 160, pp. 191-202, 2014.

[38] M. Yahya, Z. Al-Qodah, and C. Ngah, "Agricultural biowaste materials as potential sustainable precursors used for activated carbon production: a review," Renewable and Sustainable Energy Reviews, vol. 46, pp. 218-235, 2015.

[39] W. Daud and A. Houshamnd, "Textural characteristics, surface chemistry and oxidation of activated carbon," Journal of Natural Gas Chemistry, vol. 19, no. 3, pp. 267-279, 2010.

[40] S. Stankovich, D. Dikin, G. Dommett et al., "Graphene-based composite materials," Nature Letters, vol. 442, no. 7100, pp. 282-286, 2006.

[41] A. Ghosh, K. Subrahmanyam, K. Krishna et al., "Uptake of $\mathrm{H}_{2}$ and $\mathrm{CO}_{2}$ by graphene," Journal of Physical Chemistry, vol. 112, pp. 15704-15707, 2008.

[42] W. Zhang, S. Xinhao, Z. Yixuan, G. Wei, L. Bingyu, and $\mathrm{X}$. Yuezhong, "Synthesis of water-soluble magnetic graphene nanocomposites for recyclable removal of heavy metal ions," Journal of Materials Chemistry A, vol. 1, no. 5, pp. 1745-1753, 2013.

[43] A. Iqbal, N. Sakib, A. Iqbal, and D. Nuruzzaman, "Graphenebased nanocomposites and their fabrication, mechanical properties and applications," Materialia, vol. 12, p. 100815, 2020.

[44] D. Huang, W. Jizi, W. Lu et al., "Novel Insight into adsorption and co-adsorption of heavy metal ions and an organic pollutant by magnetic graphene nanomaterials in water," Chemical Engineering Journal, vol. 358, pp. 1399-1409, 2019.

[45] S. Park, J. An, I. Jung et al., "Colloidal suspensions of highly reduced graphene oxide in a wide variety of Organic solvents," Nanoletters, vol. 9, no. 4, pp. 1593-1597, 2009.

[46] V. N. Popov, "Carbon nanotubes: properties and application," Materials Science and Engineering: R: Reports, vol. 43, no. 3, pp. 61-102, 2004.

[47] K. Shah and A. Bilal, "Synthesis of carbon nanotubes by catalytic chemical vapour deposition: a review on carbon sources, catalysts and substrates," Materials Science in Semiconductor Processing, vol. 41, pp. 67-82, 2016.

[48] M. Trojanowicz, "Analytical applications of carbon nanotubes: a review," TrAC Trends in Analytical Chemistry, vol. 25, no. 5, pp. 480-489, 2006.

[49] S. Ntim and S. Mitra, "Removal of trace arsenic to meet drinking water standards using iron oxide coated multiwall carbon nanotubes," Chemical and Engineering Data, vol. 56, no. 5, pp. 2077-2083, 2011.

[50] H. Luan, X. Jingwen, T. Zhiqiang, Z. Aihua, and H. Haiou, "Adsorptive filtration of As(III) from drinking water by $\mathrm{CuFe} 2 \mathrm{O} 4$ particles embedded in carbon nanotube membranes," Journal of Chemical Technology and Biotechnology, vol. 94, no. 9, pp. 2816-2825, 2019. 
[51] Y. Huang, H. Jian, S. Xue et al., "One-pot hydrothermal synthesis carbon nanocages-reduced graphene oxide composites for simultaneous electrochemical detection of catechol and hydroquinone," Sensors and Actuators, B: Chemical, vol. 212, pp. 165-173, 2015.

[52] A. Abbas, L. T. Mariana, and A. N. Phan, "Biomass-waste derived graphene quantum dots and their applications," Carbon, vol. 140, pp. 77-99, 2018.

[53] U. A. Rani, L. Y. Ng, C. Y. Ng, and E. Mahmoudi, “A review of carbon quantum dots and their applications in wastewater treatment," Advances in Colloidand Interface Science, vol. 19, pp. 30294-30295, 2020.

[54] R. Acosta, D. Nabarlatz, A. Sánchez-Sánchez et al., "Adsorption of bisphenol A on $\mathrm{KOH}$-activated tyre pyrolysis char," Journal of Environmental Chemical Engineering, vol. 6, no. 1, pp. 823-833, 2018.

[55] N. Zúñiga-Muro, A. Bonilla-Petriciolet, D. Mendoza-Castillo et al., "Recycling of Tetra pak wastes via pyrolysis: characterization of solid products and application of the resulting char in the adsorption of mercury from water," Journal of Cleaner Production, vol. 291, 2021.

[56] E. Singh, A. Kumar, A. Khapre, P. Saikia, and S. Shukla, "Efficient removal of arsenic using plastic waste char: prevailing mechanism and sorption performance," Journal of Water Process Engineering, vol. 33, p. 101095, 2020.

[57] Y. Chen, Y. Zhu, Z. Wang et al., "Application studies of activated carbon derived from rice husks produced by chemicalthermal process-A review," Advances in Colloid and Interface Science, vol. 163, no. 1, pp. 39-52, 2011.

[58] N. Noor, O. Raihan, N. Mubarak, and E. Abdullah, "Agricultural biomass-derived magnetic adsorbents: preparation and application for heavy metals removal," Journal of the Taiwan Institute of Chemical Engineers, vol. 78, pp. 168-177, 2017.

[59] K. Fakkaew, T. Koottatep, and C. Polprasert, "Effects of hydrolysis and carbonization reactions on hydrochar production," Bioresource Technology, vol. 192, pp. 328-334, 2015.

[60] C. A. Takaya, K. R. Parmar, L. A. Fletcher, and A. B. Ross, "Biomass-derived carbonaceous adsorbents for trapping ammonia," Agriculture, vol. 9, no. 1, p. 16, 2019.

[61] A. A. Azzaz, B. Khiari, S. Jellali, C. M. Ghimbeu, and M. Jeguirim, "Hydrochars production, characterization and application for wastewater treatment: a review," Renewable and Sustainable Energy Reviews, vol. 127, p. 109882, 2020.

[62] X. Yu, S. Liu, G. Lin et al., "KOH-activated hydrochar with engineered porosity as sustainable adsorbent for volatile organic compounds," Colloids and Surfaces A, vol. 588, p. 124372, 2020.

[63] R. F. Abdullah, U. Rashid, M. L. Ibrahim, B. Hazmi, F. A. Alharthi, and I. A. Nehdi, "Bifunctional nano-catalyst produced from palm kernel shell via hydrothermal- assisted carbonization for biodiesel production from waste cooking oil," Renewable and Sustainable Energy Reviews, vol. 137, p. $110638,2021$.

[64] W. Cai, W. Jiahao, L. Zhonglei, L. Yan, Z. Jiabin, and H. Bowen, "Preparation of amino-functionalized magnetic biochar with excellent adsorption performance for $\mathrm{Cr}(\mathrm{VI})$ by a mild one-step hydrothermal method from peanut hull," Colloids and Surfaces A: Physicochemical and Engineering Aspects, vol. 563, pp. 102-111, 2019.

[65] O. Kazak, Y. Eker, H. Bingol, and A. Tor, "Novel preparation of activated carbon by cold oxygen plasma treatment com- bined with pyrolysis," Chemical Engineering Journal, vol. 325, pp. 564-575, 2017.

[66] J. Guo and A. Lua, "Preparation of activated carbons from oil-palm-stone chars by microwave- induced carbon dioxide activation," Carbon, vol. 38, no. 14, pp. 1985-1993, 2000.

[67] B. Jayasena and S. Sathyan, "A novel mechanical cleavage method for synthesizing few-layer graphenes," Nanoscale Research Letters, vol. 6, no. 1, pp. 1-7, 2011.

[68] R. Muñoz and C. Gómez-Aleixandre, "Review of CVD synthesis of graphene," Chemical Vapor Deposition, vol. 19, no. 10-11-12, pp. 297-322, 2013.

[69] T. Pham, G. Jeong, Y. Jae et al., "High areal capacitance of Ndoped graphene synthesized by arc discharge," Advanced Functional Materials, vol. 29, no. 48, pp. 1905511-1905519, 2019.

[70] R. Sinclair, L. James, and P. Coveney, "Micromechanical exfoliation of graphene on the atomistic scale," Physical Chemistry Chemical Physics, vol. 21, no. 10, pp. 5716-5722, 2019.

[71] W. Hummers and R. Offeman, "Preparation of graphitic oxide," Journal of the American Chemical Society, vol. 80, no. 6, p. 1339, 1958.

[72] L. Sun, T. Chungui, L. Meitong et al., "From coconut shell to porous graphene-like nanosheets for high-power supercapacitors," Journal of Materials Chemistry A, vol. 1, no. 21, pp. 6462-6470, 2013.

[73] Y. Choi, S. Jong, P. Lakshmi et al., "Removal of U(VI) by sugar-based magnetic pseudo-graphene oxide and its application to authentic groundwater using electromagnetic system," Environmental Science and Pollution Research, vol. 26, no. 22, pp. 22323-22337, 2019.

[74] M. Bhuyan, A. Sajibul, U. Nizam, I. Maksudul, A. Ferdaushi, and S. Sayed, "Synthesis of graphene," International Nano Letters, vol. 6, no. 2, pp. 65-83, 2016.

[75] G. Peng, M. Zhang, S. Deng, D. Shan, Q. He, and G. Yu, "Adsorption and catalytic oxidation of pharmaceuticals by nitrogen-doped reduced graphene oxide $/ \mathrm{Fe}_{3} \mathrm{O}_{4}$ nanocomposite," Chemical Engineering Journal, vol. 341, pp. 361370, 2018.

[76] J. Wang, Z. Wenhui, Z. Yuxia, Z. Nan, and Z. Changsen, "Multi-functionalization of magnetic graphene by surfaceinitiated ICAR ATRP mediated by polydopamine chemistry for adsorption and speciation of arsenic," Applied Surface Science, vol. 478, pp. 15-25, 2019.

[77] J. Shi, W. Du, Y. Yin, Y. Guo, and L. Wan, "Hydrotermal reduction of three dimensional graphene oxide for binderfree flexible supercapacitors," Journal of Materials Chemistry A, vol. 28, pp. 10830-10834, 2014.

[78] F. Iskandar, H. Utiya, S. Erythrina, and H. Akfiny, "Microwave-assisted reduction method under nitrogen atmosphere for synthesis and electrical conductivity improvement of reduced graphene oxide (RGO)," RSC Advances, vol. 7, no. 83, pp. 52391-52397, 2017.

[79] P. Zong, S. Wang, Y. Zhao, H. Wang, H. Pan, and C. He, "Synthesis and application of magnetic graphene/iron oxides composite for the removal of U(VI) from aqueous solutions," Chemical Engineering Journal, vol. 220, pp. 45-52, 2013.

[80] N. Ghorbanian, S. Seidi, J. Ghasemi, and S. Sadeghi, "Dispersive solid phase extraction of lead in water samples using embedded 1,5-diphenylcarbazone grafted graphene oxide in microporous magnetic chitosan coupled with flame atomic 
absorption spectrometry," Journal of the Iranian Chemical Society, vol. 16, no. 7, pp. 1411-1421, 2019.

[81] Z. Wang, S. Dekui, W. Chunfei, and G. Sai, "State-of-the-art on the production and application of carbon nanomaterials from biomass," Green Chemistry, vol. 22, pp. 5031-5057, 2018.

[82] M. Sevilla, C. Sanchis, T. Valdes-Solis, E. Morallon, and A. Fuertes, "Synthesis of graphitic carbon nanostructures from sawdust and their application as electrocatalyst supports," Journal of Physics and Chemistry, vol. 111, pp. 97499756, 2007.

[83] K. S. Ibrahim, "Carbon nanotubes-properties and applications: a review," Carbon Letters, vol. 14, no. 3, pp. 131-144, 2013.

[84] Y. Guan, J. Cheng, H. Chaofan, and J. Li, "Preparation of multi-walled carbon nanotubes functionalized magnetic particles by sol-gel technology and its application in extraction of estrogens," Talanta, vol. 83, no. 2, pp. 337-343, 2010.

[85] D. Xiao, D. Pierre, H. Hua et al., "Magnetic carbon nanotubes: synthesis by a simple solvothermal process and application in magnetic targeted drug delivery system," Journal of Nanoparticle Research, vol. 14, no. 7, p. 984, 2012.

[86] Y. Zhang and J. Son, "Fluorescent magnetic silica nanotubes with high photostability prepared by the conventional reverse micro-emulsion method," Bulletin of the Korean Chemical Society, vol. 33, no. 12, pp. 4165-4168, 2012.

[87] H. Fazelirad, R. Mehdi, A. Mohammad, and S. Ghasem, "Preparation of magnetic multi-walled carbon nanotubes for an efficient adsorption and spectrophotometric determination of amoxicillin," Journal of Industrial and Engineering Chemistry, vol. 21, pp. 889-892, 2015.

[88] M. Ahmadi, M. Tayyebeh, and A. Abbas, "Solid phase extraction of amoxicillin using dibenzo-18-crown-6 modified magnetic-multiwalled carbon nanotubes prior to its spectrophotometric determination," Talanta, vol. 148, pp. 122-128, 2016.

[89] B. Chen, Z. Zhiliang, M. Jie, Q. Yanling, and C. Junhong, "Iron oxide supported sulfhydryl-functionalized multiwalled carbon nanotubes for removal of arsenite from aqueous solution," ChemPlusChem, vol. 80, no. 4, pp. 740-748, 2015.

[90] Y. Cao, "Preparation and magnetic properties of a multiwalled carbon nanotube-iron oxide nanoparticle composite," Fullerenes Nanotubes and Carbon Nanostructures, vol. 23, no. 7, pp. 623-626, 2015.

[91] C. G. Lee and S. Kim, "Removal of arsenic and selenium from aqueous solutions using magnetic iron oxide nanoparticle/multi-walled carbon nanotube adsorbents," Desalination and Water Treatment, vol. 57, no. 58, pp. 2832328339, 2016.

[92] A. Ahangari, S. Raygan, and A. Ataie, "Capabilities of nickel zinc ferrite and its nanocomposite with CNT for adsorption of arsenic (V) ions from wastewater," Journal of Environmental Chemical Engineering, vol. 7, no. 6, p. 103493, 2019.

[93] J. Ma, N. Jian, and X. Xiao, "Large-diameter and waterdispersible single-walled carbon nanotubes: synthesis, characterization and applications," Journal of Materials Chemistry, vol. 19, no. 19, pp. 3033-3041, 2009.

[94] H. Qin, H. Yongkui, L. Siyu, F. Yao, L. Xi, and K. Shifei, "Synthesis and properties of magnetic carbon nanocages particles for dye removal," Journal of Nanomaterials, vol. 2015, 8 pages, 2015.
[95] D. Cho, L. Jechan, S. Yong, E. Eilhann, and S. Hocheol, "Fabrication of a novel magnetic carbon nanocomposite adsorbent via pyrolysis of sugar," Chemosphere, vol. 163, pp. 305-312, 2016.

[96] W. Zuo, C. Gaosong, C. Fengjuan, L. Siliang, and W. Baodui, "Green synthesis and characterization of gold nanoparticles embedded into magnetic carbon nanocages and their highly efficient degradation of methylene Blue," RSC Advances, vol. 6, no. 34, pp. 28774-28780, 2016.

[97] M. Mashkani, A. Mehdinia, A. Jabbari, Y. Bide, and M. R. Nabid, "Preconcentration and extraction of lead ions in vegetable and water samples by $\mathrm{N}$-doped carbon quantum dot conjugated with $\mathrm{Fe}_{3} \mathrm{O}_{4}$ as a green and facial adsorbent," Food Chemistry, vol. 15, no. 239, pp. 1019-1026, 2018.

[98] A. Tadesse, D. RamaDevi, M. Hagos, G. Battu, and K. Basavaiah, "Synthesis of nitrogen doped carbon quantum dots/magnetite nanocomposites for efficient removal of methyl blue dye pollutant from contaminated water," RSC Advances, vol. 8, no. 16, pp. 8528-8536, 2018.

[99] P. Nuengmatcha, "Mercapto-functionalized magnetic graphene quantum dots as adsorbent for $\mathrm{Cd} 2+$ removal from wastewater," Environmental Processes, vol. 8, no. 3, pp. 1289-1306, 2021.

[100] P. Kahrizi, F. S. Mohseni-Shahri, and F. Moeinpour, "Adsorptive removal of cadmium from aqueous solutions using $\mathrm{NiFe}_{2} \mathrm{O}_{4}$ /hydroxyapatite/graphene quantum dots as a novel nano-adsorbent," Journal of Nanostructure in Chemistry, vol. 8, no. 4, pp. 441-452, 2018.

[101] Y. Huang, J. Peng, and X. Huang, "One-pot preparation of magnetic carbon adsorbent derived from pomelo peel for magnetic solid-phase extraction of pollutants in environmental waters," Journal of Chromatography A, vol. 1546, pp. 2035, 2018.

[102] T. A. Saleh and A. A. Al-Absi, "Kinetics, isotherms and thermodynamic evaluation of amine functionalized magnetic carbon for methyl red removal from aqueous solutions," Journal of Molecular Liquids, vol. 248, pp. 577-585, 2017.

[103] L. Tang, J. Yu, Y. Pang et al., "Sustainable efficient adsorbent: alkali-acid modified magnetic biochar derived from sewage sludge for aqueous organic contaminant removal," Chemical Engineering Journal, vol. 336, pp. 160-169, 2018.

[104] M. Ahmed, M. Aziziha, R. Anwar, M. B. Johnson, and L. Lin, "Magnetic sludge byproducts for adsorptive phosphorus removal: resource recovery from iron-based anaerobic sewage sludge," Waste Management, vol. 120, pp. 269-276, 2021.

[105] Y. Deng, Y. Ok, D. Mohan, C. Pittman, and X. Dou, "Carbamazepine removal from water by carbon dot-modified magnetic carbon nanotubes," Environmental Research, vol. 169, pp. 434-444, 2019.

[106] S. Gao, Q. Wang, J. Nie, C. Poon, H. Yin, and J. Li, “Arsenate $(V)$ removal from aqueous system by using modified incinerated sewage sludge ash (ISSA) as a novel adsorbent," Chemosphere, vol. 270, article 129423, 2021.

[107] Z. Shamsi, Z. Mohamadi, A. Zamani, and A. Alizadeh, "Magnetic adsorbent based on the electric arc furnace dust for the removal of methylene blue dye from aqueous solution," Environmental Progress and Sustainable Energy, vol. 40, no. 5, 2021.

[108] B. Kwiecińska, S. Pusz, and B. Valentine, "Application of electron microscopy TEM and SEM for analysis of coals, organicrich shales and carbonaceous matter," International Journal of Coal Geology, vol. 211, article 103203, 2019. 
[109] S. Zhu, X. Lin, G. Dong et al., "Valorization of manganesecontaining groundwater treatment sludge by preparing magnetic adsorbent for $\mathrm{Cu}(\mathrm{II})$ adsorption," Journal of Environmental Management, vol. 236, pp. 446-454, 2019.

[110] S. Biyada, M. Merzouki, K. Elkarrach, and M. Benlemlih, "Spectroscopic characterization of organic matter transformation during composting of textile solid waste using UV-visible spectroscopy, infrared spectroscopy and X-ray diffraction (XRD)," Microchemical Journal, vol. 159, article 105314, 2020.

[111] G. J. Long and F. Grandjean, "Chapter "Introduction"," in Comprehensive Inorganic Chemistry II, E. C. Constable, G. Parkin, and L. Que, Eds., vol. 2Elsevier, 2nd edition, 2021.

[112] B. Singh, Y. Fang, B. C. C. Cowie, and L. Thomsen, "NEXAFS and XPS characterisation of carbon functional groups of fresh and aged biochars," Organic Geochemistry, vol. 77, pp. 1-10, 2014.

[113] L. Zubizarreta, R. Iserte, P. Llovera, and M. Gil-Agusti, "Carbon materials with tailored porosity by self-assembly method: influence of the synthesis conditions," Microporous and Mesoporous Materials, vol. 143, no. 1, pp. 30-36, 2011.

[114] EPA, National primary drinking water regulations, 2021, https://www.epa.gov/ground-water-and-drinking-water/ national-primary-drinking-water-regulations\#Organic.

[115] WHO, Guidelines for drinking-water quality, World Health Organization, 4th edition, 2006.

[116] G. Gallios, K. Athanasia, A. Ioannis, S. Katarina, V. Miroslava, and A. Eleni, "Adsorption of arsenate by nano scaled activated carbon modified by iron and manganese oxides," Sustainability, vol. 9, no. 10, p. 1684, 2017.

[117] S. Xu, L. Meina, Z. Lihao, and T. Shen, "Packed bed column investigation on As (V) adsorption using magnetic iron oxide/bagasse biomass carbon composite adsorbent," IOP Conference Series: Materials Science and Engineering, vol. 490, article 032032, 2019.

[118] K. Brahman, T. Kazi, H. Afridi et al., "Simultaneously evaluate the toxic levels of fluoride and arsenic species in underground water of Tharparkar and possible contaminant sources: a multivariate study," Ecotoxicology and Environmental Safety, vol. 89, pp. 95-107, 2013.

[119] J. Ma, Z. Zhiliang, C. Bo et al., "One-pot, large-scale synthesis of magnetic activated carbon nanotubes and their applications for arsenic removal," Journal of Materials Chemistry $A$, vol. 1, no. 15, pp. 4662-4666, 2013.

[120] A. Sherlala, A. Raman, and M. Bello, "Synthesis and characterization of magnetic graphene oxide for arsenic removal from aqueous solution," Environmental Technology, vol. 40, no. 12, pp. 1508-1516, 2019.

[121] C. Sarici-Özdemir and Y. Önal, "Study to investigate the importance of mass transfer of naproxen sodium onto activated carbon," Chemical Engineering Process: Process Intensification, vol. 49, no. 10, pp. 1058-1065, 2010.

[122] H. Bagheri, A. Roostaie, and M. Baktash, "A chitosanpolypyrrole magnetic nanocomposite as $\mu$-sorbent for isolation of naproxen," Analytica Chimica Acta, vol. 816, pp. 1-7, 2014.

[123] X. Wei, Y. Wang, J. Chen et al., "Adsorption of pharmaceuticals and personal care products by deep eutectic solventsregulated magnetic metal-organic framework adsorbents: performance and mechanism," Chemical Engineering Journal, vol. 392, p. 124808, 2020.
[124] B. Yu, B. Yitong, M. Zhu et al., “Adsorption behaviors of tetracycline on magnetic graphene oxide sponge," Materials Chemistry and Physics, vol. 198, pp. 283-290, 2017.

[125] L. Shao, R. Zongming, Z. Gaosheng, and C. Linlin, "Facile synthesis, characterization of a $\mathrm{MnFe}_{2} \mathrm{O}_{4}$ /activated carbon magnetic composite and its effectiveness in tetracycline removal," Materials Chemistry and Physics, vol. 135, no. 1, pp. 16-24, 2012.

[126] R. Baccar, M. Sarra, J. Bouzid, M. Feki, and P. Blánquez, "Removal of pharmaceutical compounds by activated carbon prepared from agricultural by-product," Chemical Engineering Journal, vol. 211-212, pp. 310-317, 2012.

[127] Q. Sui, X. Cao, S. Lu, W. Zhao, Z. Qiu, and G. Yu, "Occurrence, sources and fate of pharmaceuticals and personal care products in the groundwater: a review," Emerging Contaminants, vol. 1, no. 1, pp. 14-24, 2015.

[128] M. Huerta-Fontela, M. Galceran, and F. Ventura, "Occurrence and removal of pharmaceuticals and hormones through drinking water treatment," Water Research, vol. 45, no. 3, pp. 1432-1442, 2011.

[129] J. Hounfodji, W. Kanhounnon, G. Kpotin et al., "Molecular insights on the adsorption of some pharmaceutical residues from wastewater on kaolinite surfaces," Chemical Engineering Journal, vol. 407, p. 127176, 2021.

[130] R. H. Schreurs, "Interaction of polycyclic musks and uv filters with the estrogen receptor (ER), androgen receptor (AR), and progesterone receptor (PR) in reporter gene bioassays," Toxicological Sciences, vol. 83, no. 2, pp. 264-272, 2005.

[131] Y. Liu, L. Rong, L. Ming, Y. Fucheng, and C. He, "Removal of pharmaceuticals by novel magnetic genipin-crosslinked chitosan/graphene oxide- $\mathrm{SO}_{3} \mathrm{H}$ composite," Carbohydrate Polymers, vol. 220, pp. 141-148, 2019.

[132] K. Singh, A. Singh, U. Singh, and P. Verma, "Optimizing removal of ibuprofen from water by magnetic nanocomposite using Box-Behnken design," Environmental Science and Pollution Research, vol. 19, no. 3, pp. 724-738, 2012.

[133] A. Liyanage, S. Canaday, C. Pittman, and T. Mlsna, "Rapid remediation of pharmaceuticals from wastewater using magnetic $\mathrm{Fe}_{3} \mathrm{O}_{4}$ /Douglas fir biochar adsorbents," Chemosphere, vol. 258, p. 127336, 2020.

[134] M. Baghdadi, E. Ghaffari, and B. Aminzadeh, "Removal of carbamazepine from municipal wastewater effluent using optimally synthesized magnetic activated carbon: adsorption and sedimentation kinetic studies," Journal of Environmental Chemical Engineering, vol. 4, no. 3, pp. 3309-3321, 2016.

[135] O. Kerkez-Kuyumcu, S. Bayazit, and M. Salam, "Antibiotic amoxicillin removal from aqueous solution using magnetically modified graphene nanoplatelets," Journal of Industrial and Engineering Chemistry, vol. 36, pp. 198-205, 2016.

[136] K. Dai, F. Wang, W. Jiang, Y. Chen, J. Mao, and J. Bao, "Magnetic carbon microspheres as a reusable adsorbent for sulfonamide removal from water," Nanoscale Research Letters, vol. 12, no. 1, p. 528, 2017.

[137] H. Zakir, S. Sharmin, A. Akter, and M. Rahman, “Assessment of health risk of heavy metals and water quality indices for irrigation and drinking suitability of waters: a case study of Jamalpur Sadar area, Bangladesh," Environmental Advances, vol. 2, p. 100005, 2020.

[138] N. Soliman and A. Moustafa, "Industrial solid waste for heavy metals adsorption features and challenges; a review," Journal 
of Materials Research and Technology, vol. 9, no. 5, pp. 10235-10253, 2020.

[139] F. Zhu, Y. Zheng, B. Zhang, and Y. Dai, “A critical review on the electrospun nanofibrous membranes for the adsorption of heavy metals in water treatment," Journal of Hazardous Materials, vol. 401, p. 123608, 2021.

[140] Y. Han, X. Cao, X. Ouyang, S. Sohi, and J. Chen, “Adsorption kinetics of magnetic biochar derived from peanut hull on removal of $\mathrm{Cr}(\mathrm{VI})$ from aqueous solution: effects of production conditions and particle size," Chemosphere, vol. 145, pp. 336-341, 2016.

[141] W. Fu and Z. Huang, "Magnetic dithiocarbamate functionalized reduced graphene oxide for the removal of $\mathrm{Cu}(\mathrm{II})$, $\mathrm{Cd}(\mathrm{II}), \mathrm{Pb}(\mathrm{II})$, and $\mathrm{Hg}(\mathrm{II})$ ions from aqueous solution: synthesis, adsorption, and regeneration," Chemosphere, vol. 209, pp. 449-456, 2018.

[142] H. Wang, Y. Liu, J. Ifthikar et al., "Towards a better understanding on mercury adsorption by magnetic bio- adsorbents with $\gamma$ - $\mathrm{Fe}_{2} \mathrm{O}_{3}$ from pinewood sawdust derived hydrochar: Influence of atmosphere in heat treatment," Water and Soil Remediation, vol. 256, pp. 269-276, 2018.

[143] V. Nejadshafiee and M. Islami, "Adsorption capacity of heavy metal ions using sultone-modified magnetic activated carbon as a bio-adsorbent," Materials Science \& Engineering: C, vol. 101, pp. 42-52, 2019.

[144] P. Maneechakr and S. Mongkollertlop, "Investigation on adsorption behaviors of heavy metal ions $\left(\mathrm{Cd}^{2+}, \mathrm{Cr}^{3+}, \mathrm{Hg}^{2+}\right.$ and $\mathrm{Pb}^{2+}$ ) through low- cost/active manganese dioxidemodified magnetic biochar derived from palm kernel cake residue," Journal of Environmental Chemical Engineering, vol. 8, no. 6, p. 104467, 2020.

[145] S. Cosgrove, B. Jefferson, and P. Jarvis, "Pesticide removal from drinking water sources by adsorption: a review," Environmental Technology Reviews, vol. 8, no. 1, pp. 1-24, 2019.

[146] A. Hernández, T. Parrón, A. Tsatsakis, M. Requena, R. Alarcón, and O. López-Guarnido, "Toxic effects of pesticide mixtures at a molecular level: their relevance to human health," Toxicology, vol. 307, pp. 136-145, 2013.

[147] N. Ueda, R. Bergamasco, and S. Hamoudi, "Magnetic $\mathrm{MnFe}_{2} \mathrm{O}_{4}$-graphene hybrid composite for efficient removal of glyphosate from water," Chemical Engineering Journal, vol. 295, pp. 391-402, 2016.

[148] T. Huang, Y. Huang, Y. Huang, Y. Yang, and Y. Zhao, "Toxicity assessment of the herbicide acetochlor in the human liver carcinoma (HepG2) cell line," Chemosphere, vol. 24, p. $125345,2020$.

[149] H. Zeliger, "Human toxicology of chemical mixtures," in Toxic Consequences Beyond the Impact of One-component Product and Environmental Exposures, Elsevier, Oxford, 2nd edition, 2011.

[150] S. Zheng, B. Chen, X. Qiu, M. Chen, Z. Ma, and X. Yu, "Distribution and risk assessment of 82 pesticides in Jiulong River and estuary in South China," Chemosphere, vol. 144, pp. 1177-1192, 2016.

[151] P. Morton, R. Cassidy, S. Floyd, D. Doody, W. Colin, and P. Jordan, "Approaches to herbicide (MCPA) pollution mitigation in drinking water source catchments using enhanced space and time monitoring," Science of Total Environment, vol. 755, p. 142827, 2021.

[152] G. Liu, L. Li, X. Huang et al., "Adsorption and removal of organophosphorus pesticides from environmental water and soil samples by using magnetic multi-walled carbon nanotubes @ organic framework ZIF-8," Journal of Materials Science, vol. 53, no. 15, pp. 10772-10783, 2018.

[153] X. Jiang, Z. Ouyang, Z. Zhang, C. Yang, X. Li, and Z. Dang, "Mechanism of glyphosate removal by biochar supported nano-zero-valent iron in aqueous solutions," Colloids and Surfaces A, vol. 547, pp. 64-72, 2018.

[154] V. Wanjeri, C. Sheppard, A. Prinsloo, J. Ngila, and P. Ndungu, "Isotherm and kinetic investigations on the adsorption of organophosphorus pesticides on graphene oxide based silica coated magnetic nanoparticles functionalized with 2-phenylethylamine," Journal of Environmental Chemical Engineering, vol. 6, no. 1, pp. 1333-1346, 2018.

[155] G. Mashile, A. Mpupa, A. Nqombolo, K. Dimpe, and P. Nomngongo, "Recyclable magnetic waste tyre activated carbon-chitosan composite as an effective adsorbent rapid and simultaneous removal of methylparaben and propylparaben from aqueous solution and wastewater," Journal of Water Process Engineering, vol. 33, p. 101011, 2020.

[156] I. Agani, J. Fatombi, S. Osseni et al., "Removal of atrazine from aqueous solutions onto a magnetite/chitosan/activated carbon composite in a fixed-bed column system: optimization using response surface methodology," RSC Advances, vol. 10, no. 68, pp. 41588-41599, 2020.

[157] X. Meng, Y. Yao, Y. Ma, N. Zhong, S. Alphonse, and J. Pei, "Effect of fluoride in drinking water on the level of 5-methylcytosine in human and rat blood," Environmental Toxicoloy and Pharmacology, vol. 81, p. 103511, 2021.

[158] A. Alhassan, Y. He, L. Huang, B. Wu, L. Yan, and H. Deng, “A review on fluoride adsorption using modified bauxite: Surface modification and sorption mechanisms perspectives," Journal of Environmental Chemical Engineering, vol. 8, no. 6, p. 104532, 2020.

[159] J. He, Y. Yang, Z. Wu, C. Xie, K. Zhang, and L. Kong, "Review of fluoride removal from water environment by adsorption," Journal of Environmental Chemical Engineering, vol. 8, no. 6, p. 104516, 2020.

[160] D. Mohan, S. Kumar, and A. Srivastava, "Fluoride removal from ground water using magnetic and nonmagnetic corn stover biochars," Ecological Engineering, vol. 73, pp. 798808, 2014.

[161] N. Dewage, A. Liyanage, C. Pittman, D. Mohan, and T. Mlsna, "Fast nitrate and fluoride adsorption and magnetic separation from water on $\alpha-\mathrm{Fe}_{2} \mathrm{O}_{3}$ and $\mathrm{Fe}_{3} \mathrm{O}_{4}$ dispersed on Douglas fir biochar," Bioresource Technology, vol. 263, pp. 258-265, 2018.

[162] J. Zhou, Y. Liu, Y. Han, F. Jing, and J. Chen, "Bone derived biochar and magnetic biochar for effective removal of fluoride in groundwater: effects of synthesis method and coexisting chromium," Water environment research, vol. 91, no. 7, pp. 588-597, 2019.

[163] F. Takmil, H. Esmaeili, S. Mousavi, and S. Hashemi, "Nanomagnetically modified activated carbon prepared by oak shell for treatment of wastewater containing fluoride ion," Advanced Powder Technology, vol. 31, no. 8, pp. 3236-3245, 2020.

[164] N. Sahu, C. Bhan, and J. Singh, "Removal of fluoride from an aqueous solution by batch and column process using activated carbon derived from iron infused Pisum sativum peel: characterization, isotherm, kinetics study," Environmental Engineering Research, vol. 26, p. 200241, 2021. 
[165] I. Mall, V. Srivastava, and N. Agarwal, "Removal of Orange-G and Methyl Violet dyes by adsorption onto bagasse fly ash -kinetic study and equilibrium isotherm analyses," Dyes and Pigments, vol. 69, no. 3, pp. 210-223, 2006.

[166] W. Xiao, X. Jiang, X. Liu et al., "Adsorption of organic dyes from wastewater by metal-doped porous carbon materials," Journal of Cleaner Production, vol. 284, p. 124773, 2021.

[167] A. Eltaweil, H. Mohamed, E. El-Monaem, and G. El-Subruiti, "Mesoporous magnetic biochar composite for enhanced adsorption of malachite green dye: characterization, adsorption kinetics, thermodynamics and isotherms," Advanced Powder Technology, vol. 31, no. 3, pp. 1253-1263, 2020.

[168] P. Sirajudheen, M. Nikitha, P. Karthikeyan, and S. Meenakshi, "Perceptive removal of toxic azo dyes from water using magnetic $\mathrm{Fe}_{3} \mathrm{O}_{4}$ reinforced graphene oxide- carboxymethyl cellulose recyclable composite: Adsorption investigation of parametric studies and their mechanisms," Surfaces and Interfaces, vol. 21, article 100648, 2020.

[169] K. Thasneema, T. Dipin, M. Thayyil et al., "Removal of toxic heavy metals, phenolic compounds and textile dyes from industrial waste water using phosphonium based ionic liquids," Journal of Molecular Liquids, vol. 323, article 114645, 2021.

[170] N. Mubarak, Y. Fo, H. Al-Salim et al., "Removal of methylene blue and orange- $\mathrm{G}$ from Waste Water using magnetic biochar," International Journal of Nanoscience, vol. 14, no. 4, article 1550009, 2015.

[171] A. Oladipo and A. Ifebajo, "Highly efficient magnetic chicken bone biochar for removal of tetracycline and fluorescent dye from wastewater: two-stage adsorber analysis," Journal of Environmental Management, vol. 209, pp. 9-16, 2018.

[172] N. Liu, Y. Liu, X. Tan et al., "Synthesis a graphene-like magnetic biochar by potassium ferrate for $17 \beta$-estradiol removal: effects of $\mathrm{Al}_{2} \mathrm{O}_{3}$ nanoparticles and microplastics," Science of the Total Environment, vol. 715, p. 136723, 2020.

[173] S. M. Husnain, W. Um, W. Lee, and Y. S. Chang, "Magnetitebased adsorbents for sequestration of radionuclides: a review," RSC Advances, vol. 8, no. 5, pp. 2521-2540, 2018.

[174] L. P. Lingamdinne, Y. L. Choi, I. S. Kim, J. K. Yang, J. R. Koduru, and Y. Y. Chang, "Preparation and characterization of porous reduced graphene oxide based inverse spinel nickel ferrite nanocomposite for adsorption removal of radionuclides," Journal of Hazardous Materials, vol. 326, pp. 145156, 2017.

[175] J. W. Choi, S. Cho, and S. J. Choi, "Ecofriendly, selective removal of radioactive strontium ions in aqueous solutions using magnetic banana peels," Science of Total Environment, vol. 778, p. 146327, 2021.

[176] G. Lujaniene, S. Semcuk, A. Lecinskyte et al., "Magnetic graphene oxide based nano-composites for removal of radionuclides and metals from contaminated solutions," Journal of Environmental Radioactivity, vol. 166, Part 1, pp. 166-174, 2017.

[177] M. I. Maksoud, N. M. Sami, H. S. Hassan, M. Bekhit, and A. H. Ashour, "Novel adsorbent based on carbon-modified zirconia/spinel ferrite nanostructures: evaluation for the removal of cobalt and europium radionuclides from aqueous solutions," Journal of Colloid and Interface Science, vol. 607, 2021.

[178] C. N. Kirsten and O. M. Lammerschop, 2003, Patent No. WO2003053860A1, Germany.
[179] O. Fukunishi and K. Fukunishi, 2005, Patent No. JP2005137973A, Japan.

[180] O. Shigeo and O. Yanagiya, 2005, Patent No. JP2005046728A, Japan.

[181] Y. Noda, T. Nicki, and T. Fukunishi, 2006, Patent No. KR20060024312A, South Korea.

[182] H. Iida, S. Tabata, S. Yamada, T. Noguchi, and T. Yamanoi, 2009, Patent No. US20160243529A1, United States.

[183] L. Hua, G. Weilin, L. Xianghui, L. Zhonghua, and W. Ruiqin, 2016, Patent No. CN105688825A, China.

[184] H. Byrne, A. Khan, and D. W. Mazyck, 2018, Patent No. AU2018203359B2, Australia.

[185] A. Harutyunyan, 2019, Patent No. US20190091661A1, United States.

[186] Q. Ngo, T. Yamada, M. Suzuki et al., "Structural and electrical characterization of carbon nanofibers for interconnect via applications," IEEE Transactions on Nanotechnology, vol. 6, no. 6, pp. 688-695, 2007.

[187] R. M. Reily, "Carbon nanotubes: potential benefits and risks of nanotechnology in nuclear medicine," Nanotechnology in Nuclear Medicine, vol. 48, no. 7, pp. 1039-1042, 2007.

[188] P. Suvarnaphaet and S. Pechprasarn, "Graphene-based materials for biosensors: a review," Sensors, vol. 17, no. 10, p. 2161, 2017.

[189] F. Yu, S. Sainan, M. Jie, and H. Sheng, "Enhanced removal performance of arsenate and arsenite by magnetic graphene oxide with high iron oxide loading," Physical Chemistry Chemical Physics, vol. 17, no. 6, pp. 4388-4397, 2015.

[190] W. Park, Y. Yoon, S. Kim et al., "Feasible water flow filter with facilely functionalized $\mathrm{Fe}_{3} \mathrm{O}_{4}$-non-oxidative graphene/CNT composites for arsenic removal," Journal of Environmental Chemical Engineering, vol. 4, no. 3, pp. 3246-3252, 2016.

[191] N. Rashidi, W. Ibrahim, I. Ali, and M. Sanagi, "Development of magnetic graphene oxide adsorbent for the removal and preconcentration of As(III) and As(V) species from environmental water samples," Environmental Science and Pollution Research, vol. 23, no. 10, pp. 9759-9773, 2016.

[192] J. Liang, B. He, P. Li et al., "Facile construction of 3D magnetic graphene oxide hydrogel via incorporating assembly and chemical bubble and its application in arsenic remediation," Chemical Engineering Journal, vol. 358, pp. 552-563, 2019.

[193] A. Zubrik, M. Matik, M. Lovás et al., "Mechanochemically synthesised coal-based magnetic carbon composites for removing $\mathrm{As}(\mathrm{V})$ and $\mathrm{Cd}(\mathrm{II})$ from aqueous solutions," Nanomaterials, vol. 9, no. 1, p. 100, 2019.

[194] L. Capobianco, F. Di Caprio, P. Altimari, M. Astolfi, and F. Pagnanelli, "Production of an iron-coated adsorbent for arsenic removal by hydrothermal carbonization of olive pomace: effect of the feedwater $\mathrm{pH}$," Journal of Environmental Management, vol. 273, article 111164, 2020.

[195] G. Tan, Y. Mao, H. Wang, and N. Xu, “A comparative study of arsenic $(\mathrm{V})$, tetracycline and nitrate ions adsorption onto magnetic biochars and activated carbon," Chemical Engineering Research and Design, vol. 159, pp. 582-591, 2020.

[196] Z. İlbay, S. Şahin, O. Kerkez, and S. Bayazit, "Isolation of naproxen from wastewater using carbon-based magnetic adsorbents," International Journal of Environmental Science and Technology, vol. 12, no. 11, pp. 3541-3550, 2015.

[197] N. Rattanachueskul, A. Saning, S. Kaowphong, N. Chumha, and L. Chuenchom, "Magnetic carbon composites with a 
hierarchical structure for adsorption of tetracycline, prepared from sugarcane bagasse _via_ hydrothermal carbonization coupled with simple heat treatment process," Bioresource Technology, vol. 226, pp. 164-172, 2017.

[198] D. Shan, S. Deng, T. Zhao et al., "Preparation of ultrafine magnetic biochar and activated carbon for pharmaceutical adsorption and subsequent degradation by ball milling," Journal of Hazardous Materials, vol. 305, pp. 156-163, 2016.

[199] F. Wang, B. Yang, H. Wang, Q. Song, F. Tan, and Y. Cao, "Removal of ciprofloxacin from aqueous solution by a magnetic chitosan grafted graphene oxide composite," Journal of Molecular Liquids, vol. 222, pp. 188-194, 2016.

[200] K. T. Wong, Y. Yoon, S. Snyder, and M. Jang, "Phenyl-functionalized magnetic palm-based powdered activated carbon for the effective removal of selected pharmaceutical and endocrine-disruptive compounds," Chemosphere, vol. 152, pp. 71-80, 2016.

[201] D. Balarak, F. Mostafapour, and A. Joghtaei, "Thermodynamic analysis for adsorption of amoxicillin onto magnetic carbon nanotubes," British Journal of Pharmaceutical Research, vol. 16, no. 6, pp. 1-11, 2017.

[202] X. Kong, Y. Liu, J. Pi, W. Li, Q. Liao, and J. Shang, "Low-cost magnetic herbal biochar: characterization and application for antibiotic removal," Environmental Science and Pollution Research, vol. 24, no. 7, pp. 6679-6687, 2017.

[203] W. Xiong, Z. Zeng, G. Zeng et al., "Metal-organic frameworks derived magnetic carbon- $\alpha \mathrm{Fe} / \mathrm{Fe}_{3} \mathrm{C}$ composites as a highly effective adsorbent for tetracycline removal from aqueous solution," Chemical Engineering Journal, vol. 374, pp. 9199, 2019.

[204] C. Li, C. Chen, and W. Chen, "Different influences of nanopore dimension and $\mathrm{pH}$ between chlorpheniramine adsorptions on graphene oxide-iron oxide suspension and particle," Chemical Engineering Journal, vol. 307, pp. 447$455,2017$.

[205] C. Saucier, P. Karthickeyan, V. Ranjithkumar, E. Lima, G. Reis, and I. Brum, "Efficient removal of amoxicillin and paracetamol from aqueous solutions using magnetic activated carbon," Environmental Science and Pollution Research, vol. 24, no. 6, pp. 5918-5932, 2017.

[206] B. Wang, S. Yan, Y. Fa, and Y. Deng, "Preparation of biochar by simultaneous carbonization, magnetization and activation for norfloxacin removal in water," Bioresource Technology, vol. 233, pp. 159-165, 2017.

[207] I. Hussain, Y. Li, J. Qi et al., "Synthesis of magnetic yolk-shell mesoporous carbon architecture for the effective adsorption of sulfamethazine drug," Microporous and Mesoporous Materials, vol. 255, pp. 110-118, 2018.

[208] M. Li, Y. Liu, S. Liu et al., "Performance of magnetic graphene oxide/diethylenetriaminepentaacetic acid nanocomposite for the tetracycline and ciprofloxacin adsorption in single and binary systems," Journal of Colloid And Interface Science, vol. 521, pp. 150-159, 2018.

[209] R. Li, Z. Wang, X. Zhao, X. Li, and X. Xie, "Magnetic biocharbased manganese oxide composite for enhanced fluoroquinolone antibiotic removal from water," Environmental Science and Pollution Research, vol. 25, no. 31, pp. 31136-31148, 2018.

[210] M. Nodeh, S. Soltani, S. Shahabuddin, R. Nodeh, and H. Sereshti, "Equilibrium, kinetic and thermodynamic study of magnetic polyaniline/graphene oxide based nanocomposites for ciprofloxacin removal from water," Journal of Inor- ganic and Organometallic Polymers and Materials, vol. 28, no. 3, pp. 1226-1234, 2018.

[211] F. Reguyal and A. Sarmah, "Adsorption of sulfamethoxazole by magnetic biochar: effects of $\mathrm{pH}$, ionic strength, natural organic matter and $17 \alpha$-ethinylestradiol," Science of the Total Environment, vol. 628-629, pp. 722-730, 2018.

[212] D. Shan, S. Deng, Y. Wang, and J. Huang, "Hydrophilic and strengthened 3D reduced graphene oxide/nano- $\mathrm{Fe}_{3} \mathrm{O}_{4}$ hybrid hydrogel for enhanced adsorption and catalytic oxidation of typical pharmaceuticals," Environmental Sciencie: Nano, vol. 5, pp. 1650-1660, 2018.

[213] Y. Binglong, J. Wang, X. Yang, W. Wang, and X. Cai, "Preparation of polyglycerol mediated superparamagnetic graphene oxide nanocomposite and evaluation of its adsorption properties on tetracycline," Environmental Science and Pollution Research, vol. 26, pp. 32345-32359, 2019.

[214] A. Fröhlich, E. Foletto, and G. Dotto, "Preparation and characterization of $\mathrm{NiFe}_{2} \mathrm{O}_{4}$ /activated carbon composite as potential magnetic adsorbent for removal of ibuprofen and ketoprofen pharmaceuticals from aqueous solutions," Journal of Cleaner Production, vol. 229, pp. 828-837, 2019.

[215] A. El-Sheikh, R. Qawariq, and J. Abdelghani, "Adsorption and magnetic solid-phase extraction of NSAIDs from pharmaceutical wastewater using magnetic carbon nanotubes: Effect of sorbent dimensions, magnetite loading and competitive adsorption study," Environmental Technology and Innovation, vol. 16, article 100496, 2019.

[216] H. Luo, Y. Zhang, Y. Xie et al., "Iron-rich microorganismenabled synthesis of magnetic biocarbon for efficient adsorption of diclofenac from aqueous solution," Bioresource Technology, vol. 282, pp. 310-317, 2019.

[217] N. Ninwiwek, P. Hongsawat, P. Punyapalakul, and P. Prarat, "Removal of the antibiotic sulfamethoxazole from environmental water by mesoporous silica-magnetic graphene oxide nanocomposite technology: adsorption characteristics, coadsorption and uptake mechanism," Colloids and Surfaces A: Physicochemical and Engineering Aspects, vol. 580, article 123716, 2019.

[218] J. Wang, W. Zhang, and J. Wei, "Fabrication of poly( $\beta$-cyclodextrin)-conjugated magnetic graphene oxide by surfaceinitiated RAFT polymerization for synergetic adsorption of heavy metal ions and organic pollutants," Journal of Materials Chemistry A, vol. 7, no. 5, pp. 2055-2065, 2019.

[219] D. Wu, J. Yao, G. Lu et al., "Adsorptive removal of aqueous bezafibrate by magnetic ferrite modified carbon nanotubes," RSC Advances, vol. 7, article 39594, 2019.

[220] N. Elessawy, M. Gouda, S. Ali, M. Saleno, and M. Eldin, "Effective elimination of contaminant antibiotics using high-surface-area magnetic-functionalized graphene nanocomposites developed from plastic waste," Materials, vol. 13, no. 7, pp. 1517-1517, 2020.

[221] J. Wan, J. Ding, W. Tan, Y. Gao, S. Sun, and C. He, "Magnetic-activated carbon composites derived from iron sludge and biological sludge for sulfonamide antibiotic removal," Environmental Science and Pollution Research, vol. 27, no. 12, pp. 13436-13446, 2020.

[222] J. Zhou, F. Ma, and H. Guo, "Adsorption behavior of tetracycline from aqueous solution on ferroferric oxide nanoparticles assisted powdered activated carbon," Chemical Engineering Journal, vol. 384, p. 123290, 2020.

[223] L. Chang-Gu and S. Kim, "Cr(VI) adsorption to magnetic iron oxide nanoparticle-multi-walled carbon nanotube 
adsorbents," Water Environment Research, vol. 88, no. 11, pp. 2111-2120, 2016.

[224] T. Hou, L. Kong, X. Guo et al., "Magnetic ferrous-doped graphene for improving $\mathrm{Cr}(\mathrm{VI})$ removal," Materials Research Express, vol. 3, no. 4, article 045006, 2016.

[225] D. Zhao, X. Gao, C. Wu, R. Xie, S. Feng, and C. Chen, "Facile preparation of amino functionalized graphene oxide decorated with $\mathrm{Fe}_{3} \mathrm{O}_{4}$ nanoparticles for the adsorption of $\mathrm{Cr}(\mathrm{VI})$," Applied Surface Science, vol. 384, pp. 1-9, 2016.

[226] Y. Cao, J. Huang, X. Peng et al., "Poly(vinylidene fluoride) derived fluorine-doped magnetic carbon nanoadsorbents for enhanced chromium removal," Carbon, vol. 115, no. 3, pp. 503-514, 2017.

[227] W. Lu, J. Li, Y. Sheng, Z. Zhang, J. You, and L. Chen, "Onepot synthesis of magnetic iron oxide nanoparticlemultiwalled carbon nanotube composites for enhanced removal of $\mathrm{Cr}(\mathrm{VI})$ from aqueous solution," Journal of Colloid and Interface Science, vol. 505, pp. 1134-1146, 2017.

[228] M. A. Salam, "Preparation and characterization of chitin/magnetite/multiwalled carbon nanotubes magnetic nanocomposite for toxic hexavalent chromium removal from solution," Journal of Molecular Liquids, vol. 233, pp. 197-202, 2017.

[229] J. Huang, Y. Li, Y. Cao et al., "Hexavalent chromium removal over magnetic carbon nanoadsorbents: synergistic effect of fluorine and nitrogen co-doping," Journal of Materials Chemistry A, vol. 6, no. 27, pp. 13062-13074, 2018.

[230] K. Gong, Q. Hu, L. Yao et al., "Ultrasonic pretreated sludge derived stable magnetic active carbon for $\mathrm{Cr}(\mathrm{VI})$ removal from wastewater," ACS Sustainable Chemistry and Engineering, vol. 6, no. 6, pp. 7283-7291, 2018.

[231] C. A. Demarchi, B. Michel, N. Nedelko et al., "Preparation, characterization, and application of magnetic activated carbon from termite feces for the adsorption of $\mathrm{Cr}(\mathrm{VI})$ from aqueous solutions," Powder Technology, vol. 354, pp. 432441, 2019.

[232] A. Oladipo, E. O. Ahaka, and M. Gazi, "High adsorptive potential of calcined magnetic biochar derived from banana peels for $\mathrm{Cu} 2+, \mathrm{Hg} 2+$, and $\mathrm{Zn} 2+$ ions removal in single and ternary systems," Environmental Science and Pollution Research, vol. 26, no. 31, pp. 31887-31899, 2019.

[233] T. Hou, L. Yan, J. Li et al., "Adsorption performance and mechanistic study of heavy metals by facile synthesized magnetic layered double oxide/carbon composite from spent adsorbent," Chemical Engineering Journal, vol. 384, p. 123331, 2020.

[234] J. Pan, B. Gao, S. Wang, K. Guo, X. Xu, and Q. Yue, "Wasteto-resources: green preparation of magnetic biogas residuesbased biochar for effective heavy metal removals," Science of the Total Environment, vol. 737, p. 140283, 2020.

[235] Y. Li, X. Zhang, P. Zhang, X. Liu, and L. Han, "Facile fabrication of magnetic bio-derived chars by co-mixing with $\mathrm{Fe}_{3} \mathrm{O}_{4}$ nanoparticles for effective $\mathrm{Pb}^{2+}$ adsorption: properties and mechanism," Journal of Cleaner Production, vol. 262, p. 121350, 2020.

[236] K. Qiao, W. Tian, J. Bai et al., "Synthesis of floatable magnetic iron/biochar beads for the removal of chromium from aqueous solutions," Environmental Technology and Innovation, vol. 19, p. 100907, 2020.

[237] G. Liu, L. Li, D. Xu et al., "Metal-organic framework preparation using magnetic graphene oxide- $\beta$ - cyclodextrin for neo- nicotinoid pesticide adsorption and removal," Carbohydrate Polymers, vol. 175, pp. 584-591, 2017.

[238] X. Wang, H. Wang, M. Lu, R. Teng, and X. Du, "Facile synthesis of phenyl-modified magnetic graphene/mesoporous silica with hierarchical bridge-pore structure for efficient adsorption of pesticides," Materials Chemistry and Physics, vol. 198, pp. 393-400, 2017.

[239] S. Dai, Y. Zhao, D. Niu, Q. Li, and Y. Chen, "Preparation and re-activation of magnetic biochar by molten salt method: relevant performance for chlorine-containing pesticides abatement," Journal of the Air \& Waste Management Association, vol. 59, pp. 58-70, 2019.

[240] T. Zhou, Y. Tao, Y. Xu et al., "Facile preparation of magnetic carbon nanotubes@ZIF-67 for rapid removal of tetrabromobisphenol A from water sample," Environmental Science and Pollution Research, vol. 25, no. 35, pp. 35602-35613, 2018.

[241] D. Husein, "Facile one-pot synthesis of porous N-doped graphene based $\mathrm{NiO}$ composite for parabens removal from wastewater and its reusability," Desalination and Water Treatment, vol. 166, pp. 211-221, 2019.

[242] P. Marin, R. Bergamasco, A. Nivaldo, P. Roberto, and S. Hamoudi, "Synthesis and characterization of graphene oxide functionalized with $\mathrm{MnFe}_{2} \mathrm{O}_{4}$ and supported on activated carbon for glyphosate adsorption in fixed bed column," Process Safety and Environmental Protection, vol. 123, pp. 59-71, 2019.

[243] Y. Ma, Y. Qi, L. Yang et al., “Adsorptive removal of imidacloprid by potassium hydroxide activated magnetic sugarcane bagasse biochar: Adsorption efficiency, mechanism and regeneration," Journal of Cleaner Production, vol. 292, p. 126005, 2021.

[244] Y. Zhao, X. Li, L. Liu, and F. Chen, "Fluoride removal by $\mathrm{Fe}(\mathrm{III})$-loaded ligand exchange cotton cellulose adsorbent from drinking water," Carbohydrate Polymers, vol. 72, no. 1, pp. 144-150, 2008.

[245] S. Wen, Y. Yang, and S. Dong, "Performance and characteristics of fluoride adsorption using nanomagnetite graphite - La adsorbent," RSC Advances, vol. 5, no. 109, pp. 89594-89602, 2015.

[246] L. Chunhui, T. Jin, Z. Puli, Z. Bin, B. Duo, and L. Xuebin, "Simultaneous removal of fluoride and arsenic in geothermal water in Tibet using modified yak dung biochar as an adsorbent," Royal Society Open Science, vol. 5, no. 11, p. 181266, 2018.

[247] S. Rajkumar, S. Murugesh, V. Sivasankar, A. Darchen, T. Msagati, and T. Chaabane, "Low-cost fluoride adsorbents prepared from a renewable biowaste: syntheses, characterization and modeling studies," Arabian Journal of Chemistry, vol. 12, no. 8, pp. 3004-3017, 2019.

[248] F. Yu, J. Chen, M. Yang et al., “A facile one-pot method for synthesis of low-cost magnetic carbon nanotubes and their applications for dye removal," New Journal of Chemistry, vol. 36, no. 10, pp. 1940-1943, 2012.

[249] A. Cazzeta, O. Pezoti, K. Bedin et al., "Magnetic activated carbon derived from biomass waste by concurrent synthesis: efficient adsorbent for toxic dyes," ACS Sustainable Chemistry \& Engineering, vol. 4, no. 3, pp. 1058-1068, 2016.

[250] K. Jung, H. Choi, T. Jeong, and K. Ahn, "Facile synthesis of magnetic biochar $/ \mathrm{Fe}_{3} \mathrm{O}_{4}$ nanocomposites using electromagnetization technique and its application on the removal 
of acid orange 7 from aqueous media," Bioresource Technology, vol. 220, pp. 672-676, 2016.

[251] J. Zhang, M. Liu, T. Yang, K. Yang, and H. Wang, “A novel magnetic biochar from sewage sludge: synthesis and its application for the removal of malachite green from wastewater," Water Science \& Technology, vol. 8, pp. 1971-1979, 2016.

[252] L. Jiang, Y. Liu, S. Liu et al., "Fabrication of $\beta$-cyclodextrin/poly (l-glutamic acid) supported magnetic graphene oxide and its adsorption behavior for $17 \beta$-estradiol," Chemical Engineering Journal, vol. 308, pp. 597-605, 2017.

[253] J. Wang, Z. Liao, J. Ifthikar, L. Shi, Z. Chen, and Z. Chen, "One-step preparation and application of magnetic sludgederived biochar on acid orange 7 removal via both adsorption and persulfate based oxidation," Royal Society of Chemistry, vol. 7, p. 18696, 2017.

[254] N. Hernández, M. Oliveria, E. Macedo, P. Martins, and I. Ostroski, "Evaluation of the adsorption process using activated bone char functionalized with magnetite nanoparticles," Monitoring \& Management, vol. 10, pp. 427-434, 2018.

[255] W. Astuti, T. Sulistyaningsih, E. Kusumastuti, G. Thomas, and R. Kusnadi, "Thermal conversion of pineapple crown leaf waste to magnetized activated carbon for dye removal," Bioresource Technology, vol. 287, p. 121426, 2019.

[256] W. Jiang, L. Zhang, X. Guo et al., “Adsorption of cationic dye from water using an iron oxide/activated carbon magnetic composites prepared from sugarcane bagasse by microwave method," Environmental Technology, vol. 42, p. 2021, 2021.

[257] T. Tao, G. Li, Y. He, and L. Sheng, "Magnetic bamboo chars with fluffy graphene surface for efficient dye removal," Material Research Express, vol. 6, no. 11, p. 115069, 2019.

[258] Y. Li, A. Zimmerman, F. He et al., "Solvent-free synthesis of magnetic biochar and activated carbon through ball- mill extrusion with $\mathrm{Fe}_{3} \mathrm{O}_{4}$ nanoparticles for enhancing adsorption of methylene blue," Science of the Total Enviroment, vol. 722, p. 137972, 2020.

[259] S. S. Pradhan, K. Konwar, T. Ghosh, B. Mondal, S. Sarkar, and P. Deb, "Multifunctional Iron oxide embedded reduced graphene oxide as a versatile adsorbent candidate for effectual arsenic and dye removal," Colloid and Interface Science Communications, vol. 39, p. 100319, 2020.

[260] S. Salem, Z. Teimouri, and A. Salem, "Fabrication of magnetic activated carbon by carbothermal functionalization of agriculture waste via microwave-assisted technique for cationic dye adsorption," Advanced Powder Technology, vol. 31, no. 10, pp. 4301-4309, 2020.

[261] H. Wang, S. Wang, and Y. Gao, "Cetyl trimethyl ammonium bromide modified magnetic biochar from pine nut shells for efficient removal of acid chrome blue K," Bioresource Technology, vol. 312, p. 123564, 2020.

[262] S. Yadav, A. Ashthana, R. Chakraborty et al., "Cationic dye removal using novel magnetic/activated charcoal $/ \beta$-cyclodextrin/alginate polymer nanocomposite," Nanomaterials, vol. 10, no. 1, pp. 170-190, 2020.

[263] L. H. Sousa, C. M. Sabino, F. Soares et al., "Strategic design of magnetic carbonaceous nanocomposites and its application as multifunctional adsorbent," Carbon, vol. 161, pp. 758$771,2020$.

[264] K. Mihashi, K. Obara, H. Okada et al., 2005, Patent No. JP2005046728A, Japan.

[265] A. Stein, 2009, Patent No. JP6494468B2, Japan.
[266] S. C. Corgie, X. Duan, E. Giannelis, D. Aneshansley, and L. P. Walker, 2013, Patent. No. US20180087043A1, United States.

[267] P. Saini, M. Arora, R. K. Kotnala, S. K. Barala, R. P. Pant, and C. Puri, 2014, Patent No. US20160243523A1, United States.

[268] R. Liu, Z. Ql, H. Lan, L. Zhu, H. Liu, and J. Qu, 2015, Patent No. US10569250B2, United States. 